Tabularia

TABULARIA

Sources écrites des mondes normands médiévaux

Les bibliothèques médiévales de Normandie et des

mondes normands : échanges et circulation | 2014

\title{
Inventaires de bibliothèques normandes : l'intérêt des listes tardives
}

Norman library inventories: the importance late lists

Marie-Pierre Laffitte

\section{OpenEdition}

Journals

Édition électronique

URL : http://journals.openedition.org/tabularia/2098

DOI : 10.4000/tabularia.2098

ISSN : 1630-7364

Éditeur :

CRAHAM - Centre Michel de Boüard, Presses universitaires de Caen

Référence électronique

Marie-Pierre Laffitte, «Inventaires de bibliothèques normandes : l'intérêt des listes tardives », Tabularia [En ligne], Les bibliothèques médiévales de Normandie et des mondes normands : échanges et

circulation, mis en ligne le 12 juin 2014, consulté le 24 avril 2019. URL : http://

journals.openedition.org/tabularia/2098; DOI : 10.4000/tabularia.2098

CRAHAM - Centre Michel de Boüard 


\title{
Inventaires de bibliothèques normandes: l'intérêt des listes tardives
}

\section{Norman library inventories: the importance late lists}

\author{
Marie-Pierre LAFFITTE \\ Bibliothèque nationale de France \\ marie-pierre.laffitte@orange.fr
}

Résumé:

Les archives de la bibliothèque de Jean-Baptiste Colbert permettent de reconstituer une bonne partie des collections des abbayes cisterciennes normandes et d'identifier 350 manuscrits qu'Étienne Baluze a acquis pour le ministre entre 1677 et 1683 . Aujourd'hui conservés à la Bibliothèque nationale de France, ces volumes proviennent de Mortemer, Savigny, La Noë, Foucarmont et Bonport. Ils forment un ensemble cohérent, datable surtout du IX ${ }^{\mathrm{e}}$ au $\mathrm{XIV}^{\mathrm{e}}$ siècle, qui mériterait une étude textuelle et codicologique approfondie.

Mots-clés: Jean-Baptiste Colbert, Étienne Baluze, Mortemer, Savigny, La Noë, Foucarmont, Bonport, manuscrits cisterciens normands, abbayes cisterciennes en Normandie

\begin{abstract}
:
The archives of the library of Jean-Baptiste Colbert permit us to reconstruct a large part of the collections of the Norman cistercian abbeys and identify 350 manuscripts that Etienne Baluze purchased for the Minister between 1677 and 1683. Now preserved in the National Library of France, these volumes come from the Abbeys of Mortemer, Savigny, La Noë, Foucarmont and Bonport. They form a coherent group, dating mainly from the ninth to the fourteenth century, which deserves a thorough textual and codicological study.
\end{abstract}

Keywords: Jean-Baptiste Colbert, Etienne Baluze, Mortemer, Savigny, La Noë, Foucarmont, Bonport, Norman cistercian manuscripts, Norman cistercian abbeys

Les inventaires médiévaux sont d'un grand intérêt, car ils sont le reflet des activités intellectuelles et des penchants artistiques d'un collectionneur ou d'une institution; ils aident aussi à retracer les chemins parcourus par les textes et à identifier les exemplaires subsistants et quand ils n'existent pas, la reconstitution des collections dépend des traces laissées dans les manuscrits et de listes tardives liées à leur histoire. Pour les abbayes cisterciennes de Normandie, un seul inventaire ancien subsiste pour Mortemer ${ }^{1}$, mais les archives de Colbert

1. Dolbeau, 1988, passim.

Tabularia "Études», n 14, 2014, p. 89-150, 12 juin 2014 http://www.unicaen.fr/mrsh/craham/revue/tabularia/print.php?dossier=dossier12\&file=02laffitte.xml 
contiennent des documents qui aident à reconstituer leurs collections pillées par le ministre. Léopold Delisle en a déjà publié certains et a donné des identifications des manuscrits conservés ${ }^{2}$. Je propose ici une édition de tous les inventaires tardifs réunis par Baluze ${ }^{3}$, avec le signalement de tous les manuscrits trouvés à la BnF. Ce travail doit aussi beaucoup à Madame Bondéelle-Souchier mais la comparaison des listes et la réalisation de concordances, l'utilisation d'éléments codicologiques tels que les formats et les tomaisons donnés par les sources du $\mathrm{XVII}^{\mathrm{e}}$ siècle, les foliotations, gardes, reliures ${ }^{4}$ et cotes anciennes visibles sur les manuscrits, permettent quelques corrections et de nouvelles identifications, bien que certains textes restent introuvables. Des concordances signalent l'ensemble des manuscrits retrouvés; leurs cotes y sont classées dans l'ordre des listes correspondant à leur arrivée chez Colbert et les documents que j'ai ajoutés sont signalés par un astérique. Je suggère au lecteur de se rapporter aux notices du catalogue en ligne de la Bibliothèque nationale de France ${ }^{5}$; pour les textes que je n'ai pu retrouver, un travail d'identification reste à faire.

\section{Colbert, Baluze et les collections médiévales normandes}

En 1666, Colbert engage Étienne Baluze (Tulle, 24 novembre 1630-Paris, 28 juillet 1719) comme bibliothécaire ${ }^{6}$. Cette nomination est déterminante pour sa bibliothèque. En effet, Baluze met son érudition, sa méthode de travail et ses relations au service de cette institution naissante, qui devient peu à peu l'une des plus importantes collections personnelles de manuscrits de l'histoire, riche en textes de toutes sortes, en particulier pour la haute époque, et largement ouverte aux savants. Parallèlement, il constitue sa propre bibliothèque, où il intègre parfois les reliquats de ses acquisitions pour Colbert ${ }^{7}$. Les archives de cette activité sont entrées à la Bibliothèque royale avec ses papiers personnels en 1719, puis avec les collections de Colbert ${ }^{8}$. Bien que lacunaires, elles apportent

2. Delisle, 1868, passim; BondéELLE-Souchier, 1991, passim; voir aussi les annotations de Léopold Delisle, Henri Omont, Charles Astruc, Denise Bloch, Pierre Gasnault, François Avril... dans les dossiers d'archives cités ci-dessous.

3. J'ai respecté le plus précisément possible l'orthographe utilisée dans tous les textes transcrits (diphtongue ae ou æ, préposition et ou \&...) ainsi que les abréviations, les éléments suscrits et la ponctuation, mais j'ai dû unifier l'utilisation des majuscules, trop différente d'un document à l'autre, en réduisant leur utilisation au début de chaque notice, aux noms propres et au début des incipit, signalés entre parenthèses. Les mots corrigés par les rédacteurs sont barrés et les descriptions qui n'ont pu être mises en relation avec un manuscrit Colbert sont transcrites en italique.

4. Les reliures des $\mathrm{XI}^{e}$-XIII ${ }^{e}$ siècles sont signalées rel. 1 dans les tableaux, celles du XV siècle rel. 2; LAFFITTE, 1999, passim.

5. http://archivesetmanuscrits.bnf.fr/

6. BOutier (dir.), 2008, passim.

7. BlOCH, 1983, p. 402-404; EAD., 1988; pour les manuscrits anciens de Baluze, DelisLe, 1868 , p. 364-367; OMONT, 1903, p. 38-42.

8. Paris, BnF, Baluze 96-103, 212, 276, 277, 364-366, 368, 371; ms lat. 9363-9364 («Papiers relatifs à la formation de la bibliothèque de Colbert. Volume 1 ann. 1666-1678 - Volume 2 ann. 1679$1690 »)$, ms lat. 9365 («Papiers relatifs à l'acquisition de la bibliothèque de Colbert 1727-1737») et ms lat. 9366 («registre des prêts de la bibliothèque de Colbert 1679-1731»), série provenant sans 
beaucoup à l'histoire de la «Colbertine», en particulier les listes d'acquisitions des années 1669-1700, souvent rédigées par Baluze lui-même.

La gestion de Baluze est marquée par des achats abondants, qui cessent après son départ en 1700. Le bibliothécaire recherche des fonds déjà constitués qu'il essaie d'obtenir dans leur totalité, si possible gratuitement sinon à un prix peu élevé; il s'appuie sur une administration royale toute dévouée au ministre, en premier lieu les intendants, chargés de repérages dans les provinces. Dans une lettre circulaire adressée le 29 novembre 1672 à Jean Le Camus, intendant de Riom, ainsi qu'à ceux de Caen et de Limoges, Colbert écrit ces lignes sans doute dictées par son bibliothécaire, qui illustrent une pratique d'acquisitions utilisée dès François I ${ }^{\text {er }}$ aux dépens d'institutions religieuses réputées incapables ${ }^{9}$ :

«Le plaisir de former ma bibliothèque estant presque le seul que je prenne..., je sçais pas expérience qu'il se trouve quelquefois dans les monastères et les abbayes considérables de provinces d'anciens manuscrits qui peuvent estre de considération et qui sont souvent abandonnés dans la poussière et dans l'ordure des chartriers par l'ignorance ou le défaut de cognoissance des religieux. Vous me ferez sur cela un singulier plaisir, dans le cours de visites que vous faites dans la généralité de l'Auvergne, de vous informer sans affectation si vous en pourriez trouver et en ce cas, d'en traiter ou de vous accommoder aux meilleurs conditions qu'il se pourra...».

Baluze connaît l'état des bibliothèques de son temps, qu'il fréquente comme érudit, et s'intéresse à tous les types de collections. Il achète beaucoup d'imprimés, mais ses goûts personnels le poussent à rechercher des manuscrits et en premier lieu les exemplaires de haute époque, souvent conservés dans les fonds ecclésiastiques. Les collections monastiques l'attirent donc beaucoup et l'une des premières tentatives d'acquisition d'un fonds de ce type, celui de l'abbaye SaintMartial de Limoges, est menée dès 1669 avec Pierre de Carcavy ${ }^{10}$. Elle échoue, car Baluze fait envoyer une lettre de remerciements du ministre avant même l'accord des chanoines, qui refusent de livrer leurs manuscrits sans compensation financière; Colbert furieux demande des éclaircissements et plus de rigueur à son bibliothécaire; l'ensemble n'entrera dans la Bibliothèque du roi qu'en $1730^{11}$ ! Par l'intermédiaire de l'intendant Morangis ${ }^{12}$, Baluze obtient en 1674 que les chanoines de la cathédrale de Metz donnent à Colbert une douzaine de manuscrits, dont la première Bible et le psautier de Charles le Chauve ${ }^{13}$.

doute de Colbert et classée par Léopold Delisle: les pages de titre, semblables aux intitulés de la partie consacrée à la bibliothèque de Colbert dans DelisLe, 1868, p. 439-547, sont de sa main.

9. Paris, Bibliothèque de l'École supérieure de guerre, ms Rés. 133 (1), Correspondance de Colbert, 1672; Colbert, 1873, p. 68-69; LAFfitte, sous presse.

10. Paris, BnF, ms lat. 9363 , fol. $62-79$.

11. Inventaire des manuscrits de l'abbaye Saint-Martial de Limoges; DeLisLe, 1868, p. 387-397; ID., 1895, p. 14-16; OMONT, 1903, p. 98-100.

12. Antoine Barillon de Morangis (?-18 mai 1686), seigneur de Louans et de Montigny, maître des requêtes ordinaires de l'Hôtel du roi, intendant de Metz (1674-1677), d'Alençon (1677-1682), de Caen (1682-1686) et d'Orléans (1686).

13. Paris, BnF, ms lat. 9363 , fol. 189. 
Pour la Normandie, Guy Chamillart commence des recherches dans la généralité de Caen après sa nomination comme intendant en 1666, mais comme il l'écrit à Colbert le 23 février $1673^{14}$, ses efforts sont infructueux. Comme dans les autres provinces, le ministre convoite les collections anciennes des abbayes normandes, mais les manuscrits acquis, à Mortemer en août 1677, Savigny en 1678, La Noë en 1679, Foucarmont en 1682, Bonport en 1683 sont presque exclusivement cisterciens. Le rôle principal revenant aux représentants de l'État, leur désir de satisfaire un ministre exigeant et leur connaissance des personnes et des lieux sont déterminants, même s'il ne faut pas sous-estimer l'influence de Baluze, dont il n'existe pas de preuves directes. Les émissaires de Colbert ne s'intéressent pas aux autres abbayes de l'ordre, Aulnay à Aunay-sur-Odon, Barbery, Saint-André en Gouffern ou Val-Richer dans le Calvados, Torigny dans la Manche, Le Valasse en Seine-Maritime, Le Breuil-Benoît et L'Estrée dans l'Eure, La Trappe dans l'Orne, dont certaines possèdent pourtant des manuscrits. Deux collections laïques entrent au même moment chez Colbert, les manuscrits monastiques réunis par Mareste d'Alge, et un petit lot de volumes provenant de l'échevinage de Rouen. Quelques manuscrits normands isolés figurent dans d'autres fonds acquis par Baluze: l'exemplaire provenant de l'abbaye de SaintÉvroult d'Ouche de l'Historia ecclesiastica d'Orderic Vital entre chez Colbert avec la succession de Claude Hardy ${ }^{15}$.

Environ 350 manuscrits de Colbert proviennent donc d'abbayes cisterciennes normandes. Ils sont pour la plupart en latin et datables du XII ${ }^{e}$ au XIV ${ }^{e}$ siècle. Beaucoup contiennent des textes théologiques (commentaires bibliques, textes patristiques, vies de saints...). Parmi les auteurs cisterciens, saint Bernard arrive logiquement en tête avec une vingtaine d'entrées, mais seule l'identification des textes permettra de préciser la place des écrits cisterciens dans les bibliothèques normandes. Les livres liturgiques, antiphonaires, missels, etc., conservés plutôt dans les sacristies, sont absents; ils n'intéressent pas Baluze. Les listes du $\mathrm{XVII}$ siècle sont presque muettes sur les aspects codicologiques et laconiques sur les textes, donnant épisodiquement leurs incipit (Baluze ne le fait pas). La comparaison des différentes sources aide à proposer une provenance pour plusieurs manuscrits, mais le format, la mise en page, l'écriture et le décor des volumes connus sont homogènes et seule une étude paléographique et codicologique permettrait de déterminer réellement leur origine ${ }^{16}$. Voici, comme illustration de leur identification à la $\mathrm{BnF}$, le cas de deux groupes décrits dans les listes.

14. Guy Chamillart (1624-1675), officier royal, procureur au procès de Nicolas Fouquet en 1661, intendant de Normandie (1666-1673); Paris, BnF, Clairambault 794, p. 179; Delisle, 1868, p. 448.

15. Paris, BnF, ms lat. 5506 (Colbert 3761-3762) acheté le 14 juillet 1678; Paris, BnF, ms lat. 9363 , fol. 145-148v, 191-192 et 271; Baluze 10o, fol. 121-134; Deliste, 1868, p. 469.

16. La concordance des cotes Colbert avec les cotes actuelles et les origines connues m'a donné une vision d'ensemble du fonds. Les manuscrits de même provenance y sont souvent groupés et une origine commune peut donc être proposée pour des volumes ne portant pas de marque dictinctive; mais ces suggestions doivent rester prudentes, car le classement par groupes n'est pas systématique. 
Cinq exemplaires du traité sur l'évangile de Jean de saint Augustin portent une cote Colbert. Le premier provient de Jacques-Auguste de Thou, le second de Moissac, les listes de La Noë, Foucarmont et Bonport comportent chacune une notice correspondant aux trois autres. L'un peut être identifié par sa cote Colbert placée dans une série Foucarmont, un second porte le titre exact cité pour Bonport, le troisième revient donc à La Noë ${ }^{17}$.

Après retrait des manuscrits provenant d'autres collections telles que celles de Jacques-Auguste de Thou, de Moissac ou de la papauté d'Avignon, l'examen des exemplaires conservés de la Glossa ordinaria aboutit à ce tableau ${ }^{18}$ :

\begin{tabular}{|c|c|c|c|}
\hline latin & 63 & Genesis & Mareste \\
\hline latin & 65 & Genesis, pars & Foucarmont \\
\hline latin & 66 & Genesis; Radulphus Flaviacensis & \\
\hline latin & 69 & Exodus, pars & Mortemer \\
\hline latin & 70 & Exodus; Beda & Foucarmont \\
\hline latin & 71 & Leviticus; Gaufridus Autissiodorensis & Mortemer \\
\hline latin & 72 & Numeri, pars & Foucarmont \\
\hline latin & 73 & Numeri & Mortemer \\
\hline latin & 74 & Numeri & Bonport \\
\hline latin & 75 & Deuteronomium, pars & Mortemer \\
\hline latin & 76 & Josue; Judices & La Noë \\
\hline latin & 83 & Reges & La Noë \\
\hline latin & 84 & Reges & Bonport \\
\hline latin & 92 & Esther; Tobias; Ruth; Judith & Mortemer \\
\hline latin & 99 & Job; Esdras; Evang. Marci & Mareste \\
\hline latin & 119 & Proverbia; Ecclesiasticus & \\
\hline latin & 120 & Proverbia; Ecclesiasticus & Bonport \\
\hline latin & 122 & Proverbia; Ecclesiasticus & Mortemer \\
\hline latin & 123 & $\begin{array}{l}\text { Proverbia; Ecclesiastes; Sapientia; Cant. cant.; } \\
\text { Ecclesiasticus }\end{array}$ & Mareste \\
\hline latin & 126 & Proverbia; Sapientia & Bonport \\
\hline latin & 127 & Proverbia; Ecclesiastes; Cant. cant. & \\
\hline
\end{tabular}

17. Paris, BnF, ms lat. 1959 (de Thou 5), 1961 (Moissac), 1966 (Bonport B 8), 1967 (La Noë 26) et 3329 (Foucarmont B 13).

18. Stirnemann, 1994; Zier, 2004. 


\begin{tabular}{|c|c|c|c|}
\hline latin & 129 & Proverbia; Ecclesiastes; Cant. cant.; Actus Apost. & Bonport \\
\hline latin & 131 & $\begin{array}{l}\text { Cant. cant.; Osee; Joel; Amos; Abdias; Jonas; } \\
\text { Mich.; Nahum; Habacuc; Sophonias; Agg.; } \\
\text { Zachar.; Malach. }\end{array}$ & Mortemer \\
\hline latin & 141 & Proph. Minores & La Noë \\
\hline latin & 143 & $\begin{array}{l}\text { XII Proph.; S. Hieronymus, Prol. Regum; Cant. } \\
\text { cant. }\end{array}$ & Mortemer \\
\hline latin & 144 & Isaias & Bonport \\
\hline latin & 145 & Isaias & Mortemer \\
\hline latin & 146 & Isaias & La Noë \\
\hline latin & 149 & Isaias; Daniel & La Noë \\
\hline latin & 153 & Ezechiel & La Noë \\
\hline latin & 279 & Evangelia & Bonport \\
\hline latin & 285 & Evang. Matthaei; Marci & \\
\hline latin & 287 & Evang. Matthaei & \\
\hline latin & 288 & Evang. Matthaei, pars & Bonport \\
\hline latin & 289 & Evang. Lucae; Johannis & Mortemer \\
\hline latin & 293 & Evang. Lucae & Foucarmont \\
\hline latin & 294 & Evang. Lucae; Johannis & \\
\hline latin & 295 & Evang. Lucae; Johannis & Bonport \\
\hline latin & 296 & Evang. Lucae; Johannis & La Noë \\
\hline latin & 297 & Petrus Pictavensis; Evang. Lucae; Apocalypsis & La Noë \\
\hline latin & 301 & Evang. Johannis; Marci & Bonport \\
\hline latin & 302 & Evang. Johannis; Lucae & Bonport \\
\hline latin & 307 & Actus Apost.; VII Epist. canon. & \\
\hline latin & 308 & $\begin{array}{l}\text { Actus Apost.; Epist. Jacobi, Petri ep.-Judae ep.; } \\
\text { Apocalypsis }\end{array}$ & Mortemer \\
\hline latin & 310 & Epist. Pauli, pars & Mareste \\
\hline latin & 318 & Apocalypsis; XII Proph. Minores & \\
\hline latin & 332 & Evang. Johannis & \\
\hline latin & 368 & Genesis; Exodus & \\
\hline latin & 371 & Genesis; Exodus & La Noë \\
\hline latin & 386 & Levit.; Numeri; Deuteron. & Bonport \\
\hline latin & 389 & Levit.; Numeri; Deuteron. & La Noë \\
\hline
\end{tabular}




\begin{tabular}{|l|l|l|l|}
\hline latin & 470 & $\begin{array}{l}\text { Proverbia; Ecclesiastes; Cant. cant.; Sapientia; } \\
\text { Ecclesiasticus }\end{array}$ & \\
\hline latin & 508 & Proph. Minores & La Noë \\
\hline latin & 536 & Leviticus, pars & \\
\hline latin & 571 & Ecclesiasticus; Sapientia; Cant. cant. & La Noë \\
\hline latin & 578 & Daniel & \\
\hline latin & 691 & Evang. Marci; VII Epist. canon. & Mareste \\
\hline latin & 692 & Evang. Marci & La Noë \\
\hline latin & 693 & Evang. Marci & Mortemer \\
\hline latin & 694 & Evang. Lucae & \\
\hline latin & 703 & Actus Apost. & \\
\hline
\end{tabular}

Sur les 61 manuscrits sélectionnés dans le catalogue des manuscrits latins de la $\mathrm{BnF}^{19}, 46$ peuvent être proposés avec plus ou moins de certitude pour l'une des abbayes cisterciennes normandes, en fonction de leurs caractéristiques textuelles et matérielles (ex-libris, foliotation, reliure...): pour les manuscrits latins 371 et 389, qui ne portent pas d'ex-libris et sont des «jumeaux», l'aspect de la reliure est déterminant. Une étude approfondie de l'ensemble permettrait sans doute de corriger des erreurs et d'aller plus loin.

On sait peu de choses sur la nature des accords entre les possesseurs du $\mathrm{XVII}^{e}$ siècle et Colbert. Une mention de prix n'est ajoutée par Baluze que sur deux listes, 350 livres pour Foucarmont, 440 livres pour Bonport, des sommes modérées pour l'époque. La seconde est plutôt une estimation, puisque les manuscrits de Bonport ont fait l'objet d'un échange contre des livres imprimés. Certains ensembles, comme Savigny, La Noë ou Rouen, sont vraisemblablement des dons, mais il n'en existe pas de preuve. L'ordre choisi pour évoquer les différentes opérations est chronologique, d'août 1677 à mai 1683.

\section{Mortemer (août-octobre 1677)}

Le premier fonds médiéval normand arrive chez Colbert en deux lots, l'un de 60 manuscrits le 8 août 1677 , le second de 54 le 10 octobre 1677 . Le premier se trouvait encore à Mortemer ${ }^{20}$, le suivant provient d'une collection privée,

19. Catalogue général des manuscrits latins de la Bibliothèque nationale, I, Paris, 1939; http://archivesetmanuscrits.bnf.fr/

20. Abbaye de Mortemer, dép. Eure, cant. Lyons-la-Forêt, c. Lisors, fondée en 1130 par des moines de Beaumont-le-Perreux, devenue cistercienne en 1137; Delisle, 1868, p. 455 et 524-527 (éd. de la liste Mortemer A); Bondéelle-Souchier, 1991, p. 223-229, 71 mss Colbert; DolbeAu, 1979, p. 203. 
constituée en majorité de manuscrits monastiques: Antoine Mareste d'Alge, avocat général à la cour des aides de Normandie et collectionneur, avait acquis peu avant 1640 des manuscrits provenant de plusieurs monastères normands, dont Mortemer et l'abbaye de la Trinité de Fécamp ${ }^{21}$. Quatre listes, dont trois de la main de Baluze, décrivent cet ensemble.

Deux listes de l'été 1677 répertorient le premier lot de manuscrits, venu directement de Mortemer. La plus ancienne est l'accusé de réception autographe de Baluze, daté du 8 août 1677 [= Mortemer A] ${ }^{22}$ :

«Manuscrits de Mortemer portez dans la bibliotheque de Monseigneur le 8. aoust 1677

$[1]^{23}$ Beda in Paulum epistolam ad Romanos. Fol.

[2] Secundum volumen moralium b. Gregorii. Fol.

[3] S. Augustinus in Psalmos. Fol.

[4] Biblia sacra. Fol. Finit in libro quarto Regum.

[5] Sermones s. Augustini \& Ambrosii. Fol.

[6] Beda in epistolas ad Corinthios. Fol.

[7] Bruno episcopus in Pentateuchum. Fol.

[8] Distinctio... verborum de manna in significatione verbi Dei. Fol. Il y a une epistre de Lanfranc.

[9] Summa Willelmi Altissiodorensis. Fol.

[10] Radulfus in Leviticum. Fol.

[11] Sermones varii. Fol.

Hieronymus in Prophetas minores. Fol.

[12] Ambrosius in Lucam. Fol. Il y a l'epistre de Acca à Bede, avec la response de Bede, à la fin.

[13] Pars secunda epistolarum s. Hieronymi. Fol.

[14] De natura divinitatis. Fol ${ }^{24}$.

[15] Interpretatio nominum hebraicorum. Incertus auctor de virtutibus. Seneca de quatuor virtutibus. Versus cujusdam de moribus hominum. Cujusdam excerpta ex scriptura per litteras alphabeti. Fol.

[16] Rabanus in libros Machabæorum. Fol.

[17] S. Bernardus de libero arbitrio. Fol. Et alia quædam.

[18] Quidam commentarius in Evangelia. Solinus. Narratio eorum quæ contigerunt Apollonio Tyrio. Fol.

[19] Vita s. Malachiæ, auctore s. Bernardo. Fol. Et aliæ quædam, etiam s. Anselmi. [20] Ambrosius in Psalmos. Fol. Et alia quædam. Odo Cameracensis in canonem.

[21] Quidam liber theologicus incipiens “Fides est ut dicit Apostolus \&c.”. Fol.

[22] Historia scholastica. Fol.

21. Sur La Trinité de Fécamp, voir la contribution de Stéphane Lecouteux dans ce dossier de Tabularia, qui lui consacre sa thèse de doctorat en histoire médiévale; il me parait cependant important de publier ces listes ici, car elles doivent être comparées avec les autres prélèvements réalisés en Normandie.

22. Paris, BnF, ms lat. 9363, fol. 206-207v; Genevois et al., 1987, p. 143.

23. Les numérotations entre crochets ne figurent pas sur les listes originales.

24. Il pourrait s'agir ici de Hugo de Argentina, dictus Ripelin, Compendium theologicae veritatis. 
[23] Bruno et Radulfus in Leviticum. C'est la glose ordinaire. Gaufridus in Canticum canticorum et in Pater. Fol. Videtur esse Gaufridus Saviniacensis cujus exstat sermo quidam in alio codice, post tractatum Arnulphi Lexoviensis.

[24] Sermones Petri Manducatoris. Fol.

[25] Homiliæ Johannis de Abbatisvilla. Fol.

[26] Testimonia sumpta ex operibus d. Gregorii. Fol.

[27] Hieronymus in Danielem. $4^{\circ}$.

[28] Quidam liber theologicus ex scripturis. $4^{\circ}$.

[29] Hieronymus in Danielem. $4^{\circ}$.

[30] Abbreviatio decreti. Excerpta ex libris juris civilis. Decretales.

[31] Glossæ magistri super Canticum et Stephani Cantuariensis super XII Prophetas \&c. $4^{\circ}$.

[32] Expositio Arnulfi Lexoviensis in annuntiationem dominicam et alia quædam. Fol.

[33] Ivonis episcopi Carnotensis expositio in Psalmos. Fol.

[34] Aratoris subdiaconi historia apostolica in Evangelia metrice $4^{\circ}$.

[35] Guidonis summa dictaminis. $4^{\circ}$. Sermones quidam.

[36] Abdias glossatus \& quidam tractatus de Moyse \& Aaron. $4^{\circ}$.

[37] Ordo divini officii. $4^{\circ}$.

[38] Liber scintillarum. $4^{\circ}$.

[39] Sermones quadragesimales Johannis Bartheloti. $4^{\circ}$.

[40] Breviarium sententiarum magistri Petri. Homiliæ cujusdam. Glossæ in Psalmos. $4^{\circ}$.

[41] Catonis disticha. Floretus, cum glossis. Tractatus de modo pœnitendi, auctore Joanne de Garlandia. $4^{\circ}$.

[42] Varii sermones. $4^{\circ}$.

[43] Quoestiones theologico. $4^{\circ}$.

[44] Sermones varii. $8^{\circ}$.

[45] Sermones varii. $8^{\circ}$.

[46] Sententio de virtutibus \& moribus christianorum. $12^{\circ}$.

[47] Summa magistri Johannis Beleth. $4^{\circ}$.

[48] Tractatus de jure canonico \& civili. $12^{\circ}$.

[49] Glossa ordinaria in Canticum \& in quosdam prophetas minores. Fol.

[50] Glossa ordinaria in Lucam. Fol.

[51-52] Glossa ordinaria in Prophetas minores. Summa Martini de Fugeriis. Glossa ordinaria in Cantica canticorum. Fol.

[53] Glossa ordinaria in Estherem, Tobiam, Ruth \& Judith. Fol.

[54] Glossa ordinaria in Acta apostolorum. Fol., in Epistolas canonicas \& in Apocalypsim. Fol.

[55] Glossa ordinaria in Exodum.

[56] Glossa ordinaria in Esaiam. Fol.

[57] Glossa in Numeros. Cicero de senectute, et alia quædam. Seneca de beneficiis. Fol.

[58] Glossa in Deuteronomium. Fol.

[59] Glossa in Parabolas \& ceteros libros Salomonis. Fol.

[6o] Glossa ordinaria in Lucam \& Johannem. Fol.

[61] Cujus commentarius in Psalmos incipiens a $77^{\circ}$.

En tout 59. 60. [sic] voll.». 
La seconde liste, qui est aussi de la main de Baluze, est sans doute une mise au net simplifiée de la première $[=\text { Mortemer } B]^{25}$ :

«Catalogue des manuscrits de Mortemer, portez dans la bibliotheque de Monseigneur le $8^{\mathrm{e}}$ aout 1677

[1] Beda in epistolam ad Romanos.

[2] Idem in epistolas ad Corinthios.

[3] Secundum volumen moralium b. Gregorii.

[4] Biblia sacra.

[5] Sermones s. Augustini \& Ambrosii.

[6] Bruno episcopus in Pentateuchum.

[7] Distinctio verborum de manna in significatione verbi Dei.

[8] Summa Willelmi Altissiodorensis.

[9] Radulfus Flaviacensis in Leviticum.

[10] Sermones varii.

[11] Ambrosius in Lucam.

[12] Pars secunda epistolarum s. Hieronymi.

[13] De natura divinitatis authore anonymo.

[14] Interpretatio nominum hebraicorum. Incertus auctor de virtutibus. Seneca de virtutibus. Versus cujusdam de moribus hominum.

[15] Rabanus in libros Machabæorum.

[16] S. Bernardus de libero arbitrio.

[17] Quidam commentarius in Evangelia. Solinus. Narratio eorum quæ contigerunt Apollonio Tyrio.

[18] Vita s. Malachiæ, auctore s. Bernardo.

[19] Ambrosius in Psalmos. Odo Cameracensis in canonem.

[20] Quidam liber theologicus incipiens "Fides est ut dicit Apostolus \&c."

[21] Historia scholastica.

[22] Glossa ordinaria in Leviticum. Gaufridus in Canticum.

[23] Sermones Petri Manducatoris.

[24] Homiliæ Johannis de Abbatisvilla.

[25] Testimonia sumpta ex operibus d. Gregorii.

[26] Hieronymus in Danielem.

[27] Quidam liber theologicus ex scripturis.

[28] Hieronymus in Danielem.

[29] Abbreviatio decreti. Excerpta ex libris juris civilis. Decretales.

[30] Glossæ Stephani Cantuariensis super XII. Prophetas.

[31] Expositio Arnulfi Lexoviensis in annuntiationem dominicam et alii multi sermones.

[32] Ivonis episcopi Carnotensis expositio in Psalmos.

[33] Aratoris subdiaconi historia apostolica.

[34] Guidonis summa dictaminis. Sermones quidam.

[35] Abdias glossatus \& quidam tractatus de Moyse \& Aaron.

[36] Ordo divini officii.

[37] Liber scintillarum.

25. Paris, BnF, Baluze 100, fol. 106-109. 
[38] Sermones quadragesimales Johannis Bartheloti.

[39] Breviarium sententiarum magistri Petri. Homiliæ cujusdam.

[40] Catonis disticha. Floretus, cum glossis. Tractatus de modo pœnitendi, auctore Joanne de Garlandia.

[41] Varii sermones.

[42] Quœstiones theologica.

[43] Sermones varii.

[44] Sermones varii.

[45] Sententioe de virtutibus \& moribus christianorum.

[46] Summa magistri Johannis Beleth.

[47] Tractatus de jure canonico \& civili.

[48] Glossa ordinaria in Canticum \& in quosdam prophetas minores.

[49] Glossa ordinaria in Lucam.

[50-51] Glossa ordinaria in Prophetas minores. Summa Martini de Fugeriis. Glossa ordinaria in Canticum.

[52] Glossa ordinaria in Estherem, Tobiam, Ruth \& Judith.

[53] Glossa ordinaria in Acta apostolorum, in Epistolas canonicas \& in Apocalypsim.

[54] Glossa ordinaria in Exodum.

[55] Glossa ordinaria in Esaiam.

[56] Glossa ordinaria in Numeros. Cicero de senectute, \& alia quædam. Seneca de beneficiis.

[57] Glossa in Deuteronomium.

[58] Glossa in Parabolas \& ceteros libros Salomonis.

[59] Glossa in Lucam \& Johannem.

[6o] Cujus commentarius in Psalmos incipiens a $77^{\circ}$.

En tout 6o. voll.».

Les deux listes suivent au début un ordre légèrement différent et la liste $B$ donne des descriptions plus courtes, sans indication de format. 61 volumes sont décrits par la liste A malgré le chiffrage final (deux manuscrits sont décrits dans la même notice 50-51), et seulement 60 par la liste $B$, car le $n^{\circ} 3$ de la première liste y est oublié malgré son arrivée à Paris. Les manuscrits latins 73 et 6360 f. 1-40 constituent vraisemblablement un seul volume au moment de leur arrivée à Paris. Enfin dix textes ne peuvent être identifiés chez Colbert, à cause de descriptions trop brèves ${ }^{26}$.

\begin{tabular}{|l|l|l|l|l|l|l|l|}
\hline & A & B & & $\begin{array}{l}\text { Cotes } \\
\text { actuelles }\end{array}$ & Colbert & & \\
\hline Mortemer & 1 & 1 & latin & 2363 & 5 & XII $^{\mathrm{e}}$-XIII & \\
\hline Mortemer & 6 & 2 & latin & 2365 & 352 & XII $^{\mathrm{e}}$-XIII & \\
\hline Mortemer & 2 & 3 & latin & 2217 & 26 & XII $^{\mathrm{e}}$ s. & \\
\hline
\end{tabular}

26. Il pourrait s'agir entre autres des manuscrits ms lat. $3553,3736,3746$ ? 


\begin{tabular}{|c|c|c|c|c|c|c|c|}
\hline Mortemer & 4 & 4 & latin & 57 & 28 & $\mathrm{XI}^{\mathrm{e}}-\mathrm{XII}^{\mathrm{e}} \mathrm{s}$ & \\
\hline Mortemer & 5 & 5 & latin & 3819 & 208 & $\mathrm{XII}^{\mathrm{e}}-\mathrm{XIII}{ }^{\mathrm{e}} \mathrm{s}$. & \\
\hline Mortemer & 7 & 6 & latin & 2507 & 345 & $\mathrm{XIII}^{\mathrm{e}} \mathrm{s}$. & ex-libris \\
\hline Mortemer & 8 & 7 & latin & $\begin{array}{l}3236 \mathrm{~B} f \\
1-46\end{array}$ & 2322 & $\mathrm{XIII}^{\mathrm{e}} \mathrm{s}$. & \\
\hline Mortemer & 9 & 8 & latin & 3060 & 969 & $\mathrm{XIII}^{\mathrm{e}} \mathrm{s}$. & \\
\hline Mortemer & 10 & 9 & latin & 380 & 2 & $\mathrm{XII}^{\mathrm{e}}-\mathrm{XIII}{ }^{\mathrm{e}} \mathrm{s}$. & ex-libris \\
\hline Mortemer & 11 & 10 & ${ }^{*}$ latin & 3552 & 4251 & $X V^{\mathrm{e}} \mathrm{s}$ & \\
\hline Mortemer & 12 & 11 & latin & 1744 & 2515 & $\mathrm{XIII}^{\mathrm{e}} \mathrm{s}$. & \\
\hline Mortemer & 13 & 12 & latin & 1885 & 2533 & $\mathrm{XII}^{\mathrm{e}} \mathrm{s}$. & ex-libris \\
\hline Mortemer & 14 & 13 & & & & & \\
\hline Mortemer & 15 & 14 & latin & 1860 & 959 & $\mathrm{XIII}^{\mathrm{e}} \mathrm{s}$. & ex-libris \\
\hline Mortemer & 16 & 15 & latin & 2438 & 961 & $\mathrm{XIII}^{\mathrm{e}}-\mathrm{XIV}$ s. & ex-libris \\
\hline Mortemer & 17 & 16 & latin & 2938 & 4175 & $\mathrm{XII}^{\mathrm{e}} \mathrm{s}$. & ex-libris \\
\hline Mortemer & 18 & 17 & latin & $\begin{array}{l}6487 \mathrm{f} . \\
24-40\end{array}$ & 3348 & XII ${ }^{\mathrm{s}}$. & incomplet \\
\hline Mortemer & 19 & 18 & latin & 5367 & 1664 & $\mathrm{XIV}^{\mathrm{e}} \mathrm{s}$. & \\
\hline Mortemer & 20 & 19 & latin & 1734 & 1389 & $\mathrm{XII}^{\mathrm{e}} \mathrm{s}$. & ex-libris \\
\hline Mortemer & 21 & 20 & latin & 3145 & 1979 & $\mathrm{XIII}^{\mathrm{e}} \mathrm{s}$. & \\
\hline Mortemer & 22 & 21 & latin & 5118 & 1466 & $\mathrm{XIII}^{\mathrm{e}} \mathrm{s}$. & ex-libris \\
\hline Mortemer & 23 & 22 & latin & 71 & 1439 & $\mathrm{XIII}^{\mathrm{e}}-\mathrm{XIV}^{\mathrm{e}} \mathrm{s}$ & \\
\hline Mortemer & 24 & 23 & latin & 2602 & 4128 & $\mathrm{XIII}^{\mathrm{e}} \mathrm{s}$. & \\
\hline Mortemer & 25 & 24 & latin & $2518 \mathrm{~B}$ & 724 & $\mathrm{XIII}^{\mathrm{e}} \mathrm{s}$. & \\
\hline Mortemer & 26 & 25 & ${ }^{*}$ latin & 2305 & 4263 & $\mathrm{XIII}^{\mathrm{e}} \mathrm{s}$. & \\
\hline Mortemer & 27 & 26 & latin & 2680 & 4488 & $\mathrm{XIII}^{\mathrm{e}} \mathrm{s}$. & \\
\hline Mortemer & 28 & 27 & latin & 600 & 4518 & $\mathrm{XIII}^{\mathrm{e}} \mathrm{s}$. & ex-libris \\
\hline Mortemer & 29 & 28 & & & & & \\
\hline Mortemer & 30 & 29 & latin & $3922 \mathrm{~A}$ & 718 & $\mathrm{XIV}^{\mathrm{e}} \mathrm{s}$. & ex-libris \\
\hline Mortemer & 31 & 30 & latin & 580 & 4777 & $\mathrm{XIII}^{\mathrm{e}}-\mathrm{XIV}^{\mathrm{e}} \mathrm{s}$ & ex-libris \\
\hline Mortemer & 32 & 31 & latin & 2594 & 4264 & $\mathrm{XII}^{\mathrm{e}}-\mathrm{XIII}{ }^{\mathrm{e}} \mathrm{s}$. & ex-libris \\
\hline Mortemer & 33 & 32 & latin & 2480 & 1473 & $\mathrm{XIII}^{\mathrm{e}} \mathrm{s}$. & \\
\hline Mortemer & 34 & 33 & latin & 8321 & 4734 & $\mathrm{XV}^{\mathrm{e}} \mathrm{s}$. & ex-libris \\
\hline Mortemer & 35 & 34 & latin & 8650 & 4733 & $\mathrm{XIV}^{\mathrm{e}} \mathrm{s}$. & \\
\hline Mortemer & 36 & 35 & ${ }^{*}$ latin & 583 & 5983 & & \\
\hline
\end{tabular}




\begin{tabular}{|c|c|c|c|c|c|c|c|}
\hline Mortemer & 37 & 36 & & & & & \\
\hline Mortemer & 38 & 37 & latin & 2862 & 5969 & $\mathrm{XII}^{\mathrm{e}} \mathrm{s}$. & ex-libris \\
\hline Mortemer & 39 & 38 & & & & & \\
\hline Mortemer & 40 & 39 & latin & 3412 & 4487 & $\mathrm{XIII}^{\mathrm{e}} \mathrm{s}$. & \\
\hline Mortemer & 41 & 40 & latin & 8259 & 4776 & $\mathrm{XV}^{\mathrm{e}} \mathrm{s}$. & \\
\hline Mortemer & 42 & 41 & & & & & \\
\hline Mortemer & 43 & 42 & & & & & \\
\hline Mortemer & 44 & 43 & & & & & \\
\hline Mortemer & 45 & 44 & & & & & \\
\hline Mortemer & 46 & 45 & & & & & \\
\hline Mortemer & 47 & 46 & ${ }^{*}$ latin & 714 & 1977 & $\mathrm{XII}^{\mathrm{e}} \mathrm{s}$. & \\
\hline Mortemer & 48 & 47 & & & & & \\
\hline Mortemer & 49 & 48 & latin & 131 & 1446 & $\mathrm{XIII}^{\mathrm{e}} \mathrm{s}$. & ex-libris \\
\hline Mortemer & 50 & 49 & ${ }^{*}$ latin & 694 & 3959 & $\mathrm{XIII}^{\mathrm{e}} \mathrm{s}$. & $?$ \\
\hline Mortemer & 51 & 50 & latin & 143 & 1444 & $\mathrm{XIII}^{\mathrm{e}} \mathrm{s}$. & ex-libris \\
\hline Mortemer & 52 & 51 & latin & 3116 & 752 & $\mathrm{XIV}^{\mathrm{e}} \mathrm{s}$ & ex-libris \\
\hline Mortemer & 53 & 52 & latin & 92 & 1442 & $\mathrm{XIII}^{\mathrm{e}} \mathrm{s}$. & ex-libris \\
\hline Mortemer & 54 & 53 & latin & 308 & 1448 & $\mathrm{XIII}^{\mathrm{e}} \mathrm{s}$. & ex-libris \\
\hline Mortemer & 55 & 54 & latin & 69 & 1437 & $\mathrm{XIII}^{\mathrm{e}} \mathrm{s}$. & \\
\hline Mortemer & 56 & 55 & latin & 145 & 1443 & $\mathrm{XIII}^{\mathrm{e}} \mathrm{s}$. & ex-libris \\
\hline Mortemer & 57 & 56 & latin & 73 & 1440 & $\mathrm{XIII}^{\mathrm{e}} \mathrm{s}$. & ex-libris \\
\hline Mortemer & 57 & 56 & latin & $\begin{array}{l}6360 \mathrm{f} . \\
1-40\end{array}$ & 1972 & $\mathrm{XIII}^{\mathrm{e}} \mathrm{s}$. & ex-libris \\
\hline Mortemer & 58 & 57 & latin & 75 & 1438 & $\mathrm{XIII}^{\mathrm{e}}-\mathrm{XIV}^{\mathrm{e}} \mathrm{s}$ & rel. 1 \\
\hline Mortemer & 59 & 58 & latin & 122 & 1441 & $\mathrm{XIII}^{\mathrm{e}}-\mathrm{XIV}^{\mathrm{e}} \mathrm{s}$ & rel. 1 \\
\hline Mortemer & 60 & 59 & latin & 289 & 1447 & $\mathrm{XII}^{\mathrm{e}} \mathrm{s}$. & \\
\hline Mortemer & 61 & 60 & latin & 2522 & 863 & $\mathrm{XIII}^{\mathrm{e}} \mathrm{s}$. & rel. 1 \\
\hline Mortemer & 3 & $?$ & ${ }^{*}$ latin & 1995 & 36 & $\mathrm{XIII}^{\mathrm{e}} \mathrm{s}$. & \\
\hline
\end{tabular}

Un second lot de 54 manuscrits arrive quelques mois plus tard par l'intermédiaire du premier président du parlement de Rouen, Claude Pellot ${ }^{27}$. Ami et parent de Colbert (sa première et sa seconde épouses sont des cousines du ministre), Pellot lui procure régulièrement, dès 1674, toutes sortes de livres.

27. Claude Pellot (1619-1683); O’ReIlly, 1882, II, p. 510-532. 
Fabre, son secrétaire, envoie le 3 octobre 1677 une lettre à Baluze accompagnée d'une liste antérieure à la réception des manuscrits, qui décrit 53 volumes en 52 notices $[=\text { Mareste } \mathrm{A}]^{28}$ :

«Ce dimanche matin 3 octobre 1677

Vous trouverez Monsieur cy joint le memoire ou inventaire des livres manuscrits que j'eus l'honneur de vous remettre hyer entre les mains pour Monseigneur Colbert; je ne doute pas que vous ne luy en ayez desjà parlé hyer à son arrivée. Je vous demande s'il vous plait Monsieur un peu de part dans vos bonnes graces et de me faire naistre quelqu'occasion où je puisse vous marquer l'estime que j'ay pour une personne de votre merite et combien je suis passionnement

Vostre très humble et tres obeissant serviteur Fabre secretaire de M. Pellot P. P. de Rouen».

«Elenchus mss. codicum domini de Mareste d'Alge

Codices in folio.

[1] Commentarius $\mathrm{d}^{\mathrm{i}}$ Augustini in Psalmos a psalmo $50^{\circ}$ usque ad $100^{\mathrm{m}}$.

[2] Commentarius ejusdem in Psalmos a $51^{\circ}$ usque ad $70^{\mathrm{m}}$.

[3] Commentarius ejusdem in Psalmos a psalmo $70^{\circ}$. In cujus commentarii fine exstant tres epistolæ Adæ abbatis Perseniæ ad Osmundum monachum Mortuimaris.

[4] Ejusdem confessiones.

[5] Ejusdem de trinitate libri 15.

[6] Ejusdem enchiridion \& varii tractatus.

[7] Ejusdem de verbis Domini.

[8] Ejusdem varii tractatus.

[9] Biblice sacrae tomus primus continens omnia usque ad $2^{m}$ librum Regum inclusive.

[10] Commentarius $\mathrm{d}^{\mathrm{i}}$ Ambrosii in psalmum $118^{\mathrm{m}}$.

[11] Haymo in Apocalypsim.

[12] Idem in Isaiam.

[13] Commentarius integer in Psalmos davidicos, ignoti authoris.

[14] Commentarius in Proverbia, Sapientium, Canticum canticorum \& Ecclesiasticum, authoris incerti.

[15] Commentarius in Job, Esdram et Marcum, authoris incogniti.

[16] Commentarius in epistolas $b^{i} s^{i}$ Pauli, authoris incogniti.

[17] Commentarius Hugonis de So Jacobo in Lucam.

[18] Commentarius venerabilis Bedæ in Acta apostolorum, in epistolam $\mathrm{s}^{\mathrm{i}} \mathrm{Jacobi}$, in epistolas $\mathrm{s}^{\mathrm{i}}$ Jaeobi Petri, in epistolas $\mathrm{s}^{\mathrm{i}}$ Johannis, in epistolam $\mathrm{s}^{\mathrm{i}} \mathrm{Jud}$, in Apocalypsim.

[19] Catena ss. patrum in Genesim.

[20] Magistri sententiarum libro duo.

[21] Libellus $\mathrm{s}^{\mathrm{i}}$ Ildefonsi de virginitate $\mathrm{b}^{\mathfrak{x}}$ Mariæ; in eadem volumine sermones Petri Damiani ex quibus desunt capitula.

[22] Sidonii Apollinaris epistolo.

28. Paris, BnF, ms lat. 9363, fol. 212 et 210-211; Genevors et al., 1987, p. 131. 
[23] Eusebii historia latine reddita a Ruffino. In quo volumine habetur Petrus Alphonsus contre Judæos.

[24] Ejusdem Eusebii historia in cujus fine habetur disputatio Arii contra $\mathrm{d}^{\mathrm{m}}$ Athanasum tunc diaconum \& postea episcopum.

[25] Vitæ sanctorum incipientes a martyrio si Andeoli, desinentes in vitam ${ }^{\text {si }}$ Genesii. [26] Vitæ sanctorum incipientes a vita si Fulgentii \& desinentes in vitam sæ Bathildis. [27-28] Historiæ Morinannorum Orderici Vitalis tomi duo.

Codices in $4^{\circ}$.

[29] Psalterium glossatum. Itidem ex dictis $d^{i}$ Augustini. Itidem tractatulus sic incipiens "Ferculum fecit sibi rex Salomon etc."

[30] Commentarius in Leviticum authoris incogniti.

[31] Commentarius in Mathæum \& in epistolas $\mathrm{s}^{\mathrm{i}}$ Jacobi, authoris incogniti.

[32] $\mathrm{S}^{\mathrm{i}}$ Ambrosii de officiis libri tres.

[33] $\mathrm{D}^{\text {us }}$ Augustinus de sermone domini in monte.

[34] Pastorale di Gregorii papæ.

[35] Smaragdi diadema monachorum.

[36] Monologion \& prosologion $s^{\mathrm{i}}$ Anselmi cum meditationibus ejusdem.

[37] Gaufridus prior Clarævallis in illud Ecclesiastis "Memento creatoris \&c."

[38] Dictionarium theologicum.

[39] Enarratio Leontii episcopi Neapoleos Cypriorum insulæ de vita \& actione $s^{i}$ patris nostri Joannis episcopi Alexandriæ.

[40] Epistolæ aliquot di Bernardi abbatis et Ildeberti Turonensis episcopi.

[41] Speculum Adalberti levitæ.

[42] $\mathrm{D}^{\mathrm{s}}$ Bernardus in "Missus est". Itidem dialogus magistri Hugonis de veteri testamento.

[43] Sidonii Apollinaris epistolæ.

[44] Commentarius in epistolas $\mathrm{s}^{\mathrm{i}}$ Pauli, authoris incogniti.

[45] Histoire en brief prise sur les dialogues de $s^{t}$ Gregoire.

Codices in $8^{\circ}$.

[46] Sermones authoris incogniti.

[47] Sermones Serlonis abbatis.

[48] Hugo ad Galterum de anima Christi. Itidem tractatus in hæc verba psalmi

"Quoniam fecisti judicium meum \&c.". Itidem tractatus in hæc verba "Missus est Gabriel \&c.".

[49] Summarium pulchrum de vitiis \& virtutibus in omni statu.

[50] Quæstiones magistri Hugonis de Gandavo.

[51] Commentum Macrobii in somnium Scipionis.

[52] Commentarius in hymnos ecclesiæ.

[53] Manuale $\mathrm{d}^{\mathrm{i}}$ Augustini sive tractatus de contemplatione Christi».

L'accusé de réception de Baluze ne recoupe pas totalement la liste de Fabre; il décrit 54 volumes en 53 notices $\left[=\right.$ Mareste B ${ }^{29}$ :

"Catalogue des manuscrits que M. Pelot, premier president de Rouen, a envoyez à Monseigneur le 2. octobre 1677. [add. en marge:] Il y en a en tout 54

29. Paris, BnF, ms lat. 9363, fol. 208-209. 
[1] S. Augustinus in Psalmos a 52. usque ad 100. Fol.

[2] Vitæ sanctorum. Incipit a passione $\mathrm{s}^{\mathrm{ti}}$ Fulgentii. Fol.

[3] Vitæ sanctorum. Incipiunt a passione s. Andeoli. Fol.

[4] Augustinus in Psalmos a 51. usque ad 70. Fol.

[5] Glossa ordinaria in Job \& Esdram cum fragmentis in Marcum. Fol.

[6] Eusebii historia, Rufino interprete. Disputatio de fide inter Arrium \& Athanasium. Fol.

[7] S. Ambrosius in Psalmos incipit a 118 psalmum 118. Fol.

[8] Haymo in Isaiam. Fol.

[9] Commentarius in Psalmos id est glossa ordinaria. Fol.

[10] Augustinus in Matthæum \& in Johannem. Fol.

[11] Hugonis de S. Jacobo postilla super Lucam. Fol.

[12] Eusebii historia, Rufino interprete. Petrus Alphonsus contra Judæos. Fol.

Eusebii historia, Rufino interprete.

[13] Glossa ordinaria in Proverbia, Ecclesiastem, Sapientiam, Canticum et Ecclesiasticum. Fol.

[14] Glossa ordinaria in epistolas Pauli. Fol.

[15] Hieronymus in Marcum, Beda in Marcum, Augustini quæstiones evangelii. Homelia s. Anselmi monachi Flaviacensis. Sermo Hieronymi de assumptione s. Mariæ. Fol.

[16] Prima pars bibliorum finit in libris Regum. Fol.

[17] Haymo in Esaiam. Fol.

[18] Beda in Actus Apostolorum \& in Epistolas canonicas \& in Apocalypsim. Fol.

[19] Confessiones s. Augustini. Fol.

[20] Glossa ordinaria in Genesim. Fol.

[21] Sententiæ Petri Lombardi. Fol.

[22] Origenes in epistolam ad Romanos. Haymo in Apocalypsim.

[23] Opera s. Hildephonsi. Visio s. Elisabeth ancillæ Domini de resurrectione s. Mariæ. Mileti narratio de assumptione s. Mariæ. Epistolæ \& opuscula quædam Petri Damiani. Fol.

[24] Augustinus de Trinitate. Fol.

[25] Epistolo Sidonii. Fol.

[26] S. Augustini enchiridion, soliloquium, de moribus ecclesiæ catholicæ, de ordine rerum. Fol.

[27] Willelmus Gemeticensis. Vita Karoli magni. Abbreviatio gestorum regum francorum. Fol.

[28] Henricus Huntindoniensis. Fol.

[29-30] Ordericus Vitali. Fol. 2 voll.

[31] Commentarius in Psalmos. Fol.

[32] Hieronymus in Mattheum \& Danielem.

[33] Vita s. Anastasiæ s. Silvestri, s. Fulgentii, s. Genovefæ. Anselmi Cantuar. de spiritu so. Fulcoius Belvacensis. Fol.

[34] S. Ambrosius de officiis. $4^{\circ}$.

[35] Monologion s. Anselmi et alia quædam. $4^{\circ}$.

[36] Epistolæ Senecæ. Epistolæ Sidonii. $4^{\circ}$.

[37] Augustinus in Psalmos a $70^{\circ}$. \& in fine quatuor epistolæ Adami abbatis Perseniæ. Folio.

[38] Dictionarium theologicum. $4^{\circ}$. 
[39] Glossa ordinaria in Leviticum. $4^{\circ}$.

[40] Gaufridus Clarævallensis in illud Ecclesiastici Memento creatoris tui. Idem in Cantica. $4^{\circ}$.

[41] Speculum Adalberti levitæ, ex moralibus s. Gregorii. $4^{\circ}$.

[42] Liber pastoralis s. Gregorii. $4^{\circ}$.

[43] Smaragdi diadema monachorum. Admonitio s. Hieronymi. S. Basilii ad monachos. $4^{\circ}$.

[44] Histoire extraicte des dialogues de s. Gregoire. Apparition de s. Hierosme. L'aiguillon d'amour divin par s. Bonaventure. $4^{\circ}$.

[45] Vita s. Joannis Eleemosynarii, interprete Anastasio. Admonitio s. Augustini ad populum, dum ad ecclesiam vadunt. Exempla quædam adversus luxuriam. Epistola s. Jacobi Apostoli, Petri \& Johannis et fragmenta Apocalypsis. $4^{\circ}$.

[46] Magistri Hugonis dialogus de veteri testamento.

[47] Sermones varii. $4^{\circ}$.

[48] Commentarius in epistolas ad Romanos \& ad Corinthios. $8^{\circ}$.

[49] Macrobius in somnium Scipionis. $8^{\circ}$.

[50] Liber theologicæ veritatis. Quæstiones Henrici de Gandavo. $8^{\circ}$

[51] Hieronymus in Evangelia. Serlonis abbatis sermones. $4^{\circ}$.

[52] Summarium de vitiis et virtutibus. $8^{\circ}$.

[53] Manuale s. Augustini.

[54] Quidam commentarius in hymnos ecclesiasticos \& alia quædam. $8^{\circ}$.».

Parmi les 53 (liste A) ou 54 volumes (liste B) décrits, une Bible incomplète, un commentaire sur les Psaumes et un Sidoine Apollinaire ne sont pas identifiés $\left(n^{\circ} 9 / 16,13 / 9,22 / 25\right)$. Les listes concordent pour les autres, à l'exception de cinq volumes qui ne figurent que dans la liste $\mathrm{A}$, de six qui ne sont inscrits que sur la liste B et enfin de deux qui ne sont dans aucune. Plusieurs manuscrits proviennent de Mortemer.

\begin{tabular}{|c|c|c|c|c|c|c|c|}
\hline & A & B & & $\begin{array}{l}\text { Cotes } \\
\text { actuelles }\end{array}$ & Colbert & & \\
\hline Mareste & 1 & 1 & latin & 1992 & 52 & $\mathrm{XII}^{\mathrm{e}} \mathrm{s}$. & \\
\hline Mareste & 26 & 2 & latin & 5341 & 59 & $\mathrm{XII}^{\mathrm{e}} \mathrm{s}$. & $\begin{array}{l}\text { ex-libris } \\
\text { Mortemer }\end{array}$ \\
\hline Mareste & 25 & 3 & latin & 5296 & 53 & $\mathrm{XIII}^{\mathrm{e}} \mathrm{s}$. & \\
\hline Mareste & 2 & 4 & latin & 1997 & 37 & $\mathrm{XIII}^{\mathrm{e}} \mathrm{s}$. & [Mortemer] \\
\hline Mareste & 15 & 5 & latin & 99 & 1421 & $\mathrm{XIII}^{\mathrm{e}} \mathrm{s}$. & rel. Mareste \\
\hline Mareste & 23 & 6 & latin & 5080 & 2044 & $\mathrm{XIII}^{\mathrm{e}} \mathrm{s}$. & \\
\hline Mareste & 10 & 7 & latin & 1736 & 594 & $\mathrm{XII}^{\mathrm{e}} \mathrm{s}$. & [Mortemer] \\
\hline Mareste & 12 & 8 & latin & 2405 & 595 & $\mathrm{XII}^{\mathrm{e}} \mathrm{s}$. & rel. Mareste \\
\hline Mareste & 13 & 9 & & & & & \\
\hline Mareste & 7 & 10 & latin & 2019 & 343 & $\mathrm{XII}^{\mathrm{e}} \mathrm{s}$. & $\begin{array}{l}\text { [Mortemer] } \\
\text { rel. } 1\end{array}$ \\
\hline
\end{tabular}




\begin{tabular}{|c|c|c|c|c|c|c|c|}
\hline Mareste & 17 & 11 & latin & 633 & 1564 & XIII ${ }^{\mathrm{e}}$ s. & \\
\hline Mareste & 24 & 12 & latin & 5073 & 598 & $\mathrm{XII}^{\mathrm{e}} \mathrm{s}$. & $\begin{array}{l}\text { ex-libris } \\
\text { Mortemer }\end{array}$ \\
\hline Mareste & 14 & 13 & latin & 123 & 1445 & $\begin{array}{l}\text { XIII'- } \\
\text { XIV }^{\mathrm{e}} \text { s. }\end{array}$ & rel. Mareste \\
\hline Mareste & 16 & 14 & latin & 658 & 2068 & $\mathrm{XII}^{\mathrm{e}} \mathrm{s}$. & \\
\hline Mareste & & 15 & latin & 1851 & 1992 & $\mathrm{XII}^{\mathrm{e}} \mathrm{s}$. & $\begin{array}{l}\text { ex-libris } \\
\text { Mortemer }\end{array}$ \\
\hline Mareste & 9 & 16 & & & & & \\
\hline Mareste & & 17 & latin & 2407 & 441 & $\mathrm{XII}^{\mathrm{e}} \mathrm{s}$. & $\begin{array}{l}\text { [Mortemer] } \\
\text { rel. } 1\end{array}$ \\
\hline Mareste & 18 & 18 & latin & 2361 & 2061 & $\mathrm{XII}^{\mathrm{e}} \mathrm{s}$. & [Mortemer] \\
\hline Mareste & 4 & 19 & latin & 1916 & 2745 & XII ${ }^{\mathrm{e}} \mathrm{s}$. & [Mortemer] \\
\hline Mareste & 19 & 20 & latin & 63 & 1485 & $\mathrm{XII}^{\mathrm{e}} \mathrm{s}$. & $\begin{array}{l}\text { [Mortemer?] } \\
\text { rel. Mareste }\end{array}$ \\
\hline Mareste & 20 & 21 & latin & 3029 & 2158 & $\mathrm{XII}^{\mathrm{e}} \mathrm{s}$. & $\begin{array}{l}\text { ex-libris } \\
\text { Mortemer }\end{array}$ \\
\hline Mareste & 11 & 22 & latin & 1642 & 1731 & $\mathrm{XII}^{\mathrm{e}} \mathrm{s}$. & \\
\hline Mareste & 21 & 23 & latin & 2332 & 2060 & $\mathrm{XII}^{\mathrm{e}} \mathrm{s}$. & $\begin{array}{l}\text { ex-libris } \\
\text { Mortemer }\end{array}$ \\
\hline Mareste & 5 & 24 & latin & 2087 & 2429 & $\mathrm{XII}^{\mathrm{e}} \mathrm{s}$. & \\
\hline Mareste & 22 & 25 & & & & & \\
\hline Mareste & 6 & 26 & latin & 2037 & 2423 & $\mathrm{XII}^{\mathrm{e}} \mathrm{s}$. & [Mortemer] \\
\hline Mareste & & 27 & latin & 5999 & 921 & XIII' s. & [Mortemer] \\
\hline Mareste & & 28 & latin & 6042 & 3969 & $\mathrm{XIV}^{\mathrm{e}} \mathrm{s}$ & \\
\hline Mareste & 27 & 29 & latin & $5123^{1}$ & 760 & $\mathrm{XIII}^{\mathrm{e}} \mathrm{s}$. & \\
\hline Mareste & 28 & 30 & latin & $5123^{2}$ & 761 & XIII's. & \\
\hline Mareste & 29 & 31 & latin & 437 & 4100 & $\mathrm{XII}^{\mathrm{e}} \mathrm{s}$. & \\
\hline Mareste & & 32 & latin & 1843 & 704 & $\mathrm{XII}^{\mathrm{e}} \mathrm{s}$. & \\
\hline Mareste & & 33 & latin & 5305 & 738 & $\mathrm{XII}^{\mathrm{e}} \mathrm{s}$. & \\
\hline Mareste & 32 & 34 & latin & 2645 & 4484 & XIII' s. & \\
\hline Mareste & 36 & 35 & latin & 2882 & 4735 & $\mathrm{XII}^{\mathrm{e}} \mathrm{s}$. & $\begin{array}{l}\text { ex-libris } \\
\text { Mortemer }\end{array}$ \\
\hline Mareste & 43 & 36 & latin & 2784 & 4771 & XIII' ${ }^{\mathrm{e}} \mathrm{s}$. & [Mortemer] \\
\hline Mareste & 3 & 37 & latin & 1998 & 2982 & XIII's. & [Mortemer] \\
\hline Mareste & 38 & 38 & latin & 3664 & 4769 & XIII' ${ }^{\mathrm{e}} \mathrm{s}$. & \\
\hline Mareste & 30 & 39 & latin & 535 & 4486 & & ex-libris, rel. 1 \\
\hline
\end{tabular}




\begin{tabular}{|c|c|c|c|c|c|c|c|}
\hline Mareste & 37 & 40 & latin & 559 & 4778 & $\begin{array}{l}\mathrm{XII}^{\mathrm{e}}- \\
\mathrm{XIII}^{\mathrm{e}} \mathrm{s} .\end{array}$ & \\
\hline Mareste & 41 & 41 & latin & 2871 & 4192 & $\mathrm{XII}^{\mathrm{e}} \mathrm{s}$. & $\begin{array}{l}\text { ex-libris } \\
\text { Mortemer }\end{array}$ \\
\hline Mareste & 34 & 42 & latin & 2801 & 4775 & $\mathrm{XII}^{\mathrm{e}} \mathrm{s}$. & rel. Mareste \\
\hline Mareste & 35 & 43 & latin & 2868 & 4489 & $\mathrm{XII}^{\mathrm{e}} \mathrm{s}$. & \\
\hline Mareste & 45 & 44 & français & 1834 & 4736 & $\mathrm{XV}^{\mathrm{e}} \mathrm{s}$. & \\
\hline Mareste & 39 & 45 & latin & 5603 & 4483 & $\mathrm{XIII}^{\mathrm{e}}$ s. & [Mortemer] \\
\hline Mareste & 42 & 46 & latin & 2929 & 4773 & $\mathrm{XII}^{\mathrm{e}} \mathrm{s}$. & $\begin{array}{l}\text { ex-libris } \\
\text { Mortemer }\end{array}$ \\
\hline Mareste & 46 & 47 & latin & 3554 & 6022 & $\mathrm{XIV}^{\mathrm{e}}$ s. & \\
\hline Mareste & 44 & 48 & latin & 310 & 1498 & $\mathrm{XII}^{\mathrm{e}} \mathrm{s}$. & rel. Mareste \\
\hline Mareste & 51 & 49 & latin & 6764 & 6021 & $X V^{e} s$. & \\
\hline Mareste & 50 & 50 & latin & 3686 & 6507 & XIV's. & \\
\hline Mareste & 47 & 51 & latin & $2681 \mathrm{~A}$ & 6018 & $\mathrm{XIII}^{\mathrm{e}}$ s. & \\
\hline Mareste & 49 & 52 & latin & 3712 & 6508 & $\mathrm{XIII}^{\mathrm{e}}$ s. & \\
\hline Mareste & 53 & 53 & latin & 2976 & 6498 & $\mathrm{XV}^{\mathrm{e}} \mathrm{s}$. & \\
\hline Mareste & 52 & 54 & latin & 8447 & 3729 & $\mathrm{XIV}^{\mathrm{e}} \mathrm{s}$. & \\
\hline Mareste & & & latin & 2089 & 644 & $\mathrm{XII}^{\mathrm{e}} \mathrm{s}$. & [Mortemer] \\
\hline Mareste & & & latin & 4863 & 1701 & $\mathrm{XIII}^{\mathrm{e}} \mathrm{s}$. & $\begin{array}{l}\text { nécrologe } \\
\text { Mortemer }\end{array}$ \\
\hline Mareste & 8 & & latin & 1941 & 2075 & $\begin{array}{l}\mathrm{XII}^{\mathrm{e}}- \\
\mathrm{XIII}^{\mathrm{e}} \mathrm{s} .\end{array}$ & \\
\hline Mareste & 31 & & latin & 691 & 4145 & $\mathrm{XIII}^{\mathrm{e}} \mathrm{s}$. & \\
\hline Mareste & 40 & & latin & 2905 & 4168 & $\mathrm{XII}^{\mathrm{e}} \mathrm{s}$. & [Mortemer] \\
\hline Mareste & 33 & & latin & 2716 & 4774 & $\mathrm{XIII}^{\mathrm{e}} \mathrm{s}$. & [Mortemer] \\
\hline Mareste & 48 & & latin & 2914 & 6020 & $\mathrm{XII}^{\mathrm{e}} \mathrm{s}$. & [Mortemer] \\
\hline
\end{tabular}

Plusieurs volumes provenant de l'abbaye cistercienne sont signalés dans le catalogue du XIII siècle $^{30}$. Quant au recueil de sermons de saint Augustin $\mathrm{du} \mathrm{X}^{\mathrm{e}}$ siècle, l'un des plus anciens manuscrits étudiés, il ne peut être identifié précisément dans les listes, à moins qu'il ne corresponde aux recueils de sermons décrits très rapidement par la liste $\mathrm{A}$. Seule sa reliure le rattache donc à Mortemer ${ }^{31}$.

30. Paris, BnF, ms lat. 92, 131, 143, 145, 308, 380, 1734, 1885, 2332, 2507, 2938, 3116, 3922A, 5073, 5118, $5123^{1-2}$; Dolbeau, 1988, p. 95-108.

31. Paris, BnF, ms lat. 2016, (Colbert 1001); LaffitTe, 1999, p. 203. 
Enfin une liste de 14 volumes figure sous le titre "Mortui Maris" dans les dossiers manuscrits de la Bibliotheca bibliotecarum de Bernard de Montfaucon; elle n'y est pas publiée $[=\text { Mortemer } \mathrm{C}]^{32}$ :

[1] «S. Gregorius de conflictu virtutum et vitiorum - S. Augustini exhortationes ad comitem - Admonitio s. Hieronymi de appetitu virtutum - Joannis de Isauria exhortatio ne is qui peccat ad poenitendum torpescat - Decem homilioe Eusebii Emisseni ad monachos. Item alice homilice ejusdem - Apologeticum sive defensio s. Bernardi ad Villelmum abbatem - ejusdem epistola Henrico Senonensi.

[2] Ricardus de So Victore de 2. Patriarchis - Sermones duo de $s^{o}$ Benedicto. Item ejus vita metro edita ab Aimino monacho.

[3] Sermones de 7. Propugnaculis. Item de diversis et in fine versus.

[4] Sermones ss. Augustini, Greg. Et aliorum.

[5] Seminarium Petri cancellarii Carnotensis. Varii sermones ${ }^{i}$ Bernardi et Villelmi de Pontearchoe.

[6] Homilia si Joannis Chrisostomi et in fine ejus vita.

[7] Biblia sacra versionis ut puto s. Hieronimi.

[8] S. Ambrosius de bono mortis - Idem de fuga seculi.

[9] Pars biblice pluribus in locis mutila.

[1o] Historia b. Clementis pape. Ejusdem epistola ad Jacobum Jerosolimonim episcopum - Plures vite sanctorum - Dialogus s ${ }^{\text {ti }}$ Gregorii papee.

[11] Commentarium in Psalmos - De anima quid sit \&c. - Vita s. Mariæ Ægytiacæ metro edita.

[12] Sermones de tempore cum expositione antiphonarum "O sapientia \&c." numeri 9. sed cujus sint autoris non patet. Item sermones de sanctis.

[13] Glose Gaufridi Babionis super Mathoum - In fine Beda de computo vel loquela digitorum.

[14] Sermones s. Bernardi».

Ces descriptions n'ont leur équivalent dans aucune des listes précédentes et correspondent peut-être aux volumes restés à Mortemer en 1677. En effet, les numéros [11] «Commentarium in Psalmos - De anima quid sit \&c. - Vita s. Mariæ Ægytiacæ metro edita» et [14] «Sermones s. Bernardi» décrivent deux recueils du XII ${ }^{e}$ siècle entrés tardivement à la Bibliothèque nationale, qui portent l'ex-libris de Mortemer et une reliure médiévale de type ancien (rel. 1) ${ }^{33}$; un recueil de poésies de Guillaume de Digulleville, passé à Clairvaux, se trouve à la Bibliothèque de l'Arsenal ${ }^{34}$.

\section{Savigny (juin 1678-janvier 1679)}

Le cas de Savigny-le-Vieux est remarquable, car l'abondante correspondance du principal acteur de l'opération, Pierre Du Molinet ${ }^{35}$, avec ses aides et avec

32. Paris, BnF, ms lat. 13068, fol. 67-v; Dolbeau, 1988, p. 102.

33. Paris, BnF, nouv. acq. lat. 736 et 735; BondÉElle-Souchier, 1991, p. 227.

34. Bibliothèque de l'Arsenal, ms 3646; BondéELLE-Souchier, 1991, p. 226.

35. Pierre Du Molinet, conseiller du roi en ses conseils, commissaire général pour la réformation du papier terrier des domaines en Bretagne depuis 1664-1665, commissaire député par le roi 
Baluze, ainsi que quatre listes retracent les étapes successives de l'acquisition de 16 volumes : visite, rédaction d'une liste, choix de Baluze, transfert à Paris ${ }^{36}$. Basé à Fougères, Rennes ou Nantes, Du Molinet a auparavant tenté d'obtenir des manuscrits de Saint-Martin et de Saint-Gatien de Tours et écumé la Bretagne sans résultat. En juin 1678, il commence ses recherches en Normandie au Mont-Saint-Michel, où les moines lui montrent leurs manuscrits enfermés derrière des grilles ${ }^{37}$ ! Pillée par les Huguenots en 1562, l'abbaye de Savigny conserve encore au $\mathrm{XVII}^{\mathrm{e}}$ siècle au moins cent manuscrits médiévaux; elle va céder à ses avances.

Dans la première lettre, Baraton, prieur de Rillé ${ }^{38}$, raconte sa visite à Savigny avec messieurs Pocquet et Durohanys ${ }^{39}$ :

«A monsieur Du Molinet à Nantes». «A Fougeres le 16 juin 1678. Monsieur, Nous avons été à Savigny mais nous n'avons fait d'aigrir notre appetit et regretter encore plus de ne vous avoir pas tout à fait engagé à y aller, cela merite bien que vous derobiez quelques jours... Nous avons veu un bien beau $s^{t}$ Gregoire pape $^{40}$, beaucoup d'ouvrages de $\mathrm{s}^{\mathrm{t}}$ Augustin... aussy les epitres de Ciceron et celles d'Æneus Silvius d'impression de Paris de 1477 in folio... Votre très humble Baraton prieur de Rillé».

Onze jours plus tard, Durohanys confirme cet avis favorable à Du Molinet ${ }^{41}$ :

«De Fougeres le $27^{\mathrm{e}}$ juin 1678. Monsieur, Le pere prieur de Rillé desira que je l'accompagnasse à Savigné [sic], nous y fumes ensemble samedy avec monsieur Pocquet. Les relligieux nous reçeurent le plus agreablement du monde et nous y trouvames quantité de manuscrits la plupart parfaittement peints mais il leur manque les feuilletz du commencement et de la fin et pour pouvoir, Monsieur, en faire un catalogue fort exact, il faudroit y employer quelque temps \& je suis persuadé que vous en feriez plus, Monsieur, dans un seul jour, que le pere prieur ny moy ne sçaurions faire dans huict, parce que profond et habile comme vous estes vous en jugeriez à la seule inspection, au lieu que pour en pouvoir tirer quelque chose, il faudroit que le pere et moy les parcourussions quasy chascun entierement. Outre les manuscrits qui sont à Savigné, il y en a quelques autres entre les mains d'un des antiens relligieux et surtout une bible qui est tres curieuse et tres belle, ce mesme relligieux qui est un homme sçavant a quantité de medailles, ainsy Monsieur, si

pour régler la réformation et la réunion des domaines du duché de Penthièvre à partir de 1692; Godin, 1999, p. 7.

36. Abbaye de Savigny, dioc. Avranches, dép. Manche, congrégation de Savigny, fondée en 1112 par Vital, devenue cistercienne en 1147; Deville, 1916, p. 271-288; Delisle, 1868, p. 463-464 et 527-531 (éd. partielle de la liste Savigny A); Dolbeau, 1979, p. 197; Bondéelle-Souchier, 1991, p. 279-283, 15 mss Colbert, dont Paris, BnF, ms lat. 1977, cité à la place du ms lat. 1957 (?), ms lat. 2543 et 2871, qui ne viennent pas de Savigny.

37. Paris, BnF, ms lat. 9363, fol. 241 et ss.; DeLisle, 1868, p. 463.

38. Abbaye Saint-Pierre de Rillé, dép. Ille-et-Vilaine, chef-lieu de cant., c. Fougères.

39. Paris, BnF, ms lat. 9363, fol. 259-260v. Les pièces sur Savigny se trouvent dans un groupe de lettres de Du Molinet et de La Barre à Baluze concernant surtout leur mission à Tours.

40. Sans doute Paris, BnF, ms lat. 2286.

41. Paris, BnF, ms lat. 9363, fol. 261-262v. 
dans quelque temps vous pouviez prendre le loisir d'y venir... Vostre tres humble \& tres obeissant serviteur Durohanys».

À partir du 28 juin, Du Molinet envoie «A Monsieur l'abbé Baluze bibliothécaire de monseigneur Colbert rue Vivien à Paris» plusieurs lettres ${ }^{42}$ :

«... J'ay aussy envoyé en l'abbaye de Savigny un homme qui estoit a deffunct monsieur de Rennes ${ }^{43}$ qui estoit avec avec un aultre capable de faire un bon catalogue de ce qui se trouvera... $28^{\mathrm{e}}$ juin $1678 \ldots$ ».

«...J'ay aussy receu response de ceux que j'avois envoié à Savigny pour faire l'inventaire des manuscrits qui y sont mais ils ne m'ont pas donné la satisfaction que j'esperois. Je vous envoie leurs lettres... $5^{\mathrm{e}}$ juillet $1678 \ldots$..

Puis, dans une longue missive du $1^{\mathrm{er}}$ octobre 1678 , il raconte sa propre visite à Savigny ${ }^{44}$ :

«... J'ay esté en faisant mon voiage de Normandie en l'abbaye de Savigny où j'ay veu tous les mss. dont je vous envoie le memoire que j'en ay faict. J'ay pris des mesures pour vous envoier ceux que vous desirerez. Je vous diray Monsieur que j'ay remarqué deux choses assez curieuses dans ceste abbaye à ce sujest. La $1^{\text {ere }}$ est un ancien catalogue des livres qui estoient dans ceste abbaye en l'annee 1240 [corr.pro 1440] ${ }^{45}$ que ceste abbaye inventaire a esté faict et [que bien que] ce ne fust que cent vingt huit ans depuis la fondation, il y avoit plus de mil manuscripts sur differentes matieres et si cela n'avoit point esté dissipé ce seroit un tresor incomparable y ayant beaucoup de choses qui n'ont poinct paru. Cet inventaire est en velin entre les mains d'un des anciens religieux qui me l'a faict veoir. La $2^{\mathrm{e}}$ est un ancien rotulaire (ainsy qu'ils l'appellent $)^{46} \ldots$ A Nantes le $1^{\text {er }}$ octobre 1678 Du Molinet».

Le catalogue médiéval existe encore en 1687, quand Dom Julien Bellaise le décrit à Jean Mabillon. Le nombre de volumes est élevé pour une bibliothèque cistercienne du milieu du XIII ${ }^{\mathrm{e}}$ siècle, mais il s'explique si, comme l'écrit Bellaise, il s'agit d'un ouvrage collectif ${ }^{47}$ :

«... Pour l'abbaie de Savigny, j’y fus tres bien reçu, mais pour leurs mss. j'appris avec regret que meme depuis l'introduction de la reforme ils ont presque tout donné pour la bibliotheque de Monsieur Colbert. Je fus plus heureux chez Monsieur

42. Paris, BnF, ms lat. 9363, fol. 263-264v et 267-268.

43. Charles-François de La Vieuville, abbé commendataire de Savigny à partir de 1650, évêque de Rennes en 1664, mort en janvier 1676.

44. Paris, BnF, ms lat. 9363, fol. 279-28o.

45. La date de l'inventaire de Savigny est 1440 corrigée en 1240 selon Dumolinet, et 1210 selon Bellaise!

46. Rouleau mortuaire de Vital, fondateur et abbé de Savigny ( $\dagger 16$ septembre 1122): l'original incomplet du début se trouve à Paris, Arch. nat., L. 966 nº 6 (Musée, AE II 138); Dufour, 2005; une copie partielle datée de 1679, sans doute celle demandée par Du Molinet, se trouve dans le ms Baluze 45, fol. 372-389v, après la lettre du 28 janvier.

47. Paris, BnF, ms fr. 17678, fol. 43-44; Delisle, 1868, p. 531. 
Gaudin, l'un de leur anciens [?] docteur en Sorbonne que j'allai exprez trouver à la paroisse où il est curé; j'y rencontrai $1^{\circ}$ un mss. de grandeur d'un bon $8^{\circ}$ assez gros où est la translation des saints de Savigny... La $2^{\mathrm{e}}$ chose que j'ai trouvé chez lui est un ms. de grandeur de $4^{\circ}$ écrit en 1210 [sic] qui contient un inventaire des livres mss. qu'ils avoient pour lors qui sont en nombre prodigieux; ensuite duquel sont aussi d'autres catalogues des bibliothèques des autres abbaies de la province, c'est-a-dire du Mont St Michel, Caen, Le Bec, Jumieges etc... A Conches ce 12 aout $1687 \ldots$ Julien Bellaise...».

De la main de Du Molinet, la première liste [= Savigny A] accompagne sa lettre du $1^{\text {er }}$ octobre 1678 . Elle est soit l'inventaire de la bibliothèque à cette époque, soit un extrait du catalogue ancien signalé par Du Molinet et Bellaise. Les courtes descriptions des 104 manuscrits répertoriés pourraient d'ailleurs avoir une source médiévale. 21 volumes sont soulignés dans la liste par des tirets en marge (retranscrits par des flèches, ce sont les seuls retenus dans la concordance $)^{48}$ :

«Catalogue des mss. de l'abbaye de Savigny

in folio

[1] Biblia sacra. $S^{\text {tus }}$ Gregorius super vetus testamentum.

[2] $\rightarrow$ Ejusdem epistolæ. Iterum in vetus testamentum.

[3] Ejusdem homilioe et sermones.

[4] Ejusdem expositio in Job.

[5] Ejusdem comment. in Ecclesiasten et Ruth.

[6] Ejusdem in Evangelia.

[7] Ejusdem libri Moralium.

[8] $\rightarrow S^{\text {ti }}$ Bernardi epistolæ.

[9] Ejusdem sermones.

[10] [Ejusdem] in Canticum.

[11] [Ejusdem] in Leviticum.

[12] [Ejusdem] in epistolas Pauli.

[13] $S^{\text {tus }}$ Augustinus super Psalmos.

[14] $\rightarrow$ Ejusdem operum tomus.

[15] [Ejusdem] in epistolas Pauli.

[16] [Ejusdem] retractationes.

[17] [Ejusdem] in Psalmos iterum.

[18] [Ejusdem] in Genesim et Exodum.

[19-20] $\rightarrow$ [Ejusdem] varia opera. Deux tomes.

[21] [Ejusdem] in epistolam ad Galatas.

[22] [Ejusdem] in Prophetas.

[23] $\rightarrow$ [Ejusdem] contra Manicheos.

[24] [Ejusdem] in Epistolas canonicas et Apocalipsim.

[25] [Ejusdem] in Psalmos iterum.

[26] [Ejusdem] in Epistolas et Evangelia.

[27] [Ejusdem] glossa in Psalmos.

48. Paris, BnF, ms lat. 9363, fol. 281-282v; Genevois et al., 1987, p. 217. 
$[28] \rightarrow S^{\text {ti }}$ Ambrosii opera aliquot.

[29] Origenes in Epistolas et Evangelio.

[30] [Ejusdem] in Psalmos.

[31] Robertus de $S^{\text {to }}$ Victore in scripturam.

[32] Isidori ethimologice.

[33] $\rightarrow$ Beda de regibus Anglorum et de templis.

[34] $\rightarrow$ Cronicon Eusebii, Sigeberti et Roberti de Monte.

[35] Liber de tribus modis super verba Scripture.

[36] Excerpta de institutis et collationibus.

[37] $\rightarrow$ Innocentii papce opera aliquot.

[38] Joannes Constantiensis de compoto ecclesioe.

[39] $\rightarrow$ Legenda aliquot sanctorum.

[40] $\rightarrow$ Alia legenda cum libro de visionibus.

[41] Odo abbas de hujus vito quantitate.

[42] Sermones de virtutibus incerti authoris.

[43] $\rightarrow$ Statuta Cisterciensis ordinis.

[44] $\rightarrow$ [non retenu par Baluze] Decretales Gregorii.

[45] Sermones anonymi.

[46] Bibliorum varia fragmenta.

[47] $\rightarrow$ Petrus Lombardus in Sententias.

[48] Historia ecclesiastica. Imparfaict.

[49] Lira in vetus testamentum.

[50] Cantoris comment. in Hieremiam.

[51] [Ejusdem] homilice in vetus testamentum.

[52] [Ejusdem] in Deuteronomium.

[53] [Ejusdem] in Rhut.

[54] Lira in epistolas Pauli.

[55] Glossa in Exodum.

[56] $\rightarrow$ Orosius de Ormesta mundi.

[57] Hugo super Ecclesiastem.

[58] Glossa anonimi in epistolas Pauli.

[59] $\rightarrow$ [non retenu par Baluze] Fratris Petri de Tharentasia in Sententias.

[60] Summa Godofredi de jure canonico.

$[61] \rightarrow$ Liber evangeliorum.

[62] Sermones in Evangelia incerti authoris.

[63] Sermones incerti authoris.

[64] Glossa in Pentateucum.

[65] Glossa in Genesim.

[66] $\rightarrow$ Ivonis Carnotensis et Hildeberti Cenomanensis epistolæ.

[67] Liber decretalium.

[68] Quxestiones metaphisicae.

[69] Expositiones in Prophetas.

[70] Glossa in Ecclesiasticum.

[71] Anonimus in Psalmos.

[72] Liber de virtutibus et vitiis.

[73] $\rightarrow$ Innocentii epistolæ et alia opuscula.

[74] Homilix. Deest initium.

[75] Theonis abbatis fragmentum. 


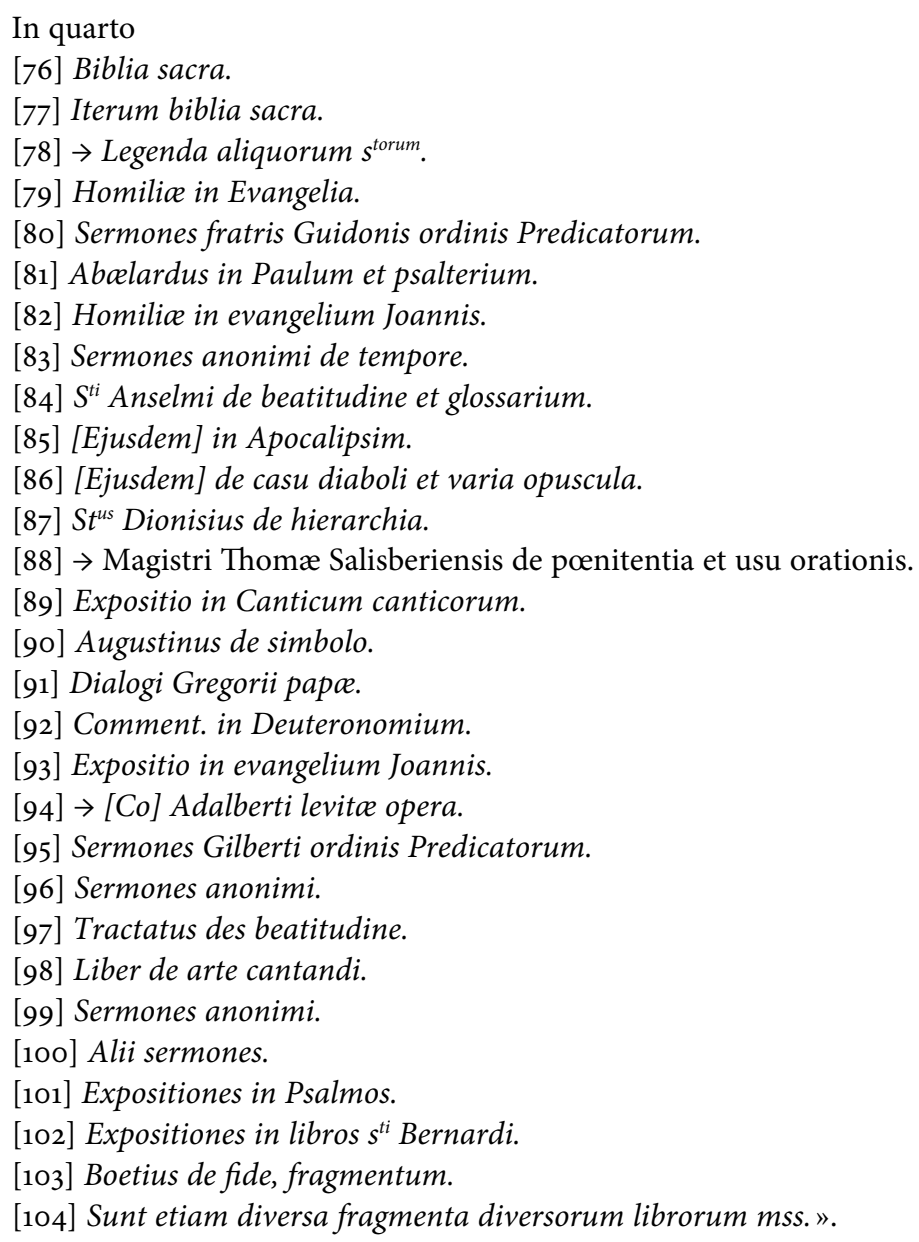

Du Molinet reçoit rapidement les instructions de Baluze et dix jours après son premier envoi, il lui écrit ${ }^{49}$ :

«... Je m'en vay escrire pour les mss. de Savigny et je traiteray si nous pouvons les avoir tous ou au moingt ceux qui sont marquez dans le memoire que nous avons envoyé... J'ay prié celuy qui avoit l'inventaire des livres qui estoient dans la bibliotheque de ceste abbaye en 1240 de m'en faire faire une coppie, il m'a promit de me l'envoyer, si vous la desirez je vous l'enverray ${ }^{50}$... Je croy pouvoir trouver des mss. en quelques abbayes de ceste province je travaille pour cela ... A Nantes le 11 octobre 1678 Du Molinet».

D'autres lettres reviennent sur le retard dans l'envoi des manuscrits, respectivement des 24 octobre, 3 et 31 décembre 1678,20 et 28 janvier $1679^{51}$ :

49. Paris, BnF, ms lat. 9363, fol. 285-286.

50. Cette copie, si elle a été réalisée, ne nous est pas parvenue.

51. Paris, BnF, ms lat. 9363, fol. 291, 300, 304-305, 306-307. 
1. «... J'attends des nouvelles de Savigny... A Nantes le 24 octobre 1678 Vostre tres humble serviteur Du Molinet»

2. «... J'attends des nouvelles du depart des mss de Savigny... A Nantes le $3^{\mathrm{e}}$ decembre 1678 Du Molinet»

3. «... Je croy que vous devez envoier veoir les mss. de Savigny et attendre [?] le retour du messager pour scavoir ce qu'il en a faict... A Nantes le dernier decembre 1678 Du Molinet»

4. «J'ay esté bien surpris Monsieur d'aprendre par votre lettre du 7 de ce mois que vous n'avez eu aucune nouvelles des mss de Savigny. Il faut qu'il y ayt quelque chose que je ne comprend pas. Je ne puis rien presumer de la part des religieux qui en ont usé le plus honnestement du monde et qui les ont livré à celuy à qui j’avois donné charge de les prendre et de les faire emballer et partir qui est un advocat de Paris qui est employé par nous dans la reformation de Fougeres (...) nommé Du Rohanys intelligent et fidelle que j'avois mené avec moy en cette abbaye et avec qui je vis ces mss. Je vous envoie les extraits de deux de ces lettres par lesquelles vous verrez qu'ilz sont tres asseurement partis... Le $20^{\mathrm{e}}$ janvier 1769 Du Molinet» ${ }^{52}$.

Mais tout rentre enfin dans l'ordre la semaine suivante ${ }^{53}$ :

«A Nantes le 28 janvier 1679. J'appris hier à mon retour de Vannes où j'estois allé depuis quinze jours la lettre que vous m'avez faict l'honneur de m'escrire qui m'aprist la reception des mss. de Savigny et que vous en estiez satisfaict dont j'ay eu bien de la joye...».

Deux autres documents figurent dans les archives de la Colbertine. Le premier [= Savigny B] est une note de travail de Du Molinet. Elle reprend les descriptions de 13 des 23 volumes cochés par Baluze et indique que trois d'entre eux n'ont pas été retrouvés ${ }^{54}$ :

«[1] Epistolæ s ${ }^{\text {ti }}$ Gregorii

[2-3] $\mathrm{S}^{\text {ti }}$ Augustini opera tom. 2

[4] Alter tomus operum $\mathrm{s}^{\mathrm{ti}}$ Augustini

[5] $S^{t i}$ Ambrosii opera aliquot

[6] Beda de regibus anglorum \&c.

[7] Cronicon Eusebii Sigiberti \&c.

[8] Innocentii papæ epistolæ et alia opera

[9-10] Legenda aliquorum sanctorum 2 vol.

[11] Petrus Lombardus in sententias

52. En annexe à cette dernière lettre, Du Molinet donne copie de missives antérieures: «Du 21 decembre 1678 à Fougeres. Je vous escrivis il y eut dimanche dernier huict jours par la poste de Nantes que j'avois faict partir le mesme jour par le messager les mss de Savigny pour monseigneur Colbert. Ils doivent sans doute estre arrivez à Paris depuis samedy dernier. J'espere monsieur que vous en escriverez bientost des nouvelles...

Du $1^{\text {er }}$ jour de janvier 1679. Je suis surpris monsieur que vous n'ayez point encor receu de nouvelles des mss. que le messager m'a asseuré estre arrivez à Paris il y eut hier quinze jours ».

53. Paris, BnF, Baluze 45, fol. 370 .

54. Paris, BnF, ms lat. 9363 , fol. 309 
[12] Origenes [sic] de ormesta mundi

[13] Thomas Salisberiensis de pœnitentia.

Les trois qu'on ne trouve pas sont [14] epistolæ $s^{\text {ti }}$ Bernardi, [15] $s^{\text {tus }}$ Augustinus contra Manicheos, [16] Ivonis et Hildeberti epistolæ mais [texte inachevé]».

La troisième liste, toujours de la main de Du Molinet [= Savigny C], accompagne sans doute sa lettre du 20 janvier. Les descriptions abrégées des volumes décrits ci-dessus, à l'exception du « $\mathrm{s}^{\text {tus }}$ Augustinus contra Manicheos», qui n'a pas été retrouvé, sont enrichies du nombre de tomes et d'une numérotation à l'encre ajoutées anciennement dans les marges. La date est de la main de Baluze ${ }^{55}$ :

«Memoire des manuscrits de Savigny [addition en marge:] receus le 21. 01. 1979

[1] Epistolæ s $s^{\text {ti }}$ Gregorii 1 tome

[2] Epistolæ sti Bernardi

[3-4] $\mathrm{S}^{\mathrm{ti}}$ Augustini operum tomi 2

[5] Alter tomus operum s ${ }^{\mathrm{ti}}$ Augustini 1

[6] $S^{\text {ti }}$ Ambrosii opera aliquot 2 [sic]

[7] Beda de regibus Angliæ \&c. 1

[8] Cronicon Eusebii Sigiberti \&c. 1

[9-10] Legendæ aliquot sanctorum 2

[11] Petrus Lombardus in sententias 1

[12] Orosius de ormesta mundi 1

[13] Ivonis Carnotensis, Hildeberti Cenomanensis epistolæ 1 imparfait

[14] Thomas Salisberiensis de penitentia 1

[15] Innocentii papæ operum 1

il y a quelques feuilletz qui manquent à quelques uns de ces livres».

Enfin la quatrième pièce [= Savigny D], elle aussi de la main de Baluze, correspond aux 16 (ou 17 ?) volumes reçus le 21 janvier $1679^{56}$. Des descriptions très détaillées permettent de les identifier facilement:

"Catalogue des manuscrits que le R. P. Prieur de l'abbaye de Savigny au diocèse d'Avranches a envoyez à Monseigneur \& que j'ay receus le 21 janvier 1679

[1] Bedæ historia ecclesiastica gentis Anglorum. Gesta Britonum a Hilda composita. De immutatione ordinis monachorum. De abbatibus \& abbatiis Normannorum \& ædificatoribus earum. Expositio Bedæ de tabernaculo testimonii. Ejusdem expositio de templo Salomonis. Ejusdem expositio super canticum Abbacuc.

[2] Chronica Eusebii, Hieronymi presbyteri, Sigeberti. Chronicon Savigniacense. Chronica magistri Hugonis Sancti Victoris.

[3] S. Ambrosius de fide ad Gratianum imp. Ejusdem libri tres de virginitate. Ejusdem de viduis libri tres. Ejusdem sermones aliquot \& epistolæ plures. Ejusdem expositio in evangelium secundum Lucam.

[4] Epistolæ Ivonis episcopi Carnotensis. Epistolæ \& sermones Hildeberti episcopi Cenomanensis.

55. Paris, BnF, ms lat. 9364, fol. 191.

56. Paris, BnF, Baluze 100 fol. 138-139v. 
[5] S. Augustini libri IV. de consensu evangelistarum. Ejusdem libri duo de sermone Domini in monte. Ejusdem liber de divinatione dæmonum. Ejusdem liber de presentia Christi. Ejusdem expositio quarundam propositionum ex epistola ad Romanos. Ejusdem liber de orando Deo. Ejusdem liber de videndo Deo. Ejusdem liber de magistro. Ejusdem liber de sex quæstionibus.

[6] S. Bernardi de consideratione libri V. Ejusdem epistolæ CCL.

[7] Tertia collectio decretalium. Quarta collectio decretalium. Quinta collectio decretalium.

[8] Fratris Petri de Tharentasia commentum in tertium \& librum quartum sententiarum.

[9] Epistolæ Gregorii magni papæ.

[10] S. Ambrosius in epistolas Pauli.

[11] Orosii historiarum libri VII. Pauli Diaconi historiæ Longobardorum libri VI. Eginhartus de vita Karoli magni. Vita Alexandri Magni. Epistola ejusdem Alexandri ad Aristotelem de situ Indiæ.

[12-13] Vitæ sanctorum. 2 voll.

[14] Augustini enchiridion. Anomymi disputatio in modum dialogi inter græcos \& Romanos de spiritu sancto \& aliis quæstionibus. Liber regulæ pastoralis s. Gregorii. Dialogus Ambrosii \& Augustini de creatione mundi.

[15] Thomas Salesberiensis de pœnitentia.

[16] S. Augustinus libri IV. de symbolo. Idem de quatuor virtutibus caritatis. Idem de cantico novo. Idem de quarta feria. Idem de cataclismo. Idem de tempore barbarico. Ejusdem altercatio contra Felicianum Arrianum. Ejusdem liber de trinitate. Ejusdem liber de decem chordis».

\begin{tabular}{|c|c|c|c|c|c|c|c|c|c|}
\hline & A & B & $\mathrm{C}$ & $\mathrm{D}$ & & $\begin{array}{l}\text { Cotes } \\
\text { actuelles }\end{array}$ & Colbert & & \\
\hline Savigny & & & & & latin & $7596 \mathrm{~A}$ & 1050 & $\mathrm{XIII}^{\mathrm{e}} \mathrm{s}$. & ex-libris \\
\hline Savigny & 23 & 15 & $?$ & & & & & & \\
\hline Savigny & 43 & & & & $\mathrm{Nal}$ & 430 & & & \\
\hline Savigny & 61 & & & & & & & & \\
\hline Savigny & 73 & & & & & & & & \\
\hline Savigny & 78 & & & & & & & & \\
\hline Savigny & 94 & & & & & & & & \\
\hline Savigny & 47 & 11 & 11 & & & & & & \\
\hline Savigny & 37 & 8 & 15 & & & & & & \\
\hline Savigny & 33 & 6 & 7 & 1 & latin & 5232 & 1059 & $\mathrm{XIII}^{\mathrm{e}} \mathrm{s}$. & ex-libris \\
\hline Savigny & 34 & 7 & 8 & 2 & *latin & 4862 & 1058 & $\mathrm{XIII}^{\mathrm{e}} \mathrm{s}$. & \\
\hline Savigny & 28 & 5 & 6 & 3 & ${ }^{\star}$ latin & 1748 & 1047 & $\mathrm{XII}^{\mathrm{e}} \mathrm{s}$. & \\
\hline Savigny & 66 & 16 & 13 & 4 & *latin & 2487 & 2131 & $\mathrm{XII}^{\mathrm{e}} \mathrm{s}$. & \\
\hline
\end{tabular}




\begin{tabular}{|c|c|c|c|c|c|c|c|c|c|}
\hline Savigny & 14 & 2 & 3 & 5 & ${ }^{*}$ latin & 1957 & 1045 & $\begin{array}{l}\mathrm{XII}^{\mathrm{e}}- \\
\mathrm{XIII}^{\mathrm{e}} \mathrm{s} .\end{array}$ & \\
\hline Savigny & 8 & 14 & 2 & 6 & latin & ${ }^{*} 2564$ & 1410 & $\mathrm{XII}^{\mathrm{e}} \mathrm{s}$. & \\
\hline Savigny & 44 & & & 7 & latin & 3933 & 1167 & $\mathrm{XIV}^{\mathrm{e}} \mathrm{s}$. & \\
\hline Savigny & 59 & & & 8 & latin & 3051 & 2295 & XIII $^{\mathrm{e}}$ s. & \\
\hline Savigny & 2 & 1 & 1 & 9 & latin & 2286 & 1052 & $\mathrm{XII}^{\mathrm{e}} \mathrm{s}$. & ex-libris \\
\hline Savigny & & & & 10 & latin & 1763 & 1117 & $\begin{array}{l}\mathrm{XII}^{\mathrm{e}}- \\
\mathrm{XIII}^{\mathrm{e}} \mathrm{s} .\end{array}$ & \\
\hline Savigny & 56 & 12 & 12 & 11 & ${ }^{*}$ latin & 4877 & 279 & $\mathrm{XIII}^{\mathrm{e}} \mathrm{s}$. & ex-libris \\
\hline Savigny & 40 & 9 & 9 & 12 & latin & 5279 & 280 & $\mathrm{XII}^{\mathrm{e}} \mathrm{s}$ & \\
\hline Savigny & 39 & 10 & 10 & 13 & ${ }^{*}$ latin & 5348 & 1049 & $\mathrm{XIII}^{\mathrm{e}} \mathrm{s}$. & \\
\hline Savigny & 19 & 3 & 4 & 14 & ${ }^{*}$ latin & 2040 & 2188 & $\begin{array}{l}\mathrm{XII}^{\mathrm{e}}- \\
\mathrm{XIII}^{\mathrm{e}} \mathrm{s} .\end{array}$ & \\
\hline Savigny & 88 & 13 & 14 & 15 & latin & $3529 \mathrm{~A}$ & 4337 & $\begin{array}{l}\mathrm{XIII}^{\mathrm{e}}- \\
\mathrm{XIV}^{\mathrm{e}} \mathrm{s} .\end{array}$ & \\
\hline Savigny & 20 & 4 & 5 & 16 & latin & 2723 & 4311 & $\mathrm{XI}^{\mathrm{e}} \mathrm{s}$. & \\
\hline
\end{tabular}

Les textes, Pères de l'Église, histoire, droit canon, vies de saints, habituels dans les choix de Baluze correspondent aux choix signalés dans la première liste. Les documents conservés apportent peu d'information sur ce sujet, mais Baluze donne vraisemblablement des instructions précises; on constate que certains textes retenus sont rares, et qu'ils sont de plus haute époque ( $\mathrm{XI}^{e}-\mathrm{XII}{ }^{e}$ s.) que dans les autres abbayes, parce que la bibliothèque est sans doute antérieure à l'adoption de la règle cistercienne. Les Visions d'Élisabeth de Schönau, dont l'abbé de Savigny aurait prêté un exemplaire à Roger de Ford à la fin du XII ${ }^{e}$ siècle ${ }^{57}$, figurent dans le choix mais un recueil de textes intéressant directement Savigny et portant un ex-libris n'y est pas décrit ${ }^{58}$. Pour ce qui concerne les Sentences de Pierre Lombard, citées sous les numéros [47] «Petrus Lombardus in Sententias» et [59] «Fratris Petri de Tharentasia in Sententias» de la liste Savigny A, le premier avait été retenu par Baluze, mais il ne fait pas partie du choix final, où figure seul le commentaire de Pierre de Tarentaise. Quant aux Statuta Cisterciensis ordinis retenus par Baluze, ils font partie de la liste A puis de celle qui fait partie des dossiers préparatoires de la Bibliotheca bibliotecarum de Bernard de Montfaucon et n'arriveront à Paris que deux siècles plus tard ${ }^{59}$.

Cette dernière liste est sans doute postérieure à 1679, car les manuscrits envoyés à Colbert n’y figurent pas. Malheureusement, les variantes dans la

57. Paris, BnF, ms lat. 5279; Dolbeau, 1979, p. 197.

58. Paris, BnF, ms lat. 7596A.

59. Paris, BnF, nouv. acq. lat. 430; Delisle, 1888, p. 24-25. 
description des textes et l'absence des volumes correspondants ne permettent pas d'en établir une concordance précise avec la liste A, mais l'ensemble aide à imaginer l'importance que garde la bibliothèque jusqu'au XVIII ${ }^{e}$ siècle $^{60}$ :

«manuscripti codices Saviniacensis abbatice ordinis cist.

1. Commentarius in Isaiam et Jeremiam, autore anonymo, de quo haec leguntur in fine commentarii in Jeremiam «Ne quaras nomen cui gratia contulit omen / Utilis \& dulcis \& sine mole lenis/Nam studii flores morumque propino sapores/Ergo non dubito quin placeam, legito/Sequitur expositio in Psal. Ecce quam bonum ». In evang. "Intravit Jesus in quoddam castellum". Ad precem Willelmi Fiscannensis, \& Arnulfi Troarnensis abbatum. In fine, rubro caractere legitur "1152. ab incarnatione Domini anno suscitavit Dominus spiritum cujusdam puelloe in Gasconia ad confutandam heresim Henrici heretici a Carcassone"; cui subjungitur vita puelloe qua octavo cetatis anno obiit, et post quatriduum revixit, sicque singulis hebdomadibus anima e corpore aberat a die Jovis ad dominicam, ita ut mortua putaretur; terque unaquaque die per id tempus sermonem populo faciebat per spatium unius circiter hore; nihil tamen de haeresi narratur. In fine rubro caractere additur "anno ab Incarnat. Domini 1153 mulier quoedam religiosa de provincia Lothariensi habens spiritum prophetice misit litteras istas capitulo cisterciensi valde obscuras et quasi per integumentum loquentis". Hoec preedixerat Eugenio Papce quod circa 8. annum sui sacerdotii et pacem habiturus esset et vitoe finem. Post hanc epistolam habetur expositio super Danielem et Ezechielem et descriptio templi cum figuris minio exaratis.

2. Glossa in Deuteronomium et Esdram. [Liste $\mathrm{A} \mathrm{n}^{\circ} 52$ ou 92]

3. Glossa in epist. ad Romanos et Corinth. Summa magistri propositivi. Ponitentiale m. Roberti de $S^{\circ}$ Victore. [Liste A ${ }^{\circ}{ }^{31}$ ]

4. Quaestiones theologica autore anonimo.

5. Comment. in Jeremiam ex si Jeronimo, Origene, Paschasio, Gregorio.

6. Glossa in Parabolas, Cantica, Eccles.

7. In lib. Numerorum.

8. In epist. ad Romanos, Corinth., Galat., Ephes., Philippenses, \& $c$. [Liste A n ${ }^{\circ} 58$ ]

9[-10]. Biblia bis. [Liste A $\left.{ }^{\circ} 76-77\right]$

11. Glossa in Exod. [Liste A n ${ }^{\circ} 55$ ]

12. Rabanus Maurus in lib. Machab. Glossa in Isaiam scripta per Brandinum monachum, in Oseam prophetam in cujus fine plures leguntur versus quorum primus "Ex agro veteri virtutum semina morum", undecimus "Ecclesice Turonensis apex omnium speculator ultimus Tobiam merito religione sequi".

13. Excerptiones s. Bernardi super vetus testamentum, ex libro primo Soliloquiorum $S^{i}$ Augustini.

14. $S^{i}$ Gregorii in Job, in cujus fine leguntur versus de sanguine Agni, de fonte Amarath, de transitu filiorum Israël, de manna, de pugna Amalech, de veste, de morsu serpentis. [Liste A n ${ }^{\circ} 4$ ]

15. Glossa in ep. ad Romanos.

16. In lib. Eccles., Tobiam, Judith, Ester.

60. Paris, BnF, ms lat. 13070, fol. 255-258, papiers préparatoires de Bernard de Montfaucon; édition imprimée avec quelques variantes, http://www.libraria.fr/fr/editions/la-bibliotheca-bibliothecarum-de-montfaucon-est-t $\% \mathrm{C}_{3} \% \mathrm{~A} 91 \% \mathrm{C}_{3} \%$ A9chargeable-en-mode-texte-sur-libraria/. 
17. Expositio in vetus testamentum secundum allegoricum sensum, misticum \& moralem.

18. Glossa in evang. $s^{i}$ Joannis \& epist. canonicas. [Liste A $n^{\circ} 93$ ?]

19. Hugo in Eccles. et lib. de Sacramentis. [Liste A n ${ }^{\circ}$ 57]

20. Tractatus de virtutibus et vitiis, cujus initium "nomina virtutum \& descriptiones", caput ult. "De proerogativis virginis". Lotarius postea Innocentius 3. dictus, de vilitate conditionis humanoe. Alcuinus in Cant. canticorum. Symbolum s $s^{i}$ Augustini. Sermo s ${ }^{i}$ Ambrosii de conflictu virtutum \& vitiorum. Sermo ad monachos. Sermo si Augustini de gloria mundi, de obedientia et humilitate. Rabanus Maurus in lib. Judith et Ester. Errorum divinatio. Conrogationes Promothœi super Bibliothecam Exodum, Num., Levit., Judices, Tobiam, Judith et novum testamentum. [Liste A n ${ }^{\circ}$ 72]

21. Commentarius in Psalmos. [Liste $\mathrm{A} \mathrm{n}^{\circ} 71$ ]

22. Interrogationes super lib. metaphisica Aristotelis secundum magistrum Petrum de Alvernia. [Liste A n ${ }^{\circ} 68$ ]

23. Definitiones multarum rerum, autore anonimo.

24. Si August. de locutionibus Genesis, Exodi, Levitici, Numeri, Deuteronomii. Sententia ex libro retractationum. Qucestiones in Genesim. De quostionibus Exodi, Levitici, \&c. De cathechizandis rudibus. De agone christiano. De ponitentia. De utilitate credendi. De fide et operibus. De fide ac symbolo. Ad inquisitiones januarii. Sermo de symbolo. De oratione dominica. De gloria mundi. De confessione. Versus de miraculo b. Marioe super canonicum Antisiodorensem.

25. Concordice evang. Zacharice Chrisopolitani.

26. $S^{i}$ Augustini exameron. De vera religione. De immortalitate animce. De libero arbitrio. De trinitate. De confessione. De quantitate anime. De natura. De doctrina Christiana. Contra mendacium. De videndo Deo. De civitate Dei. De moribus ecclesioe. De 84. quæstionibus. Aug. de littera \& spiritu. Collationes Cassiani. Exceptiones de libro Seneca. Gilbertus super Cantica, seu potius s. Bernardus.

27. Secunda pars $s^{i}$ Thomoe.

28. Expositio Hamonis in Isaiam.

29. Sermones Petri Lombardi.

30. Speculum judiciale Durandi.

31. Sermones S. Bernardi in Cantica. De consideratione ad Eugenium papam, duo tantum folia. [Liste A $\mathrm{n}^{\circ}$ 10]

32. Isidorus in vetus testamentum, sed initium deest. Retractationes s. Aug. Epistola Quodvultdei ad August. et August. ad eund. De diversis horeticis. Vita s. Augustini cujus finis deest. Electio Heraclii ad succedendum in episcopatu s. Augustino. [Liste $\mathrm{A} \mathrm{n}^{\circ} 32$ ?]

33. $S^{i}$ Gregorii pastorale. Idem in Ezechielem.

34. $S^{i}$ August. quoestiones vet. testamenti. De 84. quost. contra mendacium et Arianos. De cura pro mortuis.

35. Glosulo in epist. $s^{i}$ Pauli. Alice in Psalmos.

36. Sermones incogniti, eo quod nomen consulto sit deletum.

37. Expositio in epist. $s^{i}$ Pauli.

38. Liber juris canonici cujus initium \& finis desunt.

39. Nicolai de Lyra postilla in novum testamentum.

4o. Expositio in epist. $s^{i}$ Pauli.

41. Origenis homilioe in vetus testamentum, initium \& finis desunt. [Liste A $n^{\circ} 29$ ?]

42. Anticlaudianus Alani metro editus. In fine dicta 7. sapientum. 
43. Expositiones in evangelia legendoe in capitulo. [Liste A n ${ }^{\circ} 62$ ?]

44. Sermones varii.

45. Glosa in vetus Testamentum.

46. Liber Hugonis de sacramentis. [Liste A n ${ }^{\circ}$ 57]

47. Dialogi si Gregorii. Heraclidus episcopus de vita ss. patrum. [Liste A no 91]

48. Odonis abbatis liber de hujus vitce qualitate et de perversitate pravorum. In fine hoe leguntur: "Iste Odo qui istum librum composuit, pater monachorum fuit, extitit namque abbas Floriacensis Sanctique Dionysii, plurimarumque ecclesiarum pastor fuit"; vita quoque ipsius miraculorum clarissima. Apud $S^{u m}$ Benedictum armario continetur et illoe sunt monacus. Postea sunt quodam homilice seu expositiones epistolarum et evangeliorum. [Liste A $\mathrm{n}^{\circ}{ }^{41}$ ]

49. Biblia metro edita.

50. Summa intitulata de virtutibus. [Liste A no 42 ]

51. Sermones varii.

52. Pars operum si Thomo.

53. Varioe precationes.

54. Glosa in Apocalypsim. Parabolo Salomonis. Sermones varii.

55. Sententioe seu interpretationes alphabetico ordine digesto. Sermones varii.

56. Metaphysica Aristotelis et phisionomia. [Liste A no 68 ?]

57. S. Augustinus de bono conjugali. Qualiter homo factus est ad imaginem et similitudinem Dei. De virginitate liber.

58. Apocalypsis. Expositio Cantici canticorum secundum Anselmum. Expositio in Apocalypsim. Prologus $s^{i}$ Hieronymi et Eusebii Cosariensis in eandem. Versus de 14. Beatitudinibus. De planctu mortis \& $c$.

59. Glosa in Joannem. [Liste A no 93 ?]

6o. $S^{i}$ Gregorii moralia. [Liste A n ${ }^{\circ}$ ]

61. Sermones de sanctis.

62. Expositiones in evangelia et sermones varii.

63. Sermones Jacobi de Losana. Alii sermones anonimi.

64. Collectiones in varia scripturce loca. Epistole Innocentii 3. ad Eliensem episcopum \& alios.

65. Sermones varii.

66. Vitce sanctorum. duo volumina.

68. Rubriques du breviaire en françois.

69. Summa Gaufridi in jure canonico. [Liste $\mathrm{A} \mathrm{n}^{\circ}$ 6o]

7o. Statuta et definitiones ordinis cisterciensis. [Liste A no 43]».

\section{La Noë (juin 1679)}

Le 16 juin 1679, l'évêque de Saint-Malo Sébastien de Guémadeuc ${ }^{61}$ apporte à Colbert un lot de manuscrits provenant de l'abbaye cistercienne de La Noë ${ }^{62}$,

61. Sébastien de Guémadeuc (1626-1702), évêque de Saint-Malo en 1671, fondateur de l'abbaye bénédictine du Mont-Cassin près de Josselin, abbé de La Noë, prieur d'Iffendic, de Saint-Martin de Sigy, de Saint-Aubin de Guérande.

62. Abbaye de La Noë, dép. Eure, dioc. Évreux, c. La Bonneville-sur-Iton, fondée en 1144 par

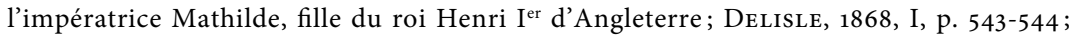


dont il est l'abbé commendataire. Les circonstances de ce don et les volumes ne sont connus que par une liste de la main de Baluze; les textes y sont décrits pièce à pièce, puis réunis par des accolades constituant des recueils $\left[=\mathrm{La} \mathrm{Noë}^{63}\right.$ :

«Manuscrits apportez par M. l'Evesque de St Malo dans la bibliotheque de Monseigneur le 16. juin 1679

Fol.

[1] Historia Trojanorum Daretis Phrygii.

[2] Augustini de civitate Dei.

[3] Glossa ordinaria in Psalmos.

[4] Vita s. Malachiæ. Sermo s. Bernardi in transitu s. Malachiæ. Gesta Barlaam. Vita s. Mariæ Magdalenæ. Translatio s. Nicolai, edita a Johanne Archidiacono Barensi. Et de initio ecclesiæ Becci. Vita s. Marthæ. Dialogi s. Gregorii Papæ.

[5] Glossa ordinaria in Leviticum, Numeros \& Deuteronomium.

Augustinus in Psalmos.

[6] Glossa ordinaria in Psalmos.

[7] Gregorius M. in Ezechielem.

[8] Expositio in regulam s. Benedicti. fort recent.

[9] Thomæ Aquinatis liber de fide catholica contra gentiles.

[10] Biblia sacra.

[11] Glossa ordinaria in Isaiam \& Danielem.

[12] Glossa ordinaria in Prophetas minores.

[13] Rabanus in Genesim et Exodum. Thomæ Maurigniacensis epistola ad s. Bernardum. Elle est considerable. S. Basilii exhortatio ad monachos.

[14] Glossa ordinaria in epistolas Pauli.

[15] Rabanus in libros Machabæorum.

[16] Aristotelis tractatus varii, quorum primus est metaphysica.

[17] Glossa ordinaria in Lucam.

[18] Glossa ordinaria in Ezechielem.

[19] Glossa ordinaria in libros Regum.

[20] Sermones s. Bernardi in Cantica canticorum.

[21] Glossa ordinaria in Matthæum et Marcum.

[22] Pars sacrorum bibliorum, incipiens a libris Regum.

[23] Glossa ordinaria in Genesim \& Exodum.

[24] Glosa [sic] magistri Stephani de Linguatone super Leviticum \&c.

[25] Sermones s. Bernardi.

[26] Augustinus in Joannem.

[27] Petri Cantoris Parisiensis verbum abbreviatum.

[28] Haymo in Apocalypsim.

[29] Liber de proprietatibus \& naturis rerum.

[30] Tertius liber sententiarum.

[31] Hugonis de S. Jacobo postillæ super Lucam.

BondÉELle-SouchieR, 1991, p. 161-165, 51 mss Colbert, dont les mss lat. 420 provenant de Bonport, lat. 1851 de Mortemer et lat. 8616 de Jacques-Auguste de Thou; Deville, 1908-1909, mss fr. 827, lat. 31, 83, 283, 300, 611, 2000, 2058, 2226-2227, 2249, 2358, 2550, 2574, 3052, 3053, $3388,3559,5641,6396,7736$.

63. Paris, BnF, lat. 9364, fol. 15-17v; Genevois et al., 1987, p. 113. 
[32] Historia scholastica.

[33] Sententiarum libri quatuor.

[34] Hieronymus in Marcum. Augustini quæstiones in Matthæum et Mareum Lucam [corr. dans l'interligne]. Ejusdem homiliæ de assumptione b. Mariæ. Proverbia Salomonis cum præfatione Hieronymi \&c. ${ }^{64}$.

[35] Expositio in Psalmos.

[36] Glossa ordinaria in XII. Prophetas.

[37] Priores duo libri sententiarum.

[38] Stephani de Languetona moralia in Osee.

[39] Le livre de la voie humaine.

[40] Petrus Plaout doctor sorbonicus in sententias. Ejusdem Tractatus de communicatione idiomatum auctore Nicolao Oresme. Aliqua dubia disputata Parisius in Sorbona.

[41] Glossa ordinaria in Josue \& Judicos.

[42] Homiliæ XL. beati Gregorii in Evangelia. Epistola Alexandri III de pace facta cum Friderico imp. Concilium turonense sub Alexandro III.

[43] Augustinus de verbis Domini.

[44] Sermones cujusdam.

[45] Qucestiones super epistolas B. Pauli. Beda in Marcum.

[46] Vocabularium quoddam theologicum.

[47] Item aliud a priore diversum.

[48] Retractationes s. Augustini. Cassiodorus de institutionibus divinarum literarum $[s i c]$. Liber proœmiorum s. Isidori episcopi \& præfatio de libris novi testamenti. Isidorus de vita vel obitu sanctorum patrum. Ejusdem ad Orosium de nominibus legis \& evangeliorum. Hieronymus de viris illustribus. Gelasii epistola decretalis de libris canonicis \& apocryphis. Gennadii catalogus virorum illustrium. Isidorus de viris illustribus.

[49] Beda in Lucam.

[50] Glossa ordinaria in Joannem.

[51] Libri Salomonis.

[52] Glossa ordinaria in Matthoum.

[53] Expositio super decem prima capitula Matthæi. Pars expositionis psalterii. Tractatus de compositione templi. Excerpta ex libro tertio sententiarum.

[54] Alexandri III. epistola de canonizatione s. Bernardi. Vita s. Bernardi a diversis auctoribus. Sermones de eodem. Hugo Farsetus de materiali claustro. Tractatus de vita sancta. Aliq Epistola s. Bernardi ad Robertum nepotem suum.

[55] S. Augustinus in Psalmos. Incipit a 81. Ejusdem epistola ad Armentarium \& Paulinum.

[56-58] S. Augustinus in Psalmos. 3 voll.

[59-61] Moralia s. Gregorii. 3 voll.

Quarto

[62] Officia ecclesiastica secundum usum monachorum.

[63] Summa allegoriarum totius bibliothecæ. Flores sermonum s. Gregorii papæ.

[64] Didimus de Spiritu sancto. Hieronymi dialogus contra Pelagianos. Liber Lanfranci contra Berengarium.

64. Un recueil presque identique se trouvait à Mortemer, aujourd'hui Paris, BnF, ms lat. 1851. 
[65] Augustinus de quatuor virtutibus caritatis. Item plures sermones ejusdem. Idem de gratia novi testamenti. Idem de natura boni. Cassiodorus de anima. Vita Abrahæ reclusi. Vita s. Ægidii abbatis. Proverbia Evagrii de græco in latinum translata ab Hieronymo. Excerpta varia ex Augustino. Ejusdem sermones de nativitate Domini.

Passio s. Blasii martyris. Passio s. Sebastiani martyris. Translatio s. Jacobi apostoli. [66] Sermones Petri Manducatoris.

[67] Glossa ordinaria super Ecclesiasten.

[68] Glossa ordinaria in Matthoum \& Johannem.

[69] Sermo[add.:]nes s. Fausti Episcopi ad monachos. S. Augustini de obedientia. Sermo[add.:]nes s. Cæsarii ad monachos. Sententia Paulini ad monachos de pœnitentia. Sententia Novati catholici de humilitate \& obedientia. Augustinus de bono disciplinæ. Ejusdem epistola ad Lætum diaconem. Sermo s. Macharii ad monachos s. Benedicti. Sermo s. Augustini de perseverantia. Pœnitentia Theophili vicedomini Athanæ civitatis. Excerpta ex Augustino. Sententiæ B. Isidori.

[70] Sermones s. Bernardi in Cantica canticorum.

[71-72] Augustinus de sermone Domini in monte. Ejusdem epistola ad Probam de orandi modo. Ejusdem sermo de verbis Apostoli "Caro concupiscit \&c.". Ejusdem sermo de beatitudinibus. Ejusdem epistola ad Probam, ad Publicolam, ad Volusianum. Ejusdem sermo de verbis Apostoli "Humanus sermo \& Si Deus pro nobis”. Omeliæ [add.:] IV. s. Joannis Chrysostomi in laude s. Pauli Apostoli. Quomodo b. Johannes Chrysostomus regressus est de Asia Constantinopolim. Homilia de muliere Chananea. Pœnitentia s. Mariæ Ægyptiacæ interprete Paulo Diacono Neapolitano. Epistola s. Hieronymi ad Eustochium de virginitate servanda. Ejusdem epistola ad Celantiam.

[73] Glossa super quatuor Evangelia.

[74] Glossa ordinaria in Lucam.

[75] Glossa ordinaria in Marcum.

[76-77] Summa vitiorum. Deux exemplaires.

[78] Legenda aurea.

[79] Sermones per annum.

[8o] Topica Aristotelis.

[81] Cassiodorus de anima. Symbolum dictatum a b. Augustino. Ejusdem disputatio contra Felicianum hæreticum. Ejusdem epistola ad Paulum \& Eutropium de perfectione justitiæ hominum. Ejusdem epistolæ [add.:] duo ad Valentinum. Ejusdem liber de gratia \& libero arbitrio ad Valentinum. Ejusdem liber de correctione \& gratia ad eundem.

[82] Collationes Cassiani.

[83] De arca Nœ - les epistres d'Hildebert estoient en cet endroit mais elles ont esté coupées. Glossa ordinaria in Cantica. Passio s. Georgii martyris. Passio s. Christophori martyris.

[84] Liber Job cum præfatione Hieronymi. Isidori epistola ad Florentinam. Liber s. Ambrosii de fuga seculi. Epistola de Pilato \& de judæis. Videtur esse evangelium Nicomedi.

[85] Glossa super Ecclesiasticum et Sapientiam.

[86] Summa magistri Joannis Beleth. Petri Cantoris verbum abbreviatum.

[87] Liber Augustini de lapsu mundi. Sunt sermones.

[88] S. Gregorii regula pastoralis. 
Octavo

[89] Beda in Tobiam. Sententiæ de sancta Trinitate ex libris Augustini. Sermo b. Bernardi in Annuntiatione dominica. Epistola s. Hieronymi ad Heliodorum. Initium Decreti Gratiani. Epistola XLI. Ivonis Carnotensis. Varia excerpta ex patribus. Sermones per annum. Epistola b. Bernardi ad Ascelinum cardinalem. [90-91] Sermones per annum. 2 voll.

[92] Ricardus abbas de sacramentis Missæ. Haymo in Apocalypsim. Glossa in Cantica canticorum.

[93] Explicatio vocabulorum bibliæ.

[94] Distructiones [sic] Nicolai de Gorhan.

[95] Vocabularium latino-gallicum.

En tout 97 [sic] voll.».

\begin{tabular}{|c|c|c|c|c|c|c|}
\hline & & & $\begin{array}{l}\text { Cotes } \\
\text { actuelles }\end{array}$ & Colbert & & \\
\hline La Noë & 1 & latin & $\begin{array}{l}3359 \mathrm{f} . \\
83-88\end{array}$ & 149 & $\mathrm{XI}^{\mathrm{e}} \mathrm{s}$. & ex-libris \\
\hline La Noë & 2 & latin & 2058 & 98 & $\mathrm{XII}^{\mathrm{e}} \mathrm{s}$. & $\begin{array}{l}\text { ex-libris, trace } \\
\text { rel. } 1\end{array}$ \\
\hline La Noë & 3 & & & & & \\
\hline La Noë & 4 & latin & 5368 & 1172 & $\mathrm{XIV}^{\mathrm{e}} \mathrm{s}$ & \\
\hline La Noë & 5 & ${ }^{*}$ latin & 389 & 396 & $\mathrm{XIII}^{\mathrm{e}}-\mathrm{XIV}^{\mathrm{e}} \mathrm{s}$ & \\
\hline La Noë & 6 & & & & & \\
\hline La Noë & 7 & latin & 2249 & 1839 & $\mathrm{XII}^{\mathrm{e}} \mathrm{s}$. & ex-libris \\
\hline La Noë & 8 & latin & 4216 & 1204 & $\mathrm{XVI}^{\mathrm{e}} \mathrm{s}$. & \\
\hline La Noë & 9 & ${ }^{*}$ latin & 3106 & 1187 & $\mathrm{XIII}^{\mathrm{e}} \mathrm{s}$. & \\
\hline La Noë & 10 & latin & 31 & 273 & XIII ${ }^{\mathrm{e}}-\mathrm{XIV}^{\mathrm{e}} \mathrm{s}$ & ex-libris, rel. 2 \\
\hline La Noë & 11 & ${ }^{*}$ latin & 149 & 917 & $\mathrm{XIII}^{\mathrm{e}} \mathrm{s}$. & \\
\hline La Noë & 12 & latin & 508 & 496 & $\mathrm{XIII}^{\mathrm{e}} \mathrm{s}$. & ex-libris \\
\hline La Noë & 13 & latin & 2424 & 1005 & $\mathrm{XII}^{\mathrm{e}} \mathrm{s}$. & \\
\hline La Noë & 14 & ${ }^{*}$ latin & 670 & 150 & $\mathrm{XIII}^{\mathrm{e}} \mathrm{s}$. & \\
\hline La Noë & 15 & ${ }^{*}$ latin & 2437 & 2076 & $\mathrm{XIII}^{\mathrm{e}-\mathrm{XIV}} \mathrm{e}$ s. & rel. 1 \\
\hline La Noë & 16 & latin & 6296 & 1064 & $\mathrm{XIV}^{\mathrm{e}} \mathrm{s}$. & ex-libris \\
\hline La Noë & 17 & & & & & \\
\hline La Noë & 18 & *latin & 153 & 1116 & $\mathrm{XIII}^{\mathrm{e}} \mathrm{s}$. & rel. 1 \\
\hline La Noë & 19 & latin & 83 & 2193 & $\mathrm{XIII}^{\mathrm{e}}-\mathrm{XIV}^{\mathrm{e}} \mathrm{s}$ & ex-libris, rel. 1 \\
\hline La Noë & 20 & ${ }^{*}$ latin & 2562 & 1405 & $\mathrm{XII}^{\mathrm{e}}-\mathrm{XIII}{ }^{\mathrm{e}} \mathrm{s}$. & \\
\hline
\end{tabular}




\begin{tabular}{|c|c|c|c|c|c|c|}
\hline La Noë & 21 & latin & 283 & 919 & $\mathrm{XIII}^{\mathrm{e}}$ s. & ex-libris \\
\hline La Noë & 22 & ${ }^{\star}$ latin & 81 & 41 & $\mathrm{XI}^{\mathrm{e}} \mathrm{s}$. & \\
\hline La Noë & 23 & ${ }^{\star}$ latin & 371 & 100 & $\mathrm{XIII}^{\mathrm{e}}-\mathrm{XIV}^{\mathrm{e}} \mathrm{s}$ & rel. 1 \\
\hline La Noë & 24 & ${ }^{\star}$ latin & 384 & 661 & XIII' s. & rel. 2 \\
\hline La Noë & 25 & latin & 2550 & 1249 & $\mathrm{XIII}^{\mathrm{e}} \mathrm{s}$. & ex-libris \\
\hline La Noë & 26 & ${ }^{\star}$ latin & 1967 & 76 & $\mathrm{XII}^{\mathrm{e}}-\mathrm{XIII}{ }^{\mathrm{e}} \mathrm{s}$ & \\
\hline La Noë & 27 & latin & 3246 & 2069 & XIII $^{\mathrm{e}} \mathrm{s}$. & ex-libris \\
\hline La Noë & 28 & ${ }^{\star}$ latin & 2416 & 2067 & $\mathrm{XII}^{\mathrm{e}}-\mathrm{XIII}{ }^{\mathrm{e}} \mathrm{s}$. & \\
\hline La Noë & 29 & ${ }^{\star}$ latin & $347 \mathrm{E}$ & 1112 & $\mathrm{XIV}^{\mathrm{e}} \mathrm{s}$ & \\
\hline La Noë & 30 & latin & 3053 & 2325 & XIII $^{\mathrm{e}}$ s. & ex-libris \\
\hline La Noë & 31 & ${ }^{\star}$ latin & 634 & 1780 & $\mathrm{XIV}^{\mathrm{e}} \mathrm{s}$ & \\
\hline La Noë & 32 & ${ }^{\star}$ latin & 5107 & 1115 & XIII ${ }^{\mathrm{e}}-\mathrm{XIV}{ }^{\mathrm{e}} \mathrm{s}$ & \\
\hline La Noë & 33 & latin & 3022 & 1083 & $\mathrm{XII}^{\mathrm{e}} \mathrm{s}$. & \\
\hline La Noë & 34 & ${ }^{*}$ latin & 1852 & 1525 & $\mathrm{XII}^{\mathrm{e}}$-XIII ${ }^{\mathrm{e}} \mathrm{s}$. & incomplet? \\
\hline La Noë & 35 & latin & 409 & 2517 & $\mathrm{XII}^{\mathrm{e}}-\mathrm{XIII}{ }^{\mathrm{e}} \mathrm{s}$. & ex-libris \\
\hline La Noë & 36 & ${ }^{\star}$ latin & 141 & 2074 & XIII $^{\mathrm{e}} \mathrm{s}$. & \\
\hline La Noë & 37 & latin & 3052 & 2324 & XIII' s. & ex-libris \\
\hline La Noë & 38 & ${ }^{*}$ latin & 504 & 1754 & $\mathrm{XIII}^{\mathrm{e}} \mathrm{s}$. & \\
\hline La Noë & 39 & français & 827 & 1826 & $\mathrm{XV}^{\mathrm{e}} \mathrm{s}$. & ex-libris \\
\hline La Noë & 40 & latin & 3074 & 1198 & $1393-1396$ & \\
\hline La Noë & 41 & ${ }^{\star}$ latin & 76 & 1120 & XIII' s. & \\
\hline La Noë & 42 & latin & 2259 & 2052 & XIII ${ }^{\mathrm{e}}$ s. & \\
\hline La Noë & 43 & & & & & \\
\hline La Noë & 44 & & & & & \\
\hline La Noë & 45 & & & & & \\
\hline La Noë & 46 & latin & 3388 & 1261 & XIII' s. & $\begin{array}{l}\text { ex-libris, trace } \\
\text { rel. } 1\end{array}$ \\
\hline La Noë & 47 & latin & 3389 & 1277 & $\mathrm{XII}^{\mathrm{e}}$-XIII ${ }^{\mathrm{e}} \mathrm{s}$. & ex-libris, rel. 2 \\
\hline La Noë & 48 & latin & 1906 & 2438 & $\mathrm{XII}^{\mathrm{e}} \mathrm{s}$. & \\
\hline La Noë & 49 & latin & 2358 & 1799 & $\mathrm{XII}^{\mathrm{e}}-\mathrm{XIII}{ }^{\mathrm{e}} \mathrm{s}$. & ex-libris, rel. 1 \\
\hline La Noë & 50 & latin & 300 & 2491 & $\mathrm{XIII}^{\mathrm{e}} \mathrm{s}$. & ex-libris \\
\hline
\end{tabular}




\begin{tabular}{|c|c|c|c|c|c|c|}
\hline La Noë & 51 & ${ }^{*}$ latin & 115 & 2968 & $\mathrm{XIII}^{\mathrm{e}} \mathrm{s}$. & \\
\hline La Nö̈ & 52 & & & & & \\
\hline La Noë & 53 & latin & 631 & 3512 & $\mathrm{XIII}^{\mathrm{e}}-\mathrm{XIV}^{\mathrm{e}} \mathrm{s}$ & \\
\hline La Noë & 54 & latin & 2574 & 1073 & $\mathrm{XII}^{\mathrm{e}} \mathrm{s}$. & ex-libris \\
\hline La Noë & 55 & latin & 2000 & 2986 & $\mathrm{XII}^{\mathrm{e}} \mathrm{s}$. & ex-libris \\
\hline La Noë & 56 & latin & $2006^{1}$ & 491 & $\mathrm{XIII}^{\mathrm{e}} \mathrm{s}$. & ex-libris \\
\hline La Noë & 57 & latin & $2006^{2}$ & 492 & $\mathrm{XIII}^{\mathrm{e}} \mathrm{s}$. & ex-libris \\
\hline La Noë & 58 & & & & & \\
\hline La Noë & 59 & ${ }^{*}$ latin & 2210 & 1595 & $\mathrm{X}^{\mathrm{e}}-\mathrm{XI}^{\mathrm{e}} \mathrm{s}$ & \\
\hline La Noë & 60 & latin & 2226 & 1593 & $\mathrm{XIII}^{\mathrm{e}} \mathrm{s}$. & ex-libris, rel. 1 \\
\hline La Noë & 61 & latin & 2227 & 1594 & $\mathrm{XIII}^{\mathrm{e}} \mathrm{s}$. & \\
\hline La Nö̈ & 62 & & & & & \\
\hline La Noë & 63 & latin & 587 & 3709 & $\mathrm{XIII}^{\mathrm{e}} \mathrm{s}$. & \\
\hline La Noë & 64 & latin & 1690 & 3691 & $\mathrm{XII}^{\mathrm{e}} \mathrm{s}$. & \\
\hline La Noë & 65 & latin & 2025 & 1201 & $\mathrm{XII}^{\mathrm{e}} \mathrm{s}$. & ex-libris \\
\hline La Noë & 66 & *latin & 2952 & 3690 & $\mathrm{XIII}^{\mathrm{e}} \mathrm{s}$. & \\
\hline La Noë & 67 & ${ }^{*}$ latin & $485 \mathrm{~A}$ & 3687 & $\mathrm{XIV}^{\mathrm{e}} \mathrm{s}$. & \\
\hline La Nö̈ & 68 & & & & & \\
\hline La Noë & 69 & latin & 2167 & 2394 & $\mathrm{XII}^{\mathrm{e}}-\mathrm{XIII}{ }^{\mathrm{e}} \mathrm{s}$. & \\
\hline La Noë & 70 & ${ }^{\star}$ latin & 2556 & 3692 & $\mathrm{XII}^{\mathrm{e}} \mathrm{s}$. & \\
\hline La Noë & 71 & latin & 2715 & 4339 & $\mathrm{XII}^{\mathrm{e}} \mathrm{s}$. & \\
\hline La Noë & 72 & latin & 1934 & 5529 & $\mathrm{XII}^{\mathrm{e}} \mathrm{s}$. & \\
\hline La Noë & 73 & *latin & 296 & 920 & $\mathrm{XIII}^{\mathrm{e}} \mathrm{s}$. & rel. 1 \\
\hline La Noë & 74 & & & & & \\
\hline La Noë & 75 & ${ }^{*}$ latin & 693 & 3693 & $\mathrm{XIII}^{\mathrm{e}} \mathrm{s}$. & trace rel. 2 \\
\hline La Noë & 76 & latin & 3507 & 4131 & $\mathrm{XIII}^{\mathrm{e}} \mathrm{s}$. & ex-libris \\
\hline La Noë & 77 & latin & 3516 & 3973 & $\mathrm{XIII}^{\mathrm{e}} \mathrm{s}$. & \\
\hline La Noë & 78 & latin & 5641 & 3688 & $\mathrm{XIV}^{\mathrm{e}} \mathrm{s}$. & ex-libris \\
\hline La Noë & 79 & & & & & \\
\hline La Noë & 80 & latin & 7736 & 3702 & $\mathrm{XIII}^{\mathrm{e}}-\mathrm{XIV}^{\mathrm{e}} \mathrm{s}$ & ex-libris \\
\hline La Noë & 81 & latin & 2202 & 3509 & $\mathrm{XII}^{\mathrm{e}} \mathrm{s}$. & \\
\hline La Noë & 82 & latin & 2140 & 3708 & $\mathrm{XII}^{\mathrm{e}} \mathrm{s}$. & ex-libris \\
\hline La Noë & 83 & latin & $\begin{array}{l}5575 \mathrm{f} . \\
113-127\end{array}$ & 3683 & $\mathrm{XIII}^{\mathrm{e}} \mathrm{s}$. & \\
\hline
\end{tabular}




\begin{tabular}{|c|c|c|c|c|c|c|}
\hline La Noë & 84 & latin & 189 & 4394 & $\mathrm{XII}^{\mathrm{e}} \mathrm{s}$. & ex-libris \\
\hline La Noë & 85 & ${ }^{*}$ latin & 571 & 3800 & $\mathrm{XII}^{\mathrm{e}} \mathrm{s}$. & \\
\hline La Noë & 86 & latin & 1000 & 4448 & $\mathrm{XII}^{\mathrm{e}} \mathrm{s}$. & \\
\hline La Noë & 87 & ${ }^{*}$ latin & 2722 & 6113 & $\mathrm{XII}^{\mathrm{e}}$-XIII ${ }^{\mathrm{e}} \mathrm{s}$. & \\
\hline La Noë & 88 & & & & & \\
\hline La Noë & 89 & latin & 2839 & 6119 & $\mathrm{XII}^{\mathrm{e}} \mathrm{s}$. & \\
\hline La Noë & 90 & latin & 3559 & 6127 & $\mathrm{XIII}^{\mathrm{e}}-\mathrm{XIV}^{\mathrm{e}} \mathrm{s}$ & \\
\hline La Noë & 91 & latin & 3573 & 6087 & $\mathrm{XIII}^{\mathrm{e}} \mathrm{s}$. & ex-libris, rel. 2 \\
\hline La Noë & 92 & latin & 3531 & 6114 & $\mathrm{XII}^{\mathrm{e}} \mathrm{s}$. & \\
\hline La Noë & 93 & latin & 611 & 6084 & $\mathrm{XIII}^{\mathrm{e}} \mathrm{s}$. & ex-libris \\
\hline La Noë & 94 & latin & 3684 & 6451 & $\mathrm{XIV}^{\mathrm{e}} \mathrm{s}$. & \\
\hline La Noë & 95 & ${ }^{\star}$ latin & 7692 & 6430 & 1399 & \\
\hline
\end{tabular}

Six recueils de la glose ordinaire figurent parmi les quatorze manuscrits non identifiés ${ }^{65}$. Quelques autres ont échappé à la saisie de Colbert, comme en témoignent deux volumes de la Bibliothèque Mazarine et d'Alençon, et cinq passés chez l'évêque d'Évreux Jean VI Le Normant (1710-1733) puis à l'archevêché et enfin à la Bibliothèque municipale de Rouen ${ }^{66}$.

\section{Foucarmont (avril 1682)}

Deux inventaires du XVII e siècle sont conservés pour Foucarmont ${ }^{67}$. Le plus ancien, conservé dans les dossiers manuscrits destinés à la publication de la Bibliotheca bibliothecarum de Bernard de Montfaucon, comporte 53 notices numérotées [= Foucarmont $\mathrm{A}]^{68}$ :

65. Correspondant peut-être à l'un des manuscrits cités sans provenance dans le tableau ci-dessus.

66. Alençon, Bibl. mun., ms 67; Paris, Bibliothèque Mazarine, ms 205; Rouen, Bibl. mun., mss 113 (A.356) 181 (A.100), 241 (A.409), 548 (A.288), 652 (A.570); Neveu, 2005.

67. Abbaye de Foucarmont, dioc. Rouen, dép. Seine-Maritime, congrégation de Savigny, fondée en 1130 par Henri I ${ }^{\text {er }}$ comte d'Eu qui s'y fait moine et y meurt en 1139, cistercienne en 1147; Delisle, 1868, p. 475 et 531-534 (éd. de la liste Foucarmont B); BondéElle-Souchier, 1991, p. 114-118, 53 mss Colbert; Genevois et al., 1987, p. 73.

68. Paris, BnF, ms lat. 13069 , fol. $44-45 \mathrm{v}\left(\mathrm{n}^{\circ} 1-37\right)$ et $47-48\left(\mathrm{n}^{\circ} 38-53\right)$, liste presque identique à la version imprimée, Libraria, Pour l'histoire des bibliothèques anciennes: http://www.libraria.fr/ fr/editions/la-bibliotheca-bibliothecarum-de-montfaucon-est- $\mathrm{t}_{3} \mathrm{C}_{3} \% \mathrm{~A} 91 \% \mathrm{C}_{3} \%$ A 9 chargeable-enmode-texte-sur-libraria; Petitmengin, 1998, p. 567. Deux index figurent dans le ms lat. 9364, «Elenchus ex biblioth. ms. Fulcardimontis», vies de saints avec renvois aux feuillets des «Tomus tertius... minoris formae..., Tomus ${ }^{\text {us }}$ in majori forma..., Tomus secundus...» (fol. 49-51v), et «in monasterio Fulcardimontis habentur sequentes cod. mss...», commentaires bibliques et sermons (fol. 51v-52v). 
«catalogus librorum manuscriptorum abbatiæ Fulcardimontis 1. Liber Genesis, liber Exodi, liber Levitici, liber Numerorum, liber Deutoronomii, lib. Josue, lib. Judicum, lib. Ruth. Volumen

2. Libri Regum, Isayas, Jeremixe, Baruch, Lamentationes Jeremixe, Ezechiel. Volumen 3. Paralipomenon, libri Esdræ, libri Nehemia, Tobio, Hesther, Judith, libri Machaboerum, Osee lib. unus, proph. Amos, Abdias, Jonas, Michceas, Abacuch, Sophonias, Aggci lib., Zacharias, Malach. \& Daniel. Volumen

4. Libri Job, Proverbiorum, Ecclesiastes, Canticorum, Sapientice, Ecclesiastici et Psalmorum. Volumen

5. Evangelia secundum Mat., Marc., Luc. et Joan., Actus Apost., Apocaly., epistoloe s. Joan., epist. Juda et omnes epist. s. Pauli. Volumen

6. Expositiones in libros Levitici, Numerorum, Deuteronomii, Josue et Judicum. Volumen

7. S. Augustini libri super Genesim, contra Manichæos. Tractatus domni Esvaldi abb. Bonævallis de delitiis Paradisi, qui liber Paradisus dicitur. Ejusdem de 6. verbis Christi in cruce pendentis. B. Augustini in epistolas s. Joan. homiliæ, seu liber de charitate $B^{\mathfrak{x}}$ Mariæ de Fulcardi-monte. Volumen

8. B. Augustinus super Genesim. Volumen

9. Bruno episcopus super Genesim, librum Exodi, Levitici necnon et Numerorum et Deuterono. Volumen

10. Glossa in librum Genesis. Liber Exodi cum notis quibusdam. Item liber de quæstionibus venerabilis Bedæ presby. super libros Regum. Ejusdem solutiones de quibusdam verbis Apostoli. Volumen

11. Domnus Radulphus monachus $S^{\text {ti }}$ Germani Flaviacensis in librum Levitici.

12. Expositiones in lib. Numerorum in quo desunt multa tam in fine quam in medio.

13. Expositiones in Psalmos a psal. 78. usque ad psalmum 144. inclusive.

14. Tractatus s. Augustini in Psal. a psalmo 101. usque ad Psal [...] inclusive desunt tamen aliqua in medio.

15. Glossoe in Psalmos a psalmo 2. usque ad Psal. 74.

16. Glosse in Psal. a psal. 65. usque ad finem psalterii. Item tractatus s. August. in Psal. 68.

17. Hugo $\mathrm{S}^{\text {ti }}$ Victoris Parisiensis super Ecclesiastem et super Lamentat. Jerem. Ejusdem tractatus pro assumptione B. Mariæ virg. ex Cant. cant. Ejusdem diversi tractatus quorum $1^{\text {us }}$ agit de 5 . statibus mutabilitatis humanæ. $2^{\text {us }}$ de 7 . vitiis. $3^{\text {us }}$ de sacram. corporis Christi. $4^{\text {us }}$ de 5 . septenis. $5^{\text {us }}$ de oblivione præteritorum malorum, et memoria, et ira. $6^{\text {us }}$ de judicio faciendo. $7^{\text {us }}$ de substantia dilectionis. $8^{\text {us }}$ quid diligendum. $9^{\text {us }}$ de refectione verbi. $10^{\text {us }}$ quot modis diabolus humilitatem impugnet. $11^{\text {us }}$ de trib. locis. $12^{\text {us }}$ de duab. piscinis. $13^{\text {us }}$ de arra animæ. $14^{\text {us }}$ de oratione. $15^{\text {us }}$ de 3. diebus. Magister Ricardus de patriarchis, studio sapientiæ, ejusque commendatione.

18. Expositio b. Hieronymi super Ecclesiastem. Ejusdem super Evangelium s. Marci. Item liber confessionum s. Augustini. Item Psalterium, desunt tamen aliqui psalmi. 19. Lectiones et Homiliæ quæ leguntur per anni circulum in ordine Cisterciensi. 20. Lectiones et Homiliæ quæ leguntur in eodem ordine Cisterciensi diebus festivis.

21. Gaufridus religiosus Clarævallensis in Canticum canticorum necnon in Apocal., desunt aliqua.

22. Sermones Gilberti abb. super Cant. canticorum. 
23. $S^{\text {ti }}$ Ambrosii epi. Mediol. de Isaac et anima liber unicus. Lib. 1. de bono mortis. De consolatione Valentiniani lib. 1. Ejusdem epistola ad Vercellensem ecclesiam. Ejusd. de Nabuthe. Petrus super leges. Liber homiliarum s. Gregorii Papæ.

24. B. Hieronymus super Ezechielem prophe. ad Eustochium virginem.

25. Commentaria in Isaiam proph.

26. Cantuariensis in libros Machabæorum, Esdræ et Neemiæ. Glossæ Magistri sup. librum Tobiæ, Judith, Esther, et Ruth, necnon sup. duos libros Regum.

27. Libri tres venerabilis Bedæ in Esdram. Ejusdem libri tres in expositione de tabernaculo ac vasis ejus et vestibus sacerdotum. Ejusdem de Templo Salomonis. Recapitulatio desolationis Jerosolimæ secundum Egesippum apost. temporaneum. Item sermo d. Augustini de resurrect. Domini.

28. B. Jeronymi in Esaiam Prophe.

29. Beda venerab. in Lucam.

30. Rabanus Maurus in Mathæum.

31. Glossæ magistri Stephani sup. 12. Prophetas ab eo lectæ in scolis. Artificium loquendi magistri Gaufridi Anglici, desunt tamen aliqua.

32. $1 \S$ Commentaria in Marcum. B Jeronymi de viris illustribus. $2 \S$ Expositio Hæmonii sup. Apocal. Item vita $s^{\text {tæ }}$ Mariæ Ægyptiacæ.

33. Petrus sup. epist. s. Pauli ad Galatas, ad Ephes., Philip., Coloss., Tessalo. Timot., Titum, Philem. et Hebræos.

34. Glossa Petri sup. epistolas s. Pauli ad Romanos, Corin. Explanatio Origenis sup. epistolam Pauli ad Roma., desunt tamen aliqua.

35. S. Augustinus in Joannem.

36. Glossa in s. Lucam.

37. Expositio in regulam s. Benedicti. S. Ambrosii libri tres de officiis. Ejusdem lib. de 12. abusionibus sæculi. Ejusd. libri duo de excessu fratris sui Satyri. Item Poema de passione s. Agnetis. Aliud poema de accusatione adversus Susannam.

38. Rufinus in libros Origenis qui vocantur Periarchon. I. de principiis. Et ejusd. Origenis tractatus sup. Joan. Item Petri Damiani sermones et epistolæ.

39. Libri s. Prosperi de vita contemplativa. Item liber s. Joan. Damasceni de vitis Barlaam \& Josaphat. Item s. Augustinus in Assumptionem b. Mariæ. Item de partu virg. b. Mariæ, liber sacris virginibus dedicatus.

40. Epistolæ s. Damasi papæ, s. Jeronymi, $\mathrm{s}^{\mathrm{ti}}$ Augustini, quas isti $\mathrm{s}^{\mathrm{ti}}$ ad se invicem scripserunt, necnon ad alios miserunt de diversis reb. et locis Sacræ Scripturæ.

41. Opera divi Bernardi.

42. Liber sermonum s. Leonis pp. Ejusd. homiliæ diversæ. Ejusd. tractatus contra hæresim Eutichetis. Item sermo s. Augustini de Pascha. Item Apologia s. Gregorii Nanz. cum prologo Rufini. Sermo ejusd. Gregorii ad populum postquam regressus est. Ejusd. apud Imperatorem pro quodam periclitante intercessio. Ejusd. homiliæ ad monachos. Epistolæ quædam Leonis papæ ad Constantinopolitanos, ad Aquileiensem Episcopum, ad Flavianum Episcopum.

43. Anselmus Lugdunensis in Apocal. Expositio Remigii in primam editionem Donati grammatici urbis Romæ. Poema de officio monachi. Aliud de triplici egestate. Sermones super illud Nolite diligere mundum. Liber Hugonis de Folleio ad amicum volentem nubere. Sermo s. Bernardi de morte Humberti. Ejusd. sermo in transitu sancti Malachiæ. Liber Hugonis de Fuldis de 12. abusionibus claustri. S. Anselmus de similitudine inter propriam voluntatem et adulteram reginam. Libri Hugonis canonici de Folleio de claustro animæ. 
44. Epistola Domni Alyldredi abb. Riævallensis ad Londiniensem episcopum. Ejusd. sermo in adventu Domini de 11. oneribus et tractatus de oneribus in Esaiam. Arnulphi Luxoviensis ecclesiæ ministri epistolæ. Ejusdem sermo in concilio Turonensi habitus. 45. Incerti autoris tractatus de Incarnatione \& Sacramentis.

46. Liber exceptionum magistri Richardi canonici S. Victoris Paris.

47. Epistola domni Guillelmi abb. S. Theodorici ad fratres de Monte Dei. Item sermones varii magistri Roberti.

48. Sermones de diversis rebus incerti authoris.

49. Liber moralium quæstionum. Item tractatus de sacramento altaris.

50. Liber Florum, seu de diversis rebus.

51. Vitæ sanctorum patrum antiquorum.

52. Vitæ s. Bernardi per G. S. Theodorici abbatem, Ernaldum Bonævallis abbatem et domnum Gaufridum Clarævallensem, necnon etiam S. Joannis Evangelistæ, s. Martialis episcopi, s. Germani episcopi, s. Malachiæ episcopi per s. Bernardum. 53. Vitæ et Passiones sanctorum Concordii presbyteri, Martinæ virg. et mart., Fulgentii episcopi, Eugendi abb. Petri martyris, Theogenii martyris, necnon multorum aliorum et aliarum».

La seconde liste, conservée dans les archives de la bibliothèque de Colbert, répertorie 58 manuscrits dont la plupart sont transférés à Paris en avril 1682. La numérotation des descriptions est originale, la date et le prix sont ajoutés par Baluze. Il s'agit d'un accusé de réception général, dont les informations ne sont certainement pas confrontées dans le détail au contenu des manuscrits arrivés chez Colbert $[=\text { Foucarmont } \mathrm{B}]^{69}$ :

«Libri manu exarati seu catalogus manuscriptorum in Bibliotheca abbatiæ de Fulcardimonte repertorum [additions en marge:] Arrivez dans la bibliothèque de Monseigneur le 14. avril 1682. $350 \mathrm{LL}$

1. Commentaria in libros Origenis de principiis seu principatibus.

2. Origenes in epistolas b. Pauli. 2 tom. [sic] ann. 1170.

3. Epistolæ dd. [bb.] Damasi presbyteri et Augustini ad b. Hieronymum cum responsis. 1 tom.

4. Libri octo b. Hieronymi in Isaiam [prophetam]. 1 tom.

5-6. Epistola b. Hieronymi ad Paulinum presbyterum de omnibus divinæ historiæ libris. 2 tom.

7. Prologus libri Bedæ presbyteri in libros commentariorum super Marcum et liber beati Hieronymi presbyteri et doctoris de viris illustribus. 1 tom.

8. Diversa $s^{\mathrm{ti}}$ Ambrosii Mediolanensis episcopi opera de diversis officiis, de duodecim abusivis sæculi, de excessus Satyri fratris sui et de passione $\mathrm{s}^{\text {tæ }}$ Agnetis virginis \&c. 1 tom.

9. Item libri plures $\mathrm{s}^{\mathrm{ti}}$ Ambrosii [episcopi], quorum duo rimi de Isaac et anima, duo de bono mortis, duo de Jacob et beata vita, unus de paradiso, unus de consolatione Valentiniani et epistola un[a] ad Vercellenses. 1 tom.

69. Paris, BnF, ms lat. 9364, fol. 78-80v; une autre copie des $n^{\circ}$ 1-19 est classée dans les papiers de travail de Bernard de Montfaucon, ms lat. 13069, fol. 46-v, avec de légères variantes de texte (indiquées entre crochets) et d'orthographe. 
10. Prologus b. Augustini super Genesim ad litteram [tom. 1].

11. Libri Aurelii Augustini [s. Augustini doctoris] contra Manichæos, super Genesim. Item B. Augustini episcopi de epistola $\mathrm{s}^{\mathrm{ti}}$ Jobis homiliæ decem. 1 tom. 12. Tractatus $\mathrm{s}^{\mathrm{ti}}$ Augustini episcopi in Psalmos, a psalmo $101^{\circ}$ usque ad 150.1 tom. 13. B. Augustinus in Johannem. 1 tom.

14. Sermones $s^{\text {ti }}$ [Fannis] Leonis papæ. Item tractatus contra hæresim Eutychetis dictus in basilica $s^{\text {tæ }}$ Anastasiæ virginis. Item sermones $\mathrm{s}^{\mathrm{ti}}$ Augustini. Homiliæ $\mathrm{b}$. Gregorii ad Manichæos et ejusdem tractatus de grandinis vastatione. 1 tom.

15. Beda super Esdram prophetam. Idem in expositione de tabernaculo ac vasis ejus et vestibus sacerdotum. De templo salomonis. Ejusdem recapitulatio desolationis Hierosolymitanæ. B. Augustinus de resurrectione domini. S. Ambrosius de episcopo si ut ordinaretur pecuniam dedit. Idem de lepre Giesi. 1 tom.

16. Libri sex Bedæ in Lucam. 1 tom.

17. Libri s ${ }^{\text {ti }}$ Bros Prosperi de vita contemplativa. Item libri ${ }^{\text {ti }}$ Joannis Damesceni de gestis Barlaam et Josaphat. $S^{\text {tus }}$ Augustinus in assumptione b. Mariæ virginis. Item liber de partu virginis Mariæ sacris virginibus dedicatus. 1 tom.

18. Beda in libros Regum. 1 tom.

19. Sermones Ayldredi, abbatis Rievallis ad Londoniensem episcopum. Epistolæ Arnulphi Lexoviensis eccesiæ [sic] ministri. Ejusdem sermones.

20. Soliloquia $s^{\text {ti }}$ Isidori, homiliæ $s^{\text {ti }}$ Eusebii episcopi, item sermones $s^{\text {ti }}$ Petri Ravennatis episcopi. 1 tom.

21. Octo libri Rabani in Matthæum. 1 tom.

22. Opera Ricardi canonici $S^{\text {ti }}$ Victoris Parisiensis induas partes completentia. Quarum prima tractat de origine et descretione artium situ terrarum \&c. 2a de allegoriarum aropologiarum [sic] mysteriis. 1 tom.

23. Septuaginta septem sermones $\mathrm{s}^{\mathrm{ti}}$ Augustini. 1 tom.

24. Glossæ Apocalypsis secundum lectionem Anselmi; versus de triplici egestate; Opera Hugonis de claustro animæ. Et de duodecim abusionibus claustri. 1 tom. 25. Epistola domini Willelmi, quondam abbatis $S^{\text {ti }}$ Theoderici ad fratres de monte Dei. Item sermones varii magistri Roberti Pulonis. 1 tom.

26. Gaufridi, religiosi Clarevallensis, dein episcopi Autissiodorensis opera in Cantica canticorum et in Apocalypsim. 1 tom.

27. Liber anonymus incipiens "De cedro et passeribus qui in ramis ejus nidificant, de pelicano, vipera, formicia et naturalibus". 1 tom.

28. Liber continens expositiones in parabolas Salomonis, expositio venerabilis Bedæ super Ecclesiastem, ejusdem liber contra Julianum pro defensione gratiæ Dei, et ejusdem expositio in Cantica canticorum.

29. Commentarium in Isaiam prophetam.

30. Opera Petri Comestoris Dionysii Hugonis Bernardi Pauli Ricardi et variorum autorum de oratione dominica, de sacramento altaris \&c. in 13 libris. 1 tom.

31. Liber homiliarum $s^{\text {ti }}$ Gregorii papæ. 1 tom.

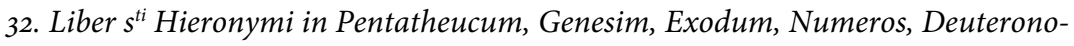
mium, Josue, Judies, Ruth. 1 tom. Biblia pars.

33. Ejusdem in librum Job, qui incipit «Tertius ordo agyographum, etc. ». 1 tom. Biblia pars.

34. Ejusdem in Paralipomenon usque ad Danielem prophetam. 1 tom. Biblia pars. 35. Ejusdem in quatuor Evangelia, Actus apostolorum et omnes canonicas Epistolas. 1 tom. Biblia pars. 
36-37. Liber variorum in Psalmos, cum glossis et commentariis. 2 tom.

38. Aliud volumen in Psalmos.

39. Glossa in librum Genesis. 1 tom.

40. Glossa in s. Lucam. 1 tom.

41. Viginti libri Radulfi Flaviacensis monachi $s^{\text {ti }}$ Germani Flaviacensis in libros Levitici. 1 tom.

42. Expositio Petri Lombardi in sanctam Scripturam seu vetus testamentum. 1 tom. 43. Glossæ magistri Stephani Cantuariensis archiepiscopi super duodecim Prophetas. Item artificium loquendi magistri Gaufridi Anglici. 1 tom.

44. Ejusdem magistri Stephani opera in libros Machabeorum, Esdræ, Nehemiæ, Tobiæ, Judith, Esther, Ruth et duos libros Regum. 1 tom.

45. Author anonymus super Leviticum, Numeros, Deuteronomen, Josue et Judicum. 1 tom.

46. Glossæ Petri super epistolas Pauli. 1 tom.

47. Bruno episcopus super Genesim, libros Exodi, Levitici, Numerorum et Deuteronomi. 1 tom.

48. Expositiones ss. Augustini, Gregorii, Origenis, Bedæ, \&c. in librum Numerorum. 1 tom.

49. Sermones Gilleberti abbatis super Cantica canticorum. 1 tom.

50. Expositio Hamonis super Apocalypsim. Vitæ Vita b. Mariæ ægyptiacæ oratione soluta et versibus descripta. 1 tom.

51. Hugo de $S^{\text {to }}$ Victore super Ecclesiasten, super lamentationes Jeremiæ. Ejusdem liber de assumptione virginis et diversi tractatus de septem vitiis, de quinque tom statibus mutabilitatis humanæ, de sacramento corporis Christi, de oratione et de judicio faciendo \&c. 1 tom.

52. Vita $s^{\text {ti }}$ Bernardi . Assumptio $s^{\text {ti }}$ Joannis apostoli et evangelistæ. B. Martialis episcopi et confessoris vita et actus. $S^{\mathrm{ti}}$ Germani episcopi vita. $S^{\mathrm{ti}}$ Malachiæ episcopi et confessoris vita. 1 tom.

53. Vitæ plurium $\mathrm{s}^{\text {torum }} .1$ tom.

54. Hieronymus in Isaiam, et lectionarium in quo continentur homiliæ ss. patrum. 2 tom.

55. Epistolæ Hildeberti Cænomanensis episcopi et libri moralium quæstionum numero undecim. Item tractatus de sacramento alteris. 1 tom.

56. Varii sermones variorum. 1 tom.

57. Tractatus de incarnatione et sacramentis. 1 tom.

58. Vitæ et passiones primorum sanctorum numero 21. 1 tom».

\begin{tabular}{|l|l|l|l|l|l|l|l|}
\hline & A & B & & $\begin{array}{l}\text { Cotes } \\
\text { actuelles }\end{array}$ & Colbert & & \\
\hline Foucarmont & $38 \mathbf{g}_{1}$ & 1 & latin & 1645 & 2355 & XIII $\mathrm{e}$ s. & $\begin{array}{l}\text { ex-libris, } \\
\text { fol. }\end{array}$ \\
\hline Foucarmont & $38 \mathbf{g}_{2}$ & 2 & latin & 1641 & 2634 & XII $\mathrm{s}$. & $\begin{array}{l}\text { ex-libris, } \\
\text { fol. }\end{array}$ \\
\hline Foucarmont & 40 & 3 & latin & 1880 & 2599 & XII ${ }^{\mathrm{e}}$ s. & $\begin{array}{l}\text { ex-libris, } \\
\text { fol. }\end{array}$ \\
\hline
\end{tabular}




\begin{tabular}{|c|c|c|c|c|c|c|c|}
\hline Foucarmont & 28 & 4 & latin & 1819 & 2629 & $\mathrm{XII}^{\mathrm{e}} \mathrm{s}$. & $\begin{array}{l}\text { ex-libris, } \\
\text { fol., rel. } 1\end{array}$ \\
\hline Foucarmont & 24 & 5 & & & & & \\
\hline Foucarmont & 24 & 6 & latin & 1826 & 2993 & & \\
\hline Foucarmont & $32 g_{1}$ & 7 & latin & 2351 & 2637 & $\begin{array}{l}\mathrm{XII}^{\mathrm{e}}- \\
\mathrm{XIII}^{\mathrm{e}} \mathrm{s} .\end{array}$ & fol. \\
\hline Foucarmont & 37 & 8 & latin & 4214 & 2661 & $\mathrm{XIV}^{\mathrm{e}} \mathrm{s}$. & fol. \\
\hline Foucarmont & $23 g_{1}$ & 9 & latin & 1730 & 5112 & $\begin{array}{l}\mathrm{XII}^{\mathrm{e}}- \\
\mathrm{XIII}^{\mathrm{e}} \mathrm{s} .\end{array}$ & fol. \\
\hline Foucarmont & 791 & 10 & latin & 1947 & 2635 & $\mathrm{XIII}^{\mathrm{e}} \mathrm{s}$. & fol. \\
\hline Foucarmont & 729 & 11 & latin & 1925 & 2647 & $\mathrm{XII}^{\mathrm{e}} \mathrm{s}$. & $\begin{array}{l}\text { ex-libris, } \\
\text { fol. }\end{array}$ \\
\hline Foucarmont & 14 & 12 & latin & 2002 & 2985 & $\mathrm{XII}^{\mathrm{e}} \mathrm{s}$. & fol. \\
\hline Foucarmont & 35 & 13 & latin & 3329 & 2649 & $\mathrm{XII}^{\mathrm{e}} \mathrm{s}$. & fol. \\
\hline Foucarmont & 42 & 14 & latin & 2160 & 2654 & $\mathrm{XIII}^{\mathrm{e}} \mathrm{s}$. & fol. \\
\hline Foucarmont & 27 & 15 & latin & 2343 & 2655 & $\mathrm{XII}^{\mathrm{e}} \mathrm{s}$. & fol. \\
\hline Foucarmont & 29 & 16 & latin & 2357 & 2646 & $\mathrm{XII}^{\mathrm{e}} \mathrm{s}$. & fol. \\
\hline Foucarmont & 39 & 17 & latin & 2153 & 2610 & $\mathrm{XIII}^{\mathrm{e}} \mathrm{s}$. & $\begin{array}{l}\text { ex-libris, } \\
\text { fol. }\end{array}$ \\
\hline Foucarmont & 1029 & 18 & latin & 70 & 2656 & $\mathrm{XIII}^{\mathrm{e}} \mathrm{s}$. & \\
\hline Foucarmont & 44 & 19 & latin & 491 & 2658 & $\mathrm{XIII}^{\mathrm{e}} \mathrm{s}$. & fol. \\
\hline Foucarmont & & 20 & latin & 2320 & 2617 & $\mathrm{XIII}^{\mathrm{e}} \mathrm{s}$. & $\begin{array}{l}\text { ex-libris, } \\
\text { fol. }\end{array}$ \\
\hline Foucarmont & 30 & 21 & latin & 2439 & 2952 & $\mathrm{XII}^{\mathrm{e}} \mathrm{s}$. & $\begin{array}{l}\text { ex-libris, } \\
\text { fol. }\end{array}$ \\
\hline Foucarmont & 46 & 22 & latin & 2585 & 2627 & $\begin{array}{l}\mathrm{XII}^{\mathrm{e}}- \\
\mathrm{XIII}^{\mathrm{e}} \mathrm{s} .\end{array}$ & fol. \\
\hline Foucarmont & 8 & 23 & latin & 2018 & 2645 & $\mathrm{XII}^{\mathrm{e}} \mathrm{s}$. & fol. \\
\hline Foucarmont & 43 & 24 & latin & 712 & 5117 & $\begin{array}{l}\mathrm{XII}^{\mathrm{e}}- \\
\mathrm{XIII}^{\mathrm{e}} \mathrm{s} .\end{array}$ & $\begin{array}{l}\text { ex-libris, } \\
\text { fol. }\end{array}$ \\
\hline Foucarmont & 47 & 25 & latin & 2945 & 5133 & $\mathrm{XII}^{\mathrm{e}} \mathrm{s}$. & fol. \\
\hline Foucarmont & 21 & 26 & latin & 476 & 2648 & $\mathrm{XIII}^{\mathrm{e}} \mathrm{s}$. & \\
\hline Foucarmont & & 27 & latin & $2495 \mathrm{~A}$ & 3030 & $\begin{array}{l}\mathrm{XII}^{\mathrm{e}}- \\
\mathrm{XIII}^{\mathrm{e}} \mathrm{s} .\end{array}$ & $\begin{array}{l}\text { ex-libris, } \\
\text { fol. }\end{array}$ \\
\hline Foucarmont & & 28 & latin & 485 & 2650 & $\mathrm{XII}^{\mathrm{e}} \mathrm{s}$. & ex-libris \\
\hline Foucarmont & 25 & 29 & latin & 1816 & 2628 & $\mathrm{XII}^{\mathrm{e}} \mathrm{s}$. & fol. \\
\hline
\end{tabular}




\begin{tabular}{|c|c|c|c|c|c|c|c|}
\hline Foucarmont & 50 & 30 & latin & 3144 & 2643 & $\begin{array}{l}\mathrm{XII}^{\mathrm{e}}- \\
\mathrm{XIII}^{\mathrm{e}} \mathrm{s}\end{array}$ & $\begin{array}{l}\text { ex-libris, } \\
\text { fol., cote } \\
« 58 »\end{array}$ \\
\hline Foucarmont & 2392 & 31 & latin & 2237 & 2653 & $\mathrm{XII}^{\mathrm{e}} \mathrm{s}$. & fol. \\
\hline Foucarmont & 1 & 32 & & & & & \\
\hline Foucarmont & 4 & 33 & & & & & \\
\hline Foucarmont & 3 & 34 & & & & & \\
\hline Foucarmont & 5 & 35 & & & & & \\
\hline Foucarmont & 15 & 36 & & & & & \\
\hline Foucarmont & 16 & 37 & & & & & \\
\hline Foucarmont & 18 & 38 & latin & 1807 & 2633 & $\mathrm{XII}^{\mathrm{e}} \mathrm{s}$. & fol. \\
\hline Foucarmont & 1019 & 39 & latin & 65 & 2926 & $\begin{array}{l}\mathrm{XII}^{\mathrm{e}}- \\
\mathrm{XIII}^{\mathrm{e}} \mathrm{s} .\end{array}$ & ex-libris \\
\hline Foucarmont & 36 & 40 & latin & 293 & 2977 & XIII' s. & ex-libris \\
\hline Foucarmont & 11 & 41 & latin & 378 & 511 & $\begin{array}{l}\mathrm{XII}^{\mathrm{e}}- \\
\mathrm{XIII}^{\mathrm{e}} \mathrm{s} .\end{array}$ & $\begin{array}{l}\text { ex-libris, } \\
\text { fol., cote } \\
\text { « } 41 »\end{array}$ \\
\hline Foucarmont & 33 & 42 & latin & 681 & 2907 & $\begin{array}{l}\mathrm{XII}^{\mathrm{e}}- \\
\mathrm{XIII}{ }^{\mathrm{e}} \text { s. }\end{array}$ & fol., rel. 1 \\
\hline Foucarmont & 31 & 43 & latin & 505 & 2640 & 1207 & $\begin{array}{l}\text { ex-libris, } \\
\text { fol. }\end{array}$ \\
\hline Foucarmont & 26 & 44 & latin & 510 & 2639 & 1207 & $\begin{array}{l}\text { ex-libris, } \\
\text { fol. }\end{array}$ \\
\hline Foucarmont & 6 & 45 & latin & 385 & 3010 & XIII ${ }^{\mathrm{e}} \mathrm{s}$. & $\begin{array}{l}\text { ex-libris, } \\
\text { fol. }\end{array}$ \\
\hline Foucarmont & 34 & 46 & latin & 673 & 2607 & $\begin{array}{l}\mathrm{XII}^{\mathrm{e}}- \\
\mathrm{XIII}{ }^{\mathrm{e}} \mathrm{s} .\end{array}$ & $\begin{array}{l}\text { ex-libris, } \\
\text { fol. }\end{array}$ \\
\hline Foucarmont & 9 & 47 & latin & 2506 & 2600 & XIII ${ }^{\mathrm{e}} \mathrm{s}$. & $\begin{array}{l}\text { ex-libris, } \\
\text { fol. }\end{array}$ \\
\hline Foucarmont & 12 & 48 & ${ }^{*}$ latin & 72 & 2927 & XIII's. & \\
\hline Foucarmont & 22 & 49 & latin & 473 & 2644 & $\begin{array}{l}\mathrm{XII}^{\mathrm{e}-} \\
\mathrm{XIII}^{\mathrm{e}} \mathrm{s} .\end{array}$ & fol. \\
\hline Foucarmont & $32 g_{2}$ & 50 & latin & 2417 & 2657 & $\begin{array}{l}\mathrm{XII}^{\mathrm{e}-} \\
\mathrm{XIII}^{\mathrm{e}} \mathrm{s} .\end{array}$ & fol. \\
\hline Foucarmont & 17 & 51 & latin & 2527 & 2652 & $\mathrm{XII}^{\mathrm{e}} \mathrm{s}$. & $\begin{array}{l}\text { ex-libris, } \\
\text { fol. }\end{array}$ \\
\hline Foucarmont & 52 & 52 & latin & 5370 & 2638 & $\mathrm{XIII}^{\mathrm{e}} \mathrm{s}$. & $\begin{array}{l}\text { ex-libris, } \\
\text { fol. }\end{array}$ \\
\hline
\end{tabular}




\begin{tabular}{|l|l|l|l|l|l|l|l|}
\hline Foucarmont & 53 & 53 & latin & 5297 & 512 & XIII s. & fol. \\
\hline Foucarmont & 53 & 53 & latin & 5291 & 515 & XIII s. & fol. \\
\hline Foucarmont & 20 & 54 & latin & 3814 & 513 & XIII s. & fol. \\
\hline Foucarmont & 19 & 54 & latin & 3809 & 514 & XIII s. & fol. \\
\hline Foucarmont & 49 & 55 & latin & 2513 & 2662 & XIII s. & $\begin{array}{l}\text { ex-libris, } \\
\text { fol., cote } \\
\text { "CII» }\end{array}$ \\
\hline Foucarmont & 48 & 56 & latin & $3301 C$ & 2663 & XII ${ }^{e}$ s. & fol. \\
\hline Foucarmont & 45 & 57 & latin & 3031 & 3012 & XII s. & fol. \\
\hline Foucarmont & 51 & 58 & latin & 5284 & 2632 & XIII s. & fol. \\
\hline Foucarmont & 2 & & & & & & \\
\hline Foucarmont & 13 & & & & & & \\
\hline Foucarmont & 41 & & & & & & \\
\hline
\end{tabular}

Les manuscrits identifiés sont foliotés au milieu de la marge supérieure d'une main du XIII siècle, sauf les numéros 18, 26, 28, 39 et 40. Les commentaires sur la Bible et les textes patristiques sont les plus nombreux et parmi eux, on remarque une riche collection d'œuvres de saint Augustin.

On peut s'interroger sur l'histoire des cinq tomes de la Bible conservée aujourd'hui au Musée Mathon-Durand de Neufchâtel-en-Bray ${ }^{70}$, dont les divisions en tomes sont semblables aux indications de Montfaucon. Les tomes 1 et 3-5 figurent sur la liste de Baluze, alors qu'ils ne sont pas arrivés chez Colbert. Ce sont sans doute les seuls volumes encore à Foucarmont au moment de la Révolution. En 1790 ou 1791, Boquet, maire de Neufchâtel-en-Bray, enlèvera les bibliothèques des abbayes de Beaubec et de Foucarmont, et ces fonds seront en grande partie détruits avec les collections de la Bibliothèque municipale de Neufchâtel le 7 juin $1944^{71}$. Le volume passé au XVII ${ }^{e}$ siècle chez Mazarin ne figure quant à lui sur aucune liste ${ }^{72}$.

\section{Rouen (1682)}

Certains volumes sont signalés à diverses reprises dans les registres de l'échevinage à partir du $\mathrm{XV}^{e}$ siècle, et une liste assez détaillée figure en 1647 dans le journal des échevins $[=\text { Rouen } \mathrm{A}]^{73}$ :

70. Mss 1-5; CoyecQue, 1888, p. 347; Trésors des abbayes normandes, 1979, nº 185.

71. Dubuc, 1979, p. 150-151; un seul ms se trouve encore à la Bibl. mun. de Neufchâtel (ms 10).

72. Paris, BnF, ms lat. 2588.

73. Extrait des registres (A. 28) des délibérations du conseil de Rouen (1671-1693), non retrouvé; Colbert, 1873, p. 371; Richard, 1845, passim; Delisle, 1868, p. 475 et 544-547 (éd. de la liste C); Genevois et al., 1987, nº 1663, p. 205. 
«Inventaire des livres manuscrits et imprimés appartenans à la ville qui ont esté transportés du grand au petit chartrier d'icelle ville

Premièrement

1. La cité de Dieu de saint Augustin translatée en françois manuscript en velin.

2. Un grand manuscript en vellin des cent nouvelles de Boccace aussi en françois.

3. Un autre grand manuscript en vellin dudit auteur des hommes et femmes illustres en françois.

4. Un autre manuscript aussy en vellin de Valere le grand en françois.

5. La bible en françois commentée par les scolastiques.

6. Bouccardin en françois.

7. De Lira super Psalmos.

8. L'histoire romaine de Suetonne en françois.

9. Un missel.

10. La conqueste de la terre saincte de Godefroy de Bouillon.

11. Histoire de France depuis le commencement de la monarchie jusques à Charles VI.

12. L'etrif entre vertu et fortune.

13. Histoire de France de Froissart.

14. Etiques et politiques d'Aristote en françois.

15. Regime des princes par $\mathrm{m}^{\mathrm{e}}$ Allain le Charetier.

16. Chroniques de Normandie.

17. Autre histoire de France.

18. Le rustique planteur.

19. La coustume de Normandie en latin.

2o. Cuvres poetiques de Jean Clopinel.

21. Les decretalles en papier.

Livres imprimés in-folio [ 28 volumes imprimés éditions des XVI ${ }^{e}$ et XVII ${ }^{e}$ siècles...] ».

Au début de 1682, le premier président au Parlement de Rouen Claude Pellot $^{74}$ demande à voir les livres gardés dans le chartrier, qui pourraient convenir à la bibliothèque de Colbert. Après délibération du conseil municipal le 28 janvier 1682, une visite est organisée le 23 mars 1682 [= Rouen B $]^{75}$ :

«Le sieur Dufour a remontré à la compagnie que M. Pellot, premier president au parlement, estoit venu ces jours derniers en l'hostel de ville et avoit demandé à entrer pour voir plusieurs manuscrits qui y estoient... il a esté arresté que l'on feroit porter à la maison de Monsieur le premier président les livres cy après nommez, scavoir

[1] une antienne bible

[2-3] Bocasse en deux tomes

[4] Valere Maxime

[5] L'histoire grecque dite Beaucachardine

[6] Saint Aug ${ }^{\text {in }}$ sur le traitté de la cité de Dieu

[7] L’histoire romaine par Saluste

\footnotetext{
74. Voir note 27.

75. RichaRd, 1845 , p. 5.
} 
[8] Le regime des princes

[9] La conqueste de Jerusalem

[10-11] Deux antiennes histoires de France

[12] et une autre histoire de Charles sixiesme

lesquelz livres seront presentez à Monsieur Colbert au nom de la ville».

L'accusé de réception de Baluze est ajouté à la fin de la liste de Foucarmont, les deux lots étant arrivés en même temps [Rouen $\mathrm{C}]^{76}$ :

«Livres mss. arrivez par la mesme voye tirez de l'hostel de ville de Rouen, tous in folio \& donnez à Monseigneur

[1-2] Valere le grand, commenté.

[3-4] S. Augustin de la cité de Dieu.

[5] Les grandes chroniques de France.

[6] Histoire de Charles VI \& Charles VII.

[7-8] Histoire escolastre.

[9] Histoire de Robert le diable.

[10] Jean de Courcy.

[11] Froissart tome premier.

[12-13] Bocace .2. voll.

[14] Guillaume de Tyr.

[15] Histoire romaine tirée de Saluste \&c.

[16] Gilles de Rome du regime des princes ».

\begin{tabular}{|l|l|l|l|l|l|}
\hline A & B & C & & Cotes actuelles & Colbert \\
\hline 4 & 4 & 1 & français & 45 & 253 \\
& & 2 & français & 46 & 254 \\
\hline 1 & 6 & 3 & français & 23 & 265 \\
& & 4 & français & 24 & 266 \\
\hline 11 & $11 ?$ & 5 & français & 2605 & 197 \\
\hline 17 & 12 & 6 & français & 2599 & 267 \\
\hline 5 & 1 & 7 & français & 3 & 201 \\
\hline 16 & $?$ & 9 & français & 4 & 202 \\
\hline 6 & 5 & 10 & français & 2623 & 434 \\
\hline 13 & $11 ?$ & 11 & français & 2647 & 92 \\
\hline 2 & 2 & 12 & français & 129 & 258 \\
\hline 3 & 3 & 13 & français & 131 & 257 \\
\hline 10 & 9 & 14 & français & 2629 & 256 \\
\hline
\end{tabular}

76. Paris, BnF, ms lat. 9364 , fol. 8 ov. 


\begin{tabular}{|l|l|l|l|l|l|}
\hline 8 & 7 & 15 & français & 295 & 301 \\
\hline 15 & 8 & 16 & français & 126 & 255 \\
\hline 7 & & & Rouen & $128($ A.38) & \\
\hline 9 & & & & & \\
\hline 12 & & & & & \\
\hline 14 & & & Rouen & 927 (I.2) & \\
\hline 18 & & & Rouen & 977 (I.1) & \\
\hline 19 & & & Dutuit & & \\
\hline 20 & & & & & \\
\hline $21^{77}$ & & & & & \\
\hline
\end{tabular}

La comparaison des trois listes permet d'identifier la plupart des volumes décrits, partagés entre Paris et Rouen. Parmi eux, plusieurs volumes sont des commandes de l'échevinage, réalisées par des artistes normands; ils illustrent le renouveau que connait Rouen au cours de la seconde moitié du $\mathrm{XV}^{\mathrm{e}}$ siècle $e^{78}$, leur contenu et leur décor annoncent ceux des manuscrits de Georges d'Amboise. Le contenu et l'aspect de ces manuscrits tardifs en français sont très différents de ceux qui viennent des abbayes, en raison de leur origine et de leur typologie, mais aussi des conditions de l'opération orchestrée par Claude Pellot.

\section{Bonport (mai 1683)}

L'envoi de Bonport ${ }^{79}$ est le dernier pour la Normandie. L'abbaye, mise en commende en 1543/1544, tombe à la fin du XVII siècle dans les mains de l'un des fils de Colbert, Louis, comte de Linières. En 1683, 58 manuscrits sont pris de force au bénéfice de la bibliothèque du ministre, en échange de 40 livres imprimés ${ }^{80}$.

Comme pour la plupart des autres abbayes, plusieurs inventaires de la fin $\mathrm{du}$ XVII ${ }^{\mathrm{e}}$ siècle sont conservés. Le premier [= Bonport $\left.\mathrm{A}\right]$ décrit $8 \mathrm{o}$ articles non

77. Ne peut correspondre aux Décrétales en français, Rouen, Bibl. mun., ms 726 (E.62), qui est en parchemin.

78. Avril et Reynaud, 1993, p. 92-93, p. 169-172.

79. Abbaye de Bonport, dép. Eure, dioc. Évreux, c. Pont-de-l'Arche, fondée en 1190 par Richard Coeur de Lion et dévastée au XIV ${ }^{\mathrm{e}}$ siècle; Delisle, 1868, p. 476 et 534-542 (éd. de la liste C); Deville, 1909, ms fr. 1893, ms lat. 21, 29, 53, 56, 74, 84, 120, 126, 129, 144, 275, 288, 295, 301, 302, 345, 363, $382,393,416,446,447,454,458$ (pour 485B), 618, 668, 672, 1882, 1945, 2007, 2022, 2052, 2228, 2230, 2260, 2265, 2523, 2529, 2537, 2538, 2795, 2933, 2934, 3020 (pour 3030), 3025, 3280, 3281, 3283, 3573, 3724, 5053, 6418, 7361; BondéElle-Souchier, 1991, p. 42-47, 84 mss Colbert, dont les ms lat. 420 qui provient plutôt de La Noë, 4248B du collège de Foix (malgré la bande de parchemin collée par erreur dans le ms; Avril et Gousset, 1984, n 229), 5317 qui n'est pas passé chez Colbert, 485 qui provient de Foucarmont et 3030 cité par erreur pour 3020.

80. BrÉAutÉ, 1843 , p. 367 en donne la liste. 
numérotés, mais des indications ajoutées en marge, un simple ou un double trait, correspondent sans doute aux souhaits de Baluze ${ }^{81}$ :

«Catalogus manuscriptorum abbatiæ de bono portu

[1] - Sancti Augustini in Psalmos.

[2] - Idem super Genesim. - Pastorale sancti Gregorii papæ.

[3] - Vitæ sanctorum.

[4] - Revelatio s. Dionisii - Epistola Stephani papæ de revelatione ejusdem. - Acta revelationis incipit "Quartus ab Clodoveo". - Acta sancti Nicasii episcopi Rothomagensis cum prologo.

[5] - Annonimus cujus titulus est de charitate incipit "Dans in evangelia".

[6] - Biblia sacra ab initio usque ad lib. Reg.

[7] - Liber exceptionum ex capitulis s. Gregorii per sancta 4. Evangelia.

[8] - Augustinus de verbis Domini.

[9] - Idem in Joannem.

[10] - Glossa ordinaria in lib. Reg.

[11] - Flavii Josephi fragmentum hist. judaice.

[12] Gregorialis incipit "Post restaurationem cœnobii s. Martini Tornacensis quæ facta est anno 1092". Passio s. Eustachii incipit "In diebus Trajani".

[13] Tractatus anonimus incipit "Quum Dominus Jesus Christus post totius vasa saculi afflixus" 82 .

[14] Decretales Gregorii papæ incipit “Gregorius".

[15] - Joannis Cassiani collationes cum duobus frag. vitæ s. Severini episcopi Coloniensis Joachimni abbatis enchiridion super librum apocalips.

[16] - Liber summorum id est solliloquiorum de Christo quum omnes prophetas incipit "Spiritus sanctus revelatione".

[17] Glossa ordinaria super Esayam incipit "Nemo cum versibus prophetias".

[18] Super parabolas latin.

[19] In epistolas divi Pauli.

[20] Glosulæ super fere omnes libros bibliæ incipit "Ego visiones multiplicavi".

[21] Flavii Josephi historia judaica.

[22] Biblia.

[23] Novum testamentum.

[24] Pars bibliæ ab initio ad librum Rut. Vitæ ss.

[25] Vita sanctæ Salabergæ per omnia notissima.

[26] - Augustinus de civitate Dei. Sermo sub nomine sancti Augustini de assumptione beatæ Mariæ.

[27] = Eutheticus Joannis in policraticorum incipit "Jocundissimus cum multis".

[28] Glossa ordinaria in Joannem et Marcum.

[29] Omelia beati Gregorii in Ezechielem.

[30] Petri Manducatoris historia scolastica.

[31] Sancti Hieronimi epistolæ.

[32] Glosso super Genesim et alia.

[33] Glossæ super Matheum.

81. Paris, BnF, ms lat. 9364, fol. 91-93v; Genevois et al., 1987, p. 33.

82. [Transitus Mariae]? 
[34] Concordantia discordantium canonum juxta determinationem Gratiani episcopi.

[35] Hugo de Sancto Victore super Lucam incipit "Vidi \& ecce quatuor quadrigæ". [36] Glossa ordinaria super parabolas Ecclesiastes, Cantica canticorum \& Acta apostolorum.

[37] Glossa super Genesim. $=S^{\text {ti }}$ Hieronimi virorum illustrium.

[38] Liber de Sybilla incipit "Sybilloe generaliter fuit hoec sybilla priami regis filia".

[39] Glossæ fratris Hugonis super Isaiam.

[40] Græcismus Hebrardi incipit "Est proprie metagræce transformatio plasmatis. Indeque transformatio dicatur methaplasmus”. Practica qui vocatur regalis dispositio Hali filii abbatis tractans de regimine sanitatis.

[41] Joannes et Lucas glossati.

[42] Pastoralis sancti Gregorii papæ.

[43] Idem de miraculis ss. patrum.

[44] Argumentum de s. Hilarii libris excerptum super adventus Domini terminum incipit "Sciendum sane est et omnibus orthodoxis"83.

[45] = Opuscula divi Paulini Nolani episcopi incipit "Dum vicinis valde partibus intendo".

[46] Tabulæ super quatuor Evangelia a fratre de Lira edit.

[47-48] Liber Hugonis de sacramentis ecclesiæ.

[49] Concordantiæ bibliæ.

[50-51] Dictionarium morale et alphabeticum.

[52] Libellus gallice chappellet des vertus.

[53] = Magnus ciclus paschalis Dionisii incipit "Hoc nomen Ecclesiastes interpretatur \&c.”. Regulæ s. Augustini.

[54] Epistolæ s. Hieronimi.

[55] Sermones s. Bernardi de adventu domini.

[56] Sermones ss. Gregorii et Hieronimi.

[57] Summa s. Thomo.

[58] Pænitentiarius $\mathrm{m}^{\text {ri }}$ Villelmi de Giolavilla incipit «Beato Petro dictum a domino tu es Petrus».

[59] Summa de vitiis abreviata incipit "Dictum de singulis vitiis".

[6o] Libellus Helperici de arte collucatoria. = Musicæ liber incipit "Omni vos quidam præcepto \&c.".

[61] Glossa ordinaria in Lucam.

[62] Summa magistri Lumbardi de sententiarum.

[63] Moralia sancti Gregorii.

[64] - Augustinus de civitate Dei.

[65] Psalterium glossatum.

[66] $\mathrm{S}^{\mathrm{ti}}$ Gregorii super librum Job.

[67] - Bedoe de trinitate.

[68] - Opuscula Thelesphori papo de jejunio septem hebdomadum ante Pascha incipit "Quare sexagesimum celebratur".

[69] - Augustinus de civitate Dei.

83. Berno abbas Augiensis? 
[70] Annonymus in quo affixus est opuscul. incipiens "Cupientes aliquid de penuria ac tenuitate in fine confessio Berangarii ad Nicolaum papam" ».

La seconde liste figure dans un recueil de catalogues divers qui ne provient pas de Baluze $\left[=\right.$ Bonport B ${ }^{84}$. Quatorze volumes y font l'objet de descriptions textuelles exceptionnellement longues: indiquant certains incipit et explicit elles garantissent l'attribution des manuscrits:

«Manuscrits de Bonport proche du Pont de l'Arche

[1-2] Un mss. de $s^{t}$ Augustin de la cité de Dieu. A la fin du $22^{\mathrm{e}}$ livre [?] on a ajouté d'une autre écriture un sermon qui commence ainsy "Sermo s. Augustini episcopi de assumptione sanctæ Mariæ. De sanctissimo ergo corpore perpetuæ virginis Mariæ ejusque sacræ animæ assumptione quantum Dominus donavit”. A la fin "sive autem ut non debui ignosce tu et tui".

[3-4] Philippi cancellarii super Evangelia.

[5] Un mss. des epistres de $s^{t}$ Hierosme qui commence par celle à Heliodore.

[6] Incipiunt capitula homiliarum sancti Augustini de verbis Domini et de quibusdam sententiis $\mathrm{s}^{\mathrm{ti}}$ Pauli. Il en contient quatrevintreize.

[7] Incipit tractatus $\mathrm{s}^{\mathrm{ti}}$ Augustini episcopi in psalmo $35^{\circ}$.

[8] Aurelii Augustini episcopi magni tractatus in evangelio beatissimi Joannis.

[9] Incipit expositio dompni foann Thomæ monachi $s^{\text {tæ }}$ Mariæ de Vaucellis super Cantica canticorum "Osculetur me osculo oris. Hæc est vox synagogæ quæ Christus venturum". A la fin "ipso prestante qui cum patre \&c. Explicit liber duodecimus".

[10] Un mss. qui contient une exposition sur l'Ecclesiastique \& à la fin d'une autre main: "Cantuariensis in Ecclesiasticum"; tabula quæ dicitur Dionisii ad [habendum] festum Paschæ per versus [?]; \& regula sti Augustini quæ incipit "Hæc sunt quæ ut observetis precipimus" \& à la fin "in temptationem non inducatur". [11] Incipit prologus beati Gregorii papæ super Cantica "Quia si ceco longe e Deo posito cordi fermo divina voce propria voce divina loqueretur". Incipit tractatus Greg. super Cantica "Osculetur me osculo oris sui. Os sponsi inspiratio Christi osculum oris est dulcis amor inspirationis".

[12] Incipit liber explanationis s ${ }^{\text {ti }}$ Hieronimi in Prophetas, in Osee, Amos etc.

[13] Incipit prologus domini Radulfi in libro Levitici "Cum inter socios aliquando sermo" explicit "Radulfus super Leviticum nomine Raduffus Radulfus præsens liber est vocitatus".

[14] Incipit prologus $s^{\text {ti }}$ Jeronimi presbiteri in libro hebraicarum questionum "Qui in principiis librorum etc. Incipit virorum prologus illustrium $\mathrm{s}^{\text {ti }}$ Jeronimi. Hortaris dexter ut tranquillum etc. Simon Petrus etc. Hieronimus patre Eusebio natus opido Stridonis etc."; cela monstre qu'il ne peut estre de $s^{t}$ Hierosme [?]. "Ambrosius Mediolanensis episcopus usque in præsentem diem scribit de quo quia superest meum judicium subtraham ne in alterutram partem aut adulatio in me repredundatur [sic] aut veritas"; le reste manque parce qu'on en a osté quelques feilles».

84. Paris, BnF, ms lat. 10397, fol. 8-9. 
La troisième est $[=$ Bonport $\mathrm{C}]$, de la main de Baluze ${ }^{85}$. C'est sans doute l'accusé de réception des 88 volumes envoyés à Colbert. Dans la marge, l'indication du prix est aussi de sa main mais la numérotation est ajoutée par Léopold Delisle:

"Catalogue des mss de l'abbaye de Bonport portez dans la bibliotheque de Monseigneur le $11^{\mathrm{e}}$ may 1683 " [add. en marge:] "440 $\amalg$ »

Folio

[1] Josephi antiquitatum judaicarum libri XIV.

[2] Biblia sacra usque ad librum Judicum.

[3] Decretum Gratiani absque glossa.

[4-5] Homiliæ variorum patrum per annum. 2. voll.

[6-9] Vitæ sanctorum. 4. voll.

[10] Homiliæ s. Gregorii in Evangelia.

[11-13] S. Augustinus de civitate Dei. 3. voll.

[14] Policraticus Joannis Sarisberiensis.

[15-16] Summa Philippi cancellarii Parisiensis super Evangelia. 2. voll.

[17] S. Gregorii homiliæ in Ezechielem.

[18] Ejusdem liber pastoralis \& dialogi.

[19] Epistolæ s. Hieronymi.

[20] Decretales Gregorii IX. cum glossa.

[21] Cujusdam commentarius in Ecclesiastem. Regula s. Augustini.

[22-23] Liber sententiarum Petri Lombardi. 2. voll.

[24] Radulfus Flaviacensis in Leviticum.

[25] Virgilii opera.

[26] Tertia pars summes. Thomo, scripta anno 1452.

[27] Vocabularium bibliæ.

[28] Glossæ divinorum librorum. Hieronymi quæstiones hebraicæ. Item alia quædam Hieronymi et liber virorum illustrium.

[29-30] Hieronymus in Prophetas minores. 2 voll.

[31] Græcismus Ebrardi. Regimentum sanitatis sive practica Pantegni.

[32] Historia scholastica.

[33] Augustinus in Joannem.

[34] Idem de verbis Domini.

[35] Thomas de Vaucellis super Cantica.

[36] Novum testamentum.

[37] Chollationes Cassiani.

[38] Biblia sacra usque as libros Regum.

[39] Moralitates super psalterium.

[40] Hugo de S. Victore in Lucam.

[41] Hugucionis glossarium.

[42-43] Glossarium Papiæ. 2. voll.

[44-45] Hugo Victorinus de sacramentis. 2. voll.

[46] Biblia sacra.

[47] Petrus Lombardus in Psalmos.

[48] Sermones s. Bernardi.

85. Paris, BnF, ms lat. 9364, fol. 89-90. 
[49] Liber de laudibus b. Mariæ. Miracula Clarevallensium.

[50-66] Glossa ordinaria \& commentaria in scripturam. 17. voll.

[67] Tomus secundus Augustini in Psalmos.

[68-69] Duo tomi moralium s. Gregorii.

[70-71] Alulfi monachi S. Martini Tornacensis exceptiones ex operibus s. Gregorii.

2. voll.

Quarto

[72] Biblia sacra.

[73] Sermones et exempla Jacobi de Vitriaco.

[74] Excerpta Oyni subprioris de Valle super IV evangelistas. Distinctiones collectæ post Meldensem. Interpretationes hebraicorum nominum. Quædam distinctiones super psalterium. Beda de quadrifario opere Dei. Exceptiones canonum Arnulfi. [75] Summa de vitiis.

[76] Glossa ordinaria in Parabolas \& in Cantica.

[77] Libellus Helprici de arte calculatoria. Adalbertus episcopus Trajectensis in Boetium. Boetius de musica.

[78] Sermones CXVIII cujusdam. Beda de quadrifario opere Dei. Liber Jesu nave. Epistola presbyteri Johannis ad Manuelem imperatorem. Anselmi elucidarius. Sermo in synodo. Epistolæ quædam Hildeberti.

[79] Sermones s. Bernardi.

[80] Summa super psalterium secundum magistrum Præpositinum.

[81] Augustinus super Genesim ad litteram. Pastorale s. Gregorii.

[82] Homiliæ Gregorii papæ in Evangelia.

[83-84] S. Bernardus in Cantica. 2 voll.

[85] Gregorius in Cantica canticorum. Homiliæ Eusebii episcopi Emeseni. Vita b. Mariæ de Oegnes.

Octavo

[86] Pœnitenciarius Willelmi de Gislarvilla.

[87] Epistolæ Hieronymi.

[88] Le chapellet des vertus».

\begin{tabular}{|l|l|l|l|l|l|l|l|l|}
\hline & A & B & C & & $\begin{array}{l}\text { Cotes } \\
\text { actuelles }\end{array}$ & Colbert & & \\
\hline Bonport & 5 & & & & & & & \\
\hline Bonport & 11 & & & & & & & \\
\hline Bonport & 13 & & & & & & & \\
\hline Bonport & 16 & & & & & & & \\
\hline Bonport & 18 & & & & & & & \\
\hline Bonport & 32 & & & & & & & \\
\hline Bonport & 38 & & & & & & & \\
\hline Bonport & 67 & & & & & & & \\
\hline Bonport & 68 & & & & & & & \\
\hline
\end{tabular}




\begin{tabular}{|c|c|c|c|c|c|c|c|c|}
\hline Bonport & 21 & & 1 & latin & 5053 & 196 & $\mathrm{XIII}^{\mathrm{e}} \mathrm{s}$. & \\
\hline Bonport & 24 & & 2 & latin & 53 & 93 & $\mathrm{XII}^{\mathrm{e}} \mathrm{s}$. & $\begin{array}{l}\text { ex-libris, } \\
\text { Faucon }\end{array}$ \\
\hline Bonport & 34 & & 3 & & & & & \\
\hline Bonport & & & 4 & latin & 3808 & 564 & $\mathrm{XIII}^{\mathrm{e}} \mathrm{s}$. & ex-libris \\
\hline Bonport & & & 5 & ${ }^{*}$ latin & 3819 & 208 & $\begin{array}{l}\mathrm{XII}^{\mathrm{e}}- \\
\mathrm{XIII}^{\mathrm{e}} \mathrm{s} .\end{array}$ & \\
\hline Bonport & 4 & & 6 & latin & 5353 & 322 & $\mathrm{XIII}^{\mathrm{e}} \mathrm{s}$. & fol. \\
\hline Bonport & 3 & & 7 & latin & 1864 & 2854 & $\mathrm{XIII}^{\mathrm{e}} \mathrm{s}$. & ex-libris \\
\hline Bonport & 25 & & 8 & latin & 5352 & 137 & $\mathrm{XIII}^{\mathrm{e}} \mathrm{s}$. & fol. \\
\hline Bonport & & & 9 & ${ }^{\star}$ latin & 5276 & 2825 & $\mathrm{XIII}^{\mathrm{e}} \mathrm{s}$. & \\
\hline Bonport & & & 10 & latin & 2260 & 2736 & $\mathrm{XII}^{\mathrm{e}} \mathrm{s}$. & ex-libris \\
\hline Bonport & 69 & & 11 & latin & 2052 & 2859 & $\mathrm{XI}^{\mathrm{e}} \mathrm{s}$. & ex-libris \\
\hline Bonport & 64 & & 12 & ${ }^{*}$ latin & $2061^{1}$ & 741 & $\begin{array}{l}\mathrm{XII}^{\mathrm{e}}- \\
\mathrm{XIII}^{\mathrm{e}} \mathrm{s} .\end{array}$ & \\
\hline Bonport & 26 & & 13 & ${ }^{\star}$ latin & $2061^{2}$ & 742 & $\begin{array}{l}\mathrm{XII}^{\mathrm{e}}- \\
\mathrm{XIII}^{\mathrm{e}} \mathrm{s} .\end{array}$ & \\
\hline Bonport & 27 & & 14 & latin & 6418 & 2791 & $\mathrm{XIV}^{\mathrm{e}} \mathrm{s}$ & \\
\hline Bonport & & 3 & 15 & latin & 3280 & 2843 & $\mathrm{XIII}^{\mathrm{e}} \mathrm{s}$. & ex-libris \\
\hline Bonport & & 4 & 16 & latin & 3281 & 2790 & $\mathrm{XIII}^{\mathrm{e}}$ s. & ex-libris \\
\hline Bonport & 29 & & 17 & ${ }^{\star}$ latin & 2250 & 2766 & $\mathrm{XII}^{\mathrm{e}}$ s. & rel. 1 \\
\hline Bonport & 42 & & 18 & latin & 2265 & 2789 & $\mathrm{XIII}^{\mathrm{e}} \mathrm{s}$. & $\begin{array}{l}\text { ex-libris, } \\
\text { Faucon }\end{array}$ \\
\hline Bonport & 31 & 5 & 19 & latin & 1882 & 2807 & $\mathrm{XIII}^{\mathrm{e}} \mathrm{s}$. & \\
\hline Bonport & 14 & & 20 & latin & 3940 & 2806 & $\mathrm{XIII}^{\mathrm{e}}$ s. & rel. 2 \\
\hline Bonport & 51 & 10 & 21 & latin & $485 \mathrm{~B}$ & 2808 & $\begin{array}{l}\mathrm{XIII}^{\mathrm{e}}- \\
\mathrm{XV}^{\mathrm{e}} \mathrm{s} .\end{array}$ & $\begin{array}{l}\text { ex-libris, } \\
\mathrm{Fa}\end{array}$ \\
\hline Bonport & 70 & & 22 & latin & 3020 & 2805 & $\mathrm{XIII}^{\mathrm{e}}$ s. & ex-libris \\
\hline Bonport & 60 & & 23 & latin & 3025 & 2849 & $\mathrm{XII}^{\mathrm{e}} \mathrm{s}$. & ex-libris \\
\hline Bonport & & 13 & 24 & latin & 382 & 2842 & XIII' s. & $\begin{array}{l}\text { ex-libris, } \\
\text { rel. } 1\end{array}$ \\
\hline Bonport & & & 25 & latin & 7944 & 2786 & $\mathrm{XV}^{\mathrm{e}} \mathrm{s}$ & rel. 2 \\
\hline Bonport & 55 & & 26 & & & & & \\
\hline Bonport & 47 & & 27 & latin & 514 & 2853 & $\mathrm{XIII}^{\mathrm{e}} \mathrm{s}$. & \\
\hline
\end{tabular}




\begin{tabular}{|c|c|c|c|c|c|c|c|c|}
\hline Bonport & 37 & 14 & 28 & latin & 345 & 2852 & $\mathrm{XIII}^{\mathrm{e}} \mathrm{s}$. & \\
\hline Bonport & & & 29 & latin & 1830 & 2810 & $\mathrm{XIII}^{\mathrm{e}}$ s. & rel. 1 \\
\hline Bonport & & & 30 & latin & 1840 & 2858 & $\mathrm{XIII}^{\mathrm{e}} \mathrm{s}$. & rel. 1 \\
\hline Bonport & 40 & & 31 & latin & 8157 & 2720 & XIVes. & rel. 2 \\
\hline Bonport & 30 & & 32 & latin & 5097 & 2787 & $\mathrm{XIII}^{\mathrm{e}}$ s. & ex-libris \\
\hline Bonport & 9 & 8 & 33 & ${ }^{*}$ latin & 1966 & 2726 & XIII' s. & $\begin{array}{l}\text { cote } « I », \\
\text { trace rel. } 1\end{array}$ \\
\hline Bonport & 8 & 6 & 34 & latin & 2022 & 2785 & $\mathrm{XIII}^{\mathrm{e}} \mathrm{s}$. & \\
\hline Bonport & & 9 & 35 & latin & 475 & 2783 & $\mathrm{XIII}^{\mathrm{e}} \mathrm{s}$. & trace rel. 1 \\
\hline Bonport & 23 & & 36 & latin & 279 & 2930 & $\mathrm{XIII}^{\mathrm{e}} \mathrm{s}$. & \\
\hline Bonport & 15 & & 37 & latin & 2142 & 2784 & $\mathrm{XIII}^{\mathrm{e}} \mathrm{s}$. & $\begin{array}{l}\text { ex-libris, } \\
\text { Faucon }\end{array}$ \\
\hline Bonport & 6 & & 38 & latin & 56 & 97 & $\mathrm{XI}^{\mathrm{e}} \mathrm{s}$. & \\
\hline Bonport & 65 & & 39 & latin & 447 & 2741 & $\mathrm{XIII}^{\mathrm{e}} \mathrm{s}$. & ex-libris \\
\hline Bonport & 35 & & 40 & latin & 2529 & 2909 & $\mathrm{XIII}^{\mathrm{e}}$ s. & ex-libris \\
\hline Bonport & & & 41 & latin & $7625 \mathrm{D}$ & 2855 & $\mathrm{XIV}^{\mathrm{e}} \mathrm{s}$ & $\begin{array}{l}\text { ex-libris, } \\
\text { rel. 2, } \\
\text { Faucon }\end{array}$ \\
\hline Bonport & 48 & & 42 & latin & $7613^{1}$ & 2836 & $\mathrm{XIV}^{\mathrm{e}} \mathrm{s}$ & $\begin{array}{l}\text { ex-libris, } \\
\text { rel. } 1 \text {, } \\
\text { Faucon }\end{array}$ \\
\hline Bonport & 49 & & 43 & latin & $7613^{2}$ & 2837 & $\mathrm{XIV}^{\mathrm{e}} \mathrm{s}$ & $\begin{array}{l}\text { ex-libris, } \\
\text { rel. } 1\end{array}$ \\
\hline Bonport & 45 & & 44 & latin & 2537 & 2861 & $\mathrm{XIII}^{\mathrm{e}} \mathrm{s}$ & \\
\hline Bonport & 22 & & 45 & latin & 21 & 2856 & XIII ${ }^{\mathrm{e}} \mathrm{s}$. & ex-libris \\
\hline Bonport & 46 & & 46 & latin & 2538 & 2862 & XIII ${ }^{\mathrm{e}} \mathrm{s}$. & \\
\hline Bonport & & & 47 & latin & 416 & 2850 & $\mathrm{XIII}^{\mathrm{e}} \mathrm{s}$. & ex-libris \\
\hline Bonport & 53 & & 48 & latin & 2554 & 2824 & $\mathrm{XIII}^{\mathrm{e}} \mathrm{s}$. & $\begin{array}{l}\text { ex-libris, } \\
\text { fol. }\end{array}$ \\
\hline Bonport & 43 & & 49 & latin & 3175 & 2848 & $\mathrm{XIII}^{\mathrm{e}} \mathrm{s}$. & $\begin{array}{l}\text { ex-libris, } \\
\text { Faucon }\end{array}$ \\
\hline Bonport & & & 50 & latin & 74 & 2956 & $\mathrm{XII}^{\mathrm{e}} \mathrm{s}$. & $\begin{array}{l}\text { ex- } \\
\text { libris, rel. } \\
\text { romane }\end{array}$ \\
\hline Bonport & 10 & & 51 & latin & 84 & 2969 & $\mathrm{XII}^{\mathrm{e}} \mathrm{s}$. & ex-libris \\
\hline
\end{tabular}




\begin{tabular}{|c|c|c|c|c|c|c|c|c|}
\hline Bonport & & & 52 & latin & 120 & 2970 & $\mathrm{XIII}^{\mathrm{e}} \mathrm{s}$. & ex-libris \\
\hline Bonport & 36 & & 53 & latin & 129 & 2928 & $\mathrm{III}^{\mathrm{e}} \mathrm{s}$. & ex-libris \\
\hline Bonport & 17 & & 54 & latin & 144 & 2929 & $\begin{array}{l}\mathrm{XIII}^{\mathrm{e}}- \\
\mathrm{XIV}^{\mathrm{e}} \mathrm{s} .\end{array}$ & ex-libris \\
\hline Bonport & 33 & & 55 & latin & 288 & 2931 & $\mathrm{XIII}^{\mathrm{e}} \mathrm{s}$. & $\begin{array}{l}\text { ex-libris, } \\
\text { rel. } 1\end{array}$ \\
\hline Bonport & 59 & & 56 & latin & 295 & 2971 & $\mathrm{XIII}^{\mathrm{e}} \mathrm{s}$. & ex-libris \\
\hline Bonport & 28 & & 57 & latin & 301 & 2972 & XIII' s. & ex-libris \\
\hline Bonport & 41 & & 58 & latin & 302 & 2978 & $\mathrm{XIII}^{\mathrm{e}} \mathrm{s}$. & ex-libris \\
\hline Bonport & & & 59 & latin & 363 & 3009 & $\mathrm{XIII}^{\mathrm{e}} \mathrm{s}$. & ex-libris \\
\hline Bonport & 20 & & 60 & latin & 386 & 353 & $\mathrm{XIII}^{\mathrm{e}} \mathrm{s}$. & ex-libris \\
\hline Bonport & & & 61 & latin & 393 & 3011 & $\mathrm{XIII}^{\mathrm{e}} \mathrm{s}$. & ex-libris \\
\hline Bonport & & & 62 & latin & 408 & 2812 & $\begin{array}{l}\mathrm{XII}^{\mathrm{e}}- \\
\mathrm{XIII}^{\mathrm{e}} \mathrm{s} .\end{array}$ & ex-libris \\
\hline Bonport & 44 & & 63 & latin & 618 & 2954 & $\begin{array}{l}\mathrm{XIII}^{\mathrm{e}}- \\
\mathrm{XIV}^{\mathrm{e}} \mathrm{s} .\end{array}$ & $\begin{array}{l}\text { ex-libris, } \\
\text { Faucon }\end{array}$ \\
\hline Bonport & 19 & & 64 & latin & 668 & 101 & $\mathrm{XIII}^{\mathrm{e}} \mathrm{s}$. & $\begin{array}{l}\text { ex-libris, } \\
\text { rel. } 1\end{array}$ \\
\hline Bonport & & & 65 & latin & 672 & 2973 & $\mathrm{XIII}^{\mathrm{e}} \mathrm{s}$. & ex-libris \\
\hline Bonport & 39 & & 66 & latin & 2523 & 2908 & $\mathrm{XIII}^{\mathrm{e}} \mathrm{s}$. & \\
\hline Bonport & 1 & 7 & 67 & latin & 2007 & 2980 & $\begin{array}{l}\mathrm{XIII}^{\mathrm{e}}- \\
\mathrm{XIV}^{\mathrm{e}} \mathrm{s} .\end{array}$ & $\begin{array}{l}\text { ex-libris, } \\
\text { rel. } 2\end{array}$ \\
\hline Bonport & 61 & & 68 & latin & 2230 & 2992 & & $\begin{array}{l}\text { ex-libris, } \\
\text { rel. } 2\end{array}$ \\
\hline Bonport & 66 & & 69 & latin & 2228 & 2989 & $\mathrm{XIII}^{\mathrm{e}} \mathrm{s}$. & $\begin{array}{l}\text { ex-libris, } \\
\text { rel. } 1\end{array}$ \\
\hline Bonport & 7 & 1 & 70 & latin & $2310^{1}$ & 2827 & $\mathrm{XIII}^{\mathrm{e}} \mathrm{s}$. & $\begin{array}{l}\text { ex-libris, } \\
\text { rel. } 1\end{array}$ \\
\hline Bonport & 12 & 2 & 71 & latin & $2310^{2}$ & 2828 & $\mathrm{XIII}^{\mathrm{e}} \mathrm{s}$. & $\begin{array}{l}\text { ex-libris, } \\
\text { rel. } 1\end{array}$ \\
\hline Bonport & & & 72 & latin & 29 & 2804 & $\mathrm{XIII}^{\mathrm{e}} \mathrm{s}$. & ex-libris \\
\hline Bonport & & & 73 & latin & 3283 & 5213 & $\mathrm{XIII}^{\mathrm{e}} \mathrm{s}$. & $\begin{array}{l}\text { ex-libris, } \\
\text { Faucon }\end{array}$ \\
\hline Bonport & & & 74 & latin & 446 & 5216 & $\begin{array}{l}\mathrm{XII}^{\mathrm{e}}- \\
\mathrm{XIII}^{\mathrm{e}} \mathrm{s} .\end{array}$ & $\begin{array}{l}\text { ex-libris, } \\
\text { Faucon }\end{array}$ \\
\hline
\end{tabular}




\begin{tabular}{|c|c|c|c|c|c|c|c|c|}
\hline Bonport & 57 & & 75 & latin & $3238^{\mathrm{E}}$ & 5211 & $\mathrm{XIII}^{\mathrm{e}} \mathrm{s}$ & \\
\hline Bonport & & & 76 & latin & 126 & 5209 & XIII' s. & $\begin{array}{l}\text { ex-libris, } \\
\text { rel. } 1\end{array}$ \\
\hline Bonport & 58 & & 77 & latin & 7361 & 5186 & $\mathrm{XIII}^{\mathrm{e}} \mathrm{s}$. & \\
\hline Bonport & & & 78 & latin & 3563 & 5217 & $\mathrm{XIII}^{\mathrm{e}}$ s. & \\
\hline Bonport & 54 & & 79 & latin & 2928 & 5208 & $\begin{array}{l}\mathrm{XII}^{\mathrm{e}}- \\
\mathrm{XIII}^{\mathrm{e}} \mathrm{s} .\end{array}$ & \\
\hline Bonport & & & 80 & latin & 454 & 5188 & XIII' ${ }^{\mathrm{e}}$ s. & \\
\hline Bonport & 2 & & 81 & latin & 1945 & 2917 & XIII' ${ }^{\mathrm{e}}$ s. & \\
\hline Bonport & & & 82 & ${ }^{\star}$ latin & 3834 & 5219 & $\mathrm{XV}^{\mathrm{e}} \mathrm{s}$ & fol. \\
\hline Bonport & & & 83 & latin & 2933 & 5214 & $\mathrm{XII}^{\mathrm{e}} \mathrm{s}$. & $\begin{array}{l}\text { ex-libris, } \\
\text { rel. } 1\end{array}$ \\
\hline Bonport & & & 84 & latin & 2934 & 5215 & XII ${ }^{e} s$. & $\begin{array}{l}\text { ex-libris, } \\
\text { rel. } 1\end{array}$ \\
\hline Bonport & & 11 & 85 & latin & 2795 & 5207 & $\mathrm{XIII}^{\mathrm{e}} \mathrm{s}$ & $\begin{array}{l}\text { ex-libris, } \\
\text { rel. 1, } \\
\text { Faucon }\end{array}$ \\
\hline Bonport & 56 & & 86 & latin & 3724 & 6272 & $\mathrm{XIII}^{\mathrm{e}} \mathrm{s}$ & ex-libris \\
\hline Bonport & 52 & & 87 & latin & 2689 & 5210 & XIII' s. & \\
\hline Bonport & 50 & & 88 & français & 1893 & 5218 & 1487 & \\
\hline
\end{tabular}

85 manuscrits des inventaires de Bonport sont identifiés grâce aux notes diverses du prieur Pierre Faucon $\left(\mathrm{XV}^{e} \mathrm{~s} .\right)^{86}$, aux ex-libris et aux cotes anciennes, à des reliures homogènes et aux cotes Colbert. En grande partie à cause de l'importante ponction de 1683 , l'abbaye ne possède plus au moment de la Révolution que 16 manuscrits pour la plupart tardifs, aujourd'hui conservés à Louviers ${ }^{87}$. Si les deux volumes de l'un des exemplaires du De Civitate Dei provenant de Bonport sont facilement identifiables dans la première liste des manuscrits (Bonport A, $\mathrm{n}^{\circ} 26$ et 64 ), ils portent aussi l'ex-libris d'une autre abbaye cistercienne normande, Beaubec, qui a échappé aux envoyés de Colbert ${ }^{88}$.

86. Pierre Faucon, prieur à Bonport entre 1423 et 1443 , donne son nom au fol. $194 \mathrm{~V}$ du latin $485 \mathrm{~B}$. On trouve aussi sa main dans un manuscrit qui n'est pas passé chez Colbert, latin 5317; DELISLE, 1868, p. 452.

87. OMONT, 1882, p. 6 et 21-22, mss 2, 4, 6, 23, 24, 28, 34, 36; Sous la couverture, 2007, passim.

88. Paris, BnF, ms lat. 2061 ${ }^{1-2}$; BondéElle-Souchier, 1991, p. 16. Le tome 2 comporte au fol. 138v le sermon apocryphe de saint Augustin intitulé De Assumptione b. Mariae, signalé sous le numéro 26. 
Les manuscrits conservés avant la fin du XVII e siècle dans les abbayes cisterciennes normandes sont un bon exemple des collections de l'ordre du point de vue textuel. Ils constituent aussi un groupe fortement homogène chronologiquement et matériellement, et méritent une étude paléographique et codicologique approfondie, qui permettrait sans doute de comprendre les circonstances de leur réalisation dans des scriptoria qui ont été actifs en Normandie au XII ${ }^{e}$ et XIII ${ }^{e}$ siècles, et de confirmer ou de rectifier leur origine pour ceux qui n'en portent pas de preuve évidente. C'est pourquoi il m'a paru important de publier cette étude imparfaite telle qu'elle est, en espérant qu'elle ouvrira la voie pour des travaux futurs.

\section{Bibliographie}

Avril, François et Gousset, Marie-Thérèse avec la collab. de Claudia RABel, Manuscrits enluminés d'origine italienne, 2, XIII ${ }^{\mathrm{e}}$ siècle, Paris, Bibliothèque nationale, 1984.

AvriL, François et Reynaud, Nicole, Les Manuscrits à peintures en France (1440-1520), Paris, Flammarion, 1993.

Auvray, Lucien et Poupardin, René, Catalogue des manuscrits de la collection Baluze, Paris, Bibliothèque nationale, 1921.

BLOCH, Denise, «La Colbertine», in Colbert 1619-1683, Catalogue de l'exposition, Paris, Hôtel de la Monnaie, 4 octobre-3o novembre 1983, Paris, Archives nationales, 1983, p. 401-404.

BLOCH, Denise, «La bibliothèque de Colbert», in Histoire des bibliothèques françaises, II, Les bibliothèques sous l'Ancien Régime, Claude Jolly (dir.), Paris, éd. du cercle de la Librairie, 1988, p. 157-179.

BondéElle-Souchier, Anne, Bibliothèques cisterciennes dans la France médiévale. Répertoire des abbayes d'hommes, Paris, éd. du CNRS [DER, 41;HBM, 6], 1991.

BréAuté, Louis, Catalogue de la Bibliothèque de la ville de Louviers, Rouen, A. Péron, 1843.

Colbert, Jean-Baptiste, Lettres, instructions et mémoires, éd. Pierre Clément, VII, Paris, Imprimerie impériale, 1873.

Coyecque, Ernest, «Manuscrits de la bibliothèque de Neufchâtel-en-Bray», in Catalogue général des manuscrits des bibliothèques publiques de France, série in-8 ${ }^{\circ}$, Paris, Librairie E. Plon, Nourrit et Cie, 1888.

Delisle, Léopold, Le Cabinet des manuscrits de la Bibliothèque impériale. Etude sur la formation de ce dépôt, comprenant les éléments d'une histoire de la calligraphie, de la miniature, de la reliure, et du commerce des livres avant l'invention de l'imprimerie..., I, Paris, Imprimerie impériale, 1868, passim.

Delisle, Léopold, Collections de Jules Desnoyers. Catalogue des manuscrits anciens et des chartes, Paris, s. n., 1888.

Delisle, Léopold, "Manuscrits de Saint-Martial de Limoges», Bulletin de la Société archéologique et historique du Limousin, 43, 1895, p. 1-61. 
Deville, Étienne, «Les manuscrits de La Noë à la Bibliothèque nationale», Revue catholique de Normandie, 18, 1908, p. 316 et 19, 1909, p. 199.

Deville, Étienne, «Les épaves de la bibliothèque de Savigny à la Bibliothèque nationale», Revue catholique de Normandie, 25, 1916, p. 271-288.

Dolbeau, François, "Anciens possesseurs des manuscrits hagiographiques latins de Paris", Revue d'histoire des textes, 9, 1979, p. 183-238.

Dolbeau, François, «Trois catalogues de bibliothèques médiévales restitués à des abbayes cisterciennes: Cheminon, Haute-Fontaine, Mortemer», Revue d'histoire des textes, 18, 1988, p. 81-108.

DuBuc, André, «Bibliothèques et œuvres d'art dans les abbayes supprimées à la Révolution en Seine-Inférieure", in Les abbayes de Normandie, Actes du $X I I I^{e}$ congrès des sociétés historiques et archéologiques de Normandie, Rouen, Société libre d'émulation de la Seine-Maritime, 1979, p. 150-151.

Dufour, Jean, Recueils des rouleaux des morts (VIII e siècle-vers 1536), I, VIII e siècle-118o, Paris, Académie des Inscriptions et Belles-Lettres (Recueil des Historiens de la France, in- $4^{\circ}$, VIII), 2005, p. 514-586.

Étienne Baluze, 1630-1718. Érudition et pouvoir dans l'Europe classique, Actes du colloque de Tulle, 21 octobre 2006, Jean Boutier (dir.), Limoges, PULIM, 2008.

Gasnault, Pierre, «Baluze éditeur de textes anciens», in Étienne Baluze, 1630-1718. Érudition et pouvoir dans l'Europe classique, Actes du colloque de Tulle, 21 octobre 2006, Jean Boutier (dir.), Limoges, PULIM, 2008, p. 129-140.

Genevois, Anne-Marie, Genest, Jean-François et Chalandon, Anne, Bibliothèques de manuscrits médiévaux en France: relevé des inventaires du VIII au XVIII siècle, Paris, Éditions du CNRS, 1987.

Godın, Xavier, La réformation des domaines de mainmorte en Bretagne sous le règne de Louis XIV..., Mémoire de DEA d'Histoire du droit, Université Rennes 1 soutenu le 22 septembre 1999. http://partages.univ-rennes1.fr/files/partages/Recherche/ Recherche\%2oDroit/Laboratoires/CHD/Theses/GodinM2.pdf

LAFfitTE, Marie-Pierre, «Les manuscrits normands de Colbert. Reliures cisterciennes», in Manuscrits et enluminures dans le monde normand ( $X^{e}-X V^{e}$ siècles): actes du Colloque de Cerisy-la-Salle, 1995, publ. sous la dir. de Pierre Boukt et Monique DosDAT, Caen, Office universitaire d'Études normandes, Université de Caen BasseNormandie, Presses universitaires de Caen, 1999, $2^{\mathrm{e}}$ éd., Caen, Office universitaire d'études normandes, Université de Caen, Presses universitaires de Caen, 2005, p. 197-205.

LAFfitte, Marie-Pierre, «Napoléon et les confiscations de livres dans les monastères italiens", in How the secularization of religious houses transformed the libraries of Europe, $16^{\text {th }}-19^{\text {th }}$ centuries, Actes du colloque, Oxford, 22-24 mars 2012, sous presse.

Neveu, Valérie, Catalogues régionaux des incunables des bibliothèques publiques de France, XVII, Haute-Normandie, Genève, Droz, 2005.

Омоnт, Henri, Catalogue des manuscrits de Louviers et Verneuil, Paris, H. Champion, 1882.

Омоnт, Henri, Concordances des mss latins de la Bibliothèque nationale, Paris, E. Leroux, 1903. 
O’Reilly, Ernest, Mémoires sur la vie privée et publique de Claude Pellot, conseiller, maître des requêtes, intendant, et premier président du Parlement de Normandie (1619-1683), Paris, Champion, Rouen, E. Cagniard, 1881-1882 et http://archive.org/ stream/mmoiressurlaviepozorei\#page/n7/mode/2up (t. 1) et http://archive.org/ stream/mmoiressurlaviepozorei\#page/n7/mode/2up (t. 2).

Petitmengin, Pierre, «Montfaucon, dom Le Maître et la Bibliotheca bibliothecarum », in Du copiste au collectionneur, mélanges d'histoire des textes et des bibliothèques en l'honneur d'André Vernet, éd. Donatella Nebbiai-Della Guarda et Jean-François Genest, Turnhout, Brepols (Bibliologia, 18), 1998.

Petitmengin, Pierre, "Baluze éditeur des Pères de l’Église», in Étienne Baluze, 1630-1718. Érudition et pouvoir dans l'Europe classique, Actes du colloque de Tulle, 21 octobre 2006, Jean Boutier (dir.), Limoges, PULIM, 2008, p. 141-161.

Richard, Charles, Notice sur l'ancienne bibliothèque des échevins de la ville de Rouen, Rouen, A. Péron, 1845.

Soll, Jacob, «Entre bibliothécaire et argent d'information: Baluze au service de JeanBaptiste Colbert», in Étienne Baluze, 1630-1718. Érudition et pouvoir dans l'Europe classique, Actes du colloque de Tulle, 21 octobre 2006, Jean Boutier (dir.), Limoges, PULIM, 2008, p. 79-91.

Sous la couverture. Dix siècles d'histoire du livre à Louviers, Louviers, Médiathèque de Louviers, 2007.

Stirnemann, Patricia, "Où ont été fabriqués les livres de la glose ordinaire dans la première moitié du XII siècle", in Le XII ${ }^{e}$ siècle, Mutations et renouveau en France dans la première moitié du XII ${ }^{e}$., Paris, Léopard d'or (Cahiers du Léopard d'or, 3), 1994, p. 257-301.

Trésors des abbayes normandes, Catalogue d'exposition, Rouen, Musée des antiquités 27 avril-22 juillet 1979, Caen, Musée des beaux-arts 12 août-28 octobre 1979, Rouen, Musée des antiquités, 1979.

ZIER, Mark, «The Development of the Glossa Ordinaria to the Bible in the Thirtheenth Century: The Evidence from the Bibliothèque Nationale, Paris", in La Bibbia del XIII secolo. Storia del testo, storia dell'esegesi, Millennio medievale. Atti di convegni 14, éd. Giuseppe Cremascoli et Francesco Santi, Firenze, SISMEL-ed. del Galluzzo, 2004, p. 155-184. 